Nerivaldo dos Reis Santos

\title{
Sistema Especialista para Seleção Otimizada de Dispositivos de Proteção de Transformadores Frente às Descargas Atmosféricas
}



Nerivaldo dos Reis Santos

\title{
Sistema Especialista para Seleção Otimizada de Dispositivos de Proteção de Transformadores Frente às Descargas Atmosféricas
}

Dissertação apresentada à Escola de Engenharia de São Carlos da Universidade de São Paulo, sendo parte dos requisitos para obtenção do título de Mestre em Ciências, Programa de Engenharia Elétrica, Área de Concentração em Sistemas Elétricos de Potência.

Orientador: Prof. Dr. Ivan Nunes da Silva

\author{
São Carlos
}


AUTORIZO A REPRODUÇÃO E DIVULGAÇ̃̃O TOTAL OU PARCIAL DESTE TRABALHO, POR QUALQUER MEIO CONVENCIONAL OU ELETRÔNICO, PARA FINS DE ESTUDO E PESQUISA, DESDE QUE CITADA A FONTE.

Ficha catalográfica preparada pela Seção de Tratamento da Informação do Serviço de Biblioteca - EESC/USP

S237s

Santos, Nerivaldo dos Reis.

Sistema especialista para seleção otimizada de dispositivos de proteção de transformadores frente às descargas atmosféricas / Nerivaldo dos Reis Santos ; orientador Ivan Nunes da Silva. São Carlos, 2011.

Dissertação (Mestrado - Programa de Pós-Graduação em Engenharia Elétrica e Área de Concentração em Sistemas Elétricos de Potência) -- Escola de Engenharia de São Carlos da Universidade de São Paulo, 2011.

1. Sistemas elétricos. 2. Linha de distribuição. 3. Sistemas especialistas. 4. Descargas atmosféricas. 5. Proteção de sistemas. 6. Transformadores. I. Título. 


\section{FOLHA DE JULGAMENTO}

Candidato: Engenheiro NERIVALDO DOS REIS SANTOS

Título da dissertação: Sistema especialista para seleção otimizada de dispositivos de proteção de transformadores frente às descargas atmosféricas.

Data da defesa: 03/08/2011:

\section{Comissão Julgadora:}

\section{Resultado:}

Prof. Associado Ivan Nunes da Silva (Orientador)

(Escola de Engenharia de São Carlos/EESC)

Prof. Dr. José Angelo Cagnon

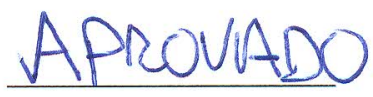

(Universidade Estadual Paulista "Julio de Mesquita Filho"/UNESP/campus de Bauru)

Prof. Dr. Rogério Andrade Flauzino

(Escola de Engenharia de São Carlos/EESC)

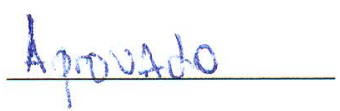

Coordenador do Programa de Pós-Graduação em Engenharia Elétrica:

Prof. Titular Denis Vinicius Coury

Presidente da Comissão de Pós-Graduação:

Prof. Associado Paulo Cesar Lima Segantine 

"Porque dele e por meio dele, e para ele, são todas as coisas. Glória, pois a ele eternamente. Amém.”

Romanos 11, 36 



\section{Agradecimentos}

A minha esposa Geraldina e a minha filha Gabriela por todo apoio, incentivo e compreensão pelas horas em que estive ausente para cumprir esta jornada.

Aos meus pais Rosival Silveira Santos e Maria dos Reis Santos, e irmãos Moacir, Irandi, Cristiane, Eliane e Rosiane, por todo apoio e incentivo.

Ao Prof. Ivan Nunes da Silva pelos ensinamentos, pela orientação deste trabalho e pela grande amizade.

Ao Prof. Rogério Flauzino pelos ensinamentos, pela grande ajuda e cooperação, e pela grande amizade.

Aos colegas de sala e do laboratório LAIPS, Danilo, Ricardo, Wesley, Suetake e Renato.

Aos colegas de trabalho que muito incentivaram minha participação nesta pesquisa acadêmica.

A empresa EDP Bandeirante, no fornecimento de dados e suporte por meio do programa de pesquisa e desenvolvimento. 



\section{Índice}

Resumo

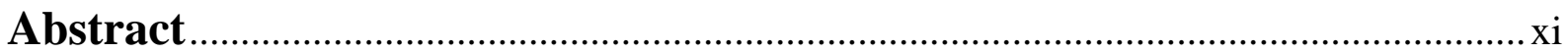

Lista de Siglas e Abreviaturas..............................................................................ii

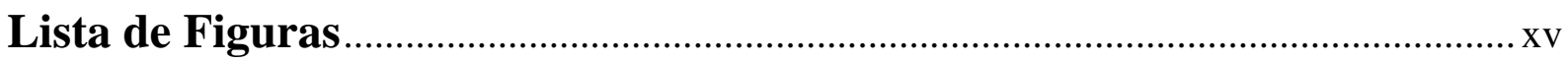

Lista de Tabelas .....................................................................................................

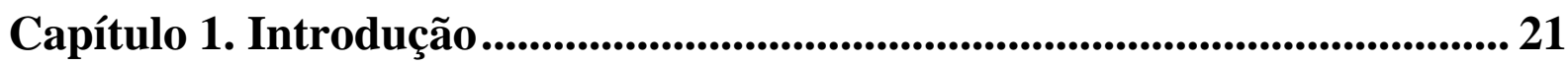

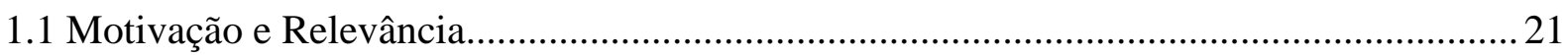

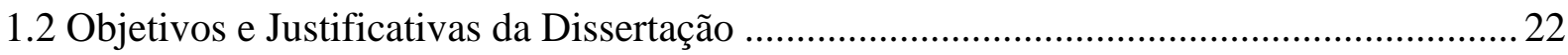

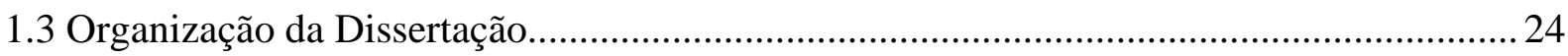

Capítulo 2. Aspectos de Investigação Técnico-Científica ............................... 27

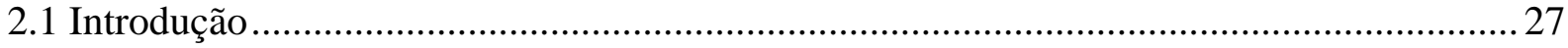

2.2 Estimação de Tensões Induzidas Utilizando o Método de Rusck ...................................... 29

2.3 Generalização da Metodologia de Rusck Para Formas de Onda de Corrente de Descarga Genéricas ...................................................................................................... 34

2.4 Considerações Para Estimação de Tensões Induzidas em Linhas Finitas .......................... 37

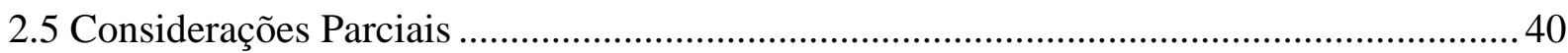

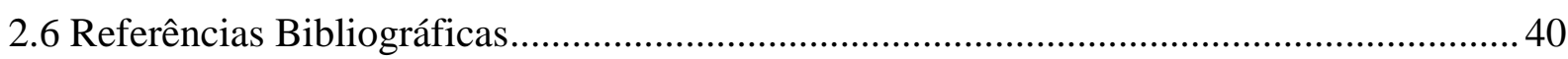

Capítulo 3. Aspectos da Implementação Computacional.................................. 43

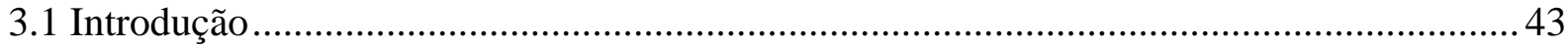

3.2 Descrição Funcional da Plataforma Computacional Para Estimação de Tensões

Induzidas Ocasionadas por Descargas Atmosféricas em Linhas de Distribuição............ 44

3.3 Iniciando um Novo Projeto de Estimação de Tensão Induzida........................................... 45

3.4 Criação de Um Novo Projeto de Estimação de Tensão Induzida em Linha de

Distribuição ............................................................................................................. 46

3.5 Configuração dos Parâmetros de Um Novo Projeto............................................................... 50

3.6 Simulações Pontuais Para o Estudo de Tensões Induzidas em Linhas de Distribuição ..... 56

3.7 Simulação Geral Para o Estudos de Tensões Induzidas em Linhas de Distribuição ............60

3.8 Salvando o Projeto de Estudo de Tensões Induzidas em Linhas de Distribuição ................ 62

3.9 Restaurando o Projeto de Estudo de Tensões Induzidas em Linhas de Distribuição.......... 63

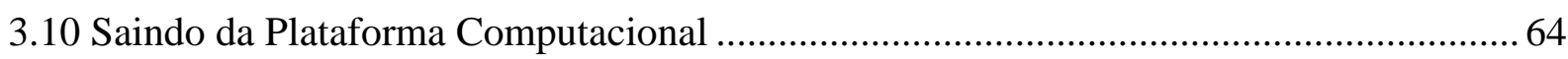

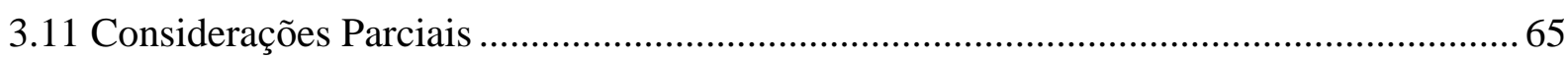


Capítulo 4. Aspectos da Elaboração de Critérios Técnicos...............................67

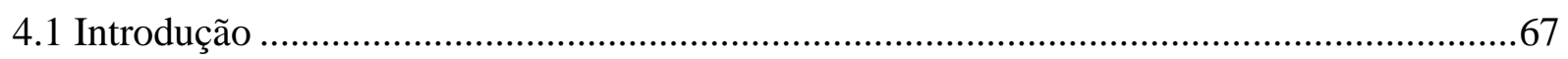

4.2 Nível de Exposição das Linhas de Distribuição................................................................67

4.3 Características Elétricas das Descargas ............................................................................68

4.4 Desempenho das Linhas de Distribuição Frente às Descargas Atmosféricas.......................70

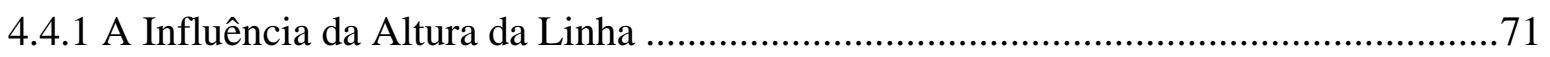

4.4.2 A Influência de Estruturas Próximas às Linhas ..........................................................71

4.5 Aspectos Relativos à Modelagem Técnica ....................................................................

4.5.1 Modelagem do Fator de Proteção ……………………..............................................73

4.5.2 Freqüências de Disrupções Devidas às Tensões Induzidas ............................................74

4.5.3 Espaçamento Entre Pára-raios Frente às Descargas Diretas ..........................................77

4.5.4 Espaçamento Entre Pára-raios Frente às Descargas Indiretas ......................................79

4.6 Métodos Para a Coordenação de Isolamento em Sistemas de Distribuição .........................80

4.7 Estratégias de Proteção de Sistemas de Distribuição...........................................................82

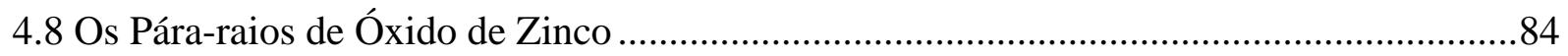

4.9 Coordenação de Isolamento em Sistemas de Distribuição ..................................................89

4.9.1 Proteção Contra Sobretensões em Sistemas de Distribuição ........................................91

4.10 Considerações Parciais........................................................................................97

4.11 Referências Bibliográficas ........................................................................................98

Capítulo 5. Sistema Especialista Para Seleção de Dispositivos de Proteção de Transformadores ....................................................................... 101

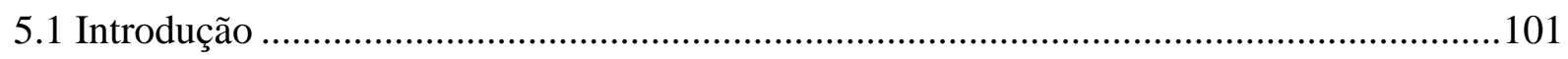

5.2 Recursos e Características do Sistema Especialista...........................................................104

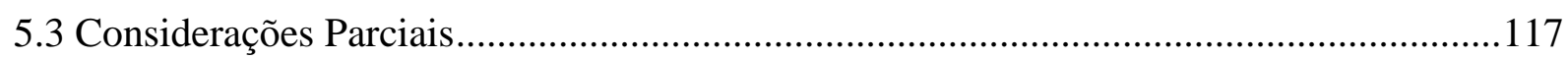

Capítulo 6. Conclusões e Trabalhos Futuros...................................................... 119 


\section{Resumo}

SANTOS, N. R. (2011). Sistema Especialista Para Seleção Otimizada de Dispositivos de Proteção de Transformadores Frente às Descargas Atmosféricas. Dissertação (Mestrado) Escola de Engenharia de São Carlos, Universidade de São Paulo, 2011.

O objetivo deste trabalho consiste em apresentar o projeto de um sistema especialista que visa auxiliar nos procedimentos envolvidos com a especificação de pára-raios de óxido de zinco para proteção de transformadores frente às descargas atmosféricas, bem como permitir que a análise do comportamento dos surtos de tensão de origem atmosférica que incidem em determinada área de concessão possa ser executada de forma detalhada e sistemática. Para tanto, o sistema especialista desenvolvido faz a integração eficiente de abordagens e técnicas que levam em consideração os aspectos característicos das descargas atmosféricas, as análises experimentais representativas do fenômeno e os modelos matemáticos que permitam mapear todo o processo de desencadeamento das descargas atmosféricas.

Palavras Chave: Linha de Distribuição, Sistemas Especialistas, Descargas Atmosféricas, Proteção de Sistemas, Transformadores. 

Abstract

SANTOS, N. R. (2011). Expert System for Optimized Selection of Transformer Protection Devices against Atmospheric Discharges. Dissertation (Master’s Degree) - São Carlos School of Engineering, University of São Paulo, 2011.

The objective of this study consists of presenting an expert system that assists the procedures involved with the protection specification of transformers against atmospheric discharges, allowing also to analyze in a detailed and systematic way the behavior of the respective voltage transients that are generated at the supplying area. For such purpose, the expert system developed in this research makes the efficient integration of approaches and techniques that take into account the characteristic aspects of the atmospheric discharges, the experimental analyses that represent the phenomenon and the mathematical models that allow to map the process involved with the formation of the lightning.

Keywords: Distribution Lines, Expert Systems, Lightning, System Protection, Transformer. 



\section{Lista de Siglas e Abreviaturas}

$\begin{array}{ll}\text { ATP } & \text { Alternative Transients Program } \\ \text { DEC } & \text { Duração Equivalente de Interrupção por Consumidor } \\ \text { EAT } & \text { Extra Alta Tensão } \\ \text { FEC } & \text { Freqüência Equivalente de Interrupção por Consumidor } \\ \text { MPFO } & \text { Margem de Proteção para Frente de Onda } \\ \text { MPOP } & \text { Margem de Proteção para Onda Plena } \\ \text { NBI } & \text { Nível Básico de Impulso } \\ \text { TLM } & \text { Transmission Line Modelling } \\ \text { TMORC } & \text { Tensão Máxima de Operação em Regime Contínuo } \\ \text { TR } & \text { Tensão Residual } \\ \text { TRT } & \text { Tensão Residual Total } \\ \text { UAT } & \text { Ultra Alta Tensão }\end{array}$





\section{Lista de Figuras}

Figura 2.1 - Tensão induzida no ponto de máxima tensão em uma linha infinita com 10m de altura e descarga atmosférica de 10 kA a uma distância perpendicular de 100m da linha.

Figura 2.2 - Tensão induzida em uma linha de distribuição infinita com 10m de altura e descarga atmosférica de 10 kA a uma distância perpendicular de 100m da linha em diversos pontos ao longo da linha

Figura 2.3 - Variação da máxima tensão induzida ao longo da linha de distribuição ..............31

Figura 2.4 - Variação do tempo de subida ao longo da linha de distribuição.......................... 32

Figura 2.5 - Variação do tempo de pico ao longo da linha de distribuição .............................. 32

Figura 2.6 - Variação do tempo de meia onda ao longo da linha de distribuição..................... 33

Figura 2.7 - Forma de onda de corrente para modelagem da descarga atmosférica................ 36

Figura 2.8 - Forma de onda de corrente discretizada em degraus .......................................... 36

Figura 2.9 - Tensão induzida no ponto de máxima tensão para uma forma de onda de

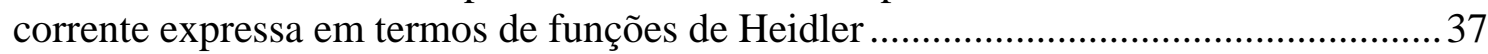

Figura 2.10 - Composição da tensão induzida em um ponto da linha ..................................... 38

Figura 2.11 - Tensão induzida em uma linha finita ............................................................ 38

Figura 3.1 - Fluxograma do cálculo da tensão induzida através da metodologia de

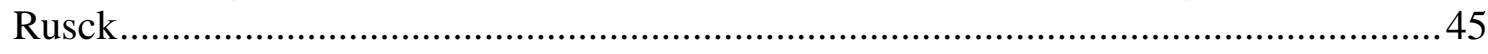

Figura 3.2 - Tela principal e área de trabalho da plataforma computacional ......................... 46

Figura 3.3 - Menu arquivo e opção novo ............................................................................... 47

Figura 3.4 - Detalhes da barra de menu, item “Arquivo” e opção “Novo” ............................. 47

Figura 3.5 - Tela de iniciação de novo projeto ..................................................................... 48

Figura 3.6 - Tela de iniciação de novo projeto devidamente preenchida ................................ 49

Figura 3.7 - Mensagem de criação do novo projeto ................................................................ 49

Figura 3.8 - Área de Trabalho após a criação de um novo projeto .......................................... 50

Figura 3.9 - Tela de configuração de descarga atmosférica................................................... 51

Figura 3.10 - Tela de configuração interativa indicando a validação da configuração da

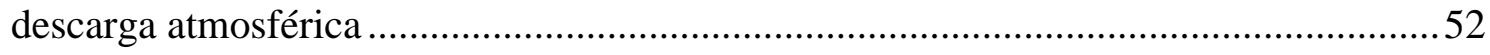

Figura 3.11 - Tela de configuração dos detalhes físicos da descarga atmosférica .................. 53

Figura 3.12 - Tela de configuração da localização da descarga atmosférica...........................54

Figura 3.13 - Representação esquemática dos parâmetros necessários para a configuração da localização da descarga atmosférica....................................................54

Figura 3.14 - Tela de configuração dos parâmetros da linha de distribuição ...........................55

Figura 3.15 - Área de trabalho após a configuração de todos os parâmetros ...........................56 
Figura 3.16 - Detalhes da barra posicional....................................................................... 57

Figura 3.17 - Detalhes do procedimento para iniciação da simulação pontual ......................... 57

Figura 3.18 - Apresentação dos resultados para o início da linha de distribuição ................... 58

Figura 3.19 - Detalhes da tela de resultados de simulação...................................................... 58

Figura 3.20 - Simulação da tensão induzida para uma distância de 250m do início da linha

Figura 3.21 - Simulação da tensão induzida para uma distância de 500m do início da linha

Figura 3.22 - Simulação da tensão induzida para uma distância de 1000m do início da linha

Figura 3.23 - Procedimento para execução da simulação geral

Figura 3.24 - Perfis de máxima tensão induzida, tempo de pico e tempo de meia onda para toda a extensão da linha de distribuição

Figura 3.25 - Procedimento para salvar o projeto de estudo de tensões induzidas em linhas de distribuição

Figura 3.26 - Interface para salvar o projeto de estudo de tensões induzidas em linhas de distribuição

Figura 3.27 - Procedimento para recuperar o projeto de estudo de tensões induzidas em linhas de distribuição

Figura 3.28 - Interface para recuperar o projeto de estudo de tensões induzidas em linhas de distribuição

Figura 3.29 - Procedimento para encerrar a execução da plataforma computacional para o cálculo de tensões induzidas em linhas de distribuição

Figura 4.1 - Descrição dos parâmetros da forma de onda da corrente de descarga ................. 68

Figura 4.2 - Fatores de proteção devido a objetos próximos da linha de distribuição ............. 72

Figura 4.3 - Modelo eletro-geométrico para determinar disrupções por descargas diretas e indiretas.

Figura 4.4 - Disrupções devidas às tensões induzidas em ambiente aberto e em ambiente protegido naturalmente . 77

Figura 4.5 - Curva típica de coordenação de isolamento ....................................................... 82

Figura 4.6 - Espaçamento entre pára-raios para descargas diretas........................................... 83

Figura 4.7 - Espaçamento entre pára-raios para descargas indiretas......................................... 83

Figura 4.8 - Característica V-I típica para pára-raios ZnO e SiC............................................ 86

Figura 4.9 - Capacidade de sobretensão temporária típica para pára-raios ZnO ..................... 87

Figura 4.10 - Tensão residual em função do tempo da frente de onda para as correntes de descarga normalizadas para pára-raios do fabricante GE .......................................... 88

Figura 4.11 - Energia máxima dissipada em função da corrente de descarga.......................... 89

Figura 4.12 - Distribuição das correntes de descargas de pára-raios ........................................ 94 
Figura 4.13 - Curva típica de coordenação de isolamento entre pára-raios e transformador imerso em óleo mineral 96

Figura 4.14 - Distâncias de proteção......................................................................................96

Figura 5.1 - Diagrama esquemático do inter-relacionamento das bases de informações ....... 102

Figura 5.2 - Diagrama ilustrativo dos procedimentos dos módulos ...................................... 104

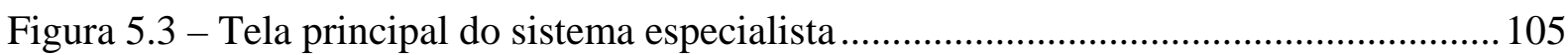

Figura 5.4 - Tela de cadastro de novos transformadores ................................................... 106

Figura 5.5 - Tela de cadastro de transformador devidamente preenchida ............................. 107

Figura 5.6 - Tela principal após o cadastro do transformador .............................................. 107

Figura 5.7 - Informações cadastrais do transformador selecionado ..................................... 108

Figura 5.8 - Editando ou excluindo registros através de menu pop-up ............................... 108

Figura 5.9 - Tela de cadastro de uma nova linha de distribuição devidamente preenchida .. 109

Figura 5.10 - Árvore de registros apresentado a linha de distribuição cadastrada ................ 110

Figura 5.11 - Árvore de registro apresentando o pára-raios cadastrado ................................110

Figura 5.12 - Tela de cadastro de descargas atmosféricas devidamente preenchida ..............111

Figura 5.13 - Árvore de registros indicando a descarga atmosférica cadastrada...................112

Figura 5.14 - Tela de cadastro de um novo projeto devidamente preenchida ....................... 112

Figura 5.15 - Árvore de registro indicando o novo projeto criado ....................................... 113

Figura 5.16 - Tela de cadastro de projeto apresentado os resultados de simulação................113

Figura 5.17 - Tela de resultados avançados apresentando a análise de desempenho .............114

Figura 5.18 - Tela de perfil de tensão induzida ao longo da linha de distribuição .................115

Figura 5.19 - Tela de resultados avançados apresentando informações referentes à proteção do transformador

Figura 5.20 - Tela de resultados avançados apresentando os dados referentes à proteção da linha de distribuição. 



\section{Lista de Tabelas}

Tabela 2.1 - Valor de constantes usadas para a simulação da corrente de descarga .................... 35

Tabela 4.1 - Parâmetros da corrente de descarga (polaridade negativa) .................................... 69

Tabela 4.2 - Disrupções em função do espaçamento dos pára-raios (descargas diretas) .............. 78

Tabela 4.3 - Número equivalente de disrupções por tensões induzidas ..................................... 79

Tabela 4.4 - Disrupções por tensões induzidas em função do espaçamento entre pára-raios ...... 79

Tabela 4.5 - Níveis de proteção típicos de pára-raios do fabricante ABB ................................... 88

Tabela 4.6 - Níveis de isolamento para tensões máximas de equipamentos entre 7,2 e 36,2

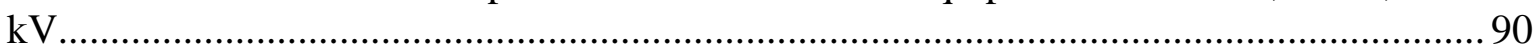

Tabela 4.7 - Tabela de escolha de pára-raios ZnO para sistemas de distribuição ........................ 92

Tabela 4.8 - Características típicas dos para ZnO desprovidos de centelhadores ........................ 94 



\section{Capítulo 1}

\section{Introdução}

\subsection{MOTIVAÇÃO E RELEVÂNCIA}

Em estudos de coordenação de isolamento em classe de tensão $15 \mathrm{kV}$, o procedimento metodológico mais corriqueiro para especificação dos dispositivos e equipamentos resume-se em selecionar uma margem aceitável entre o surto convencional admitido e a suportabilidade do equipamento. Essa margem determina um fator de segurança que, na maioria das vezes, é baseada na experiência acumulada na operação do sistema de distribuição.

As conseqüências desse procedimento metodológico levam, na maioria dos casos, a duas situações extremas. A primeira é o superdimensionamento dos dispositivos de proteção, onerando os custos de implantação de redes de distribuição. A segunda é o subdimensionamento que pode acarretar perdas materiais e financeiras, tanto para a concessionária como para o consumidor de energia elétrica, além dos prejuízos quanto aos indicadores de continuidade de conjunto de unidades consumidoras, especialmente o DEC (Duração equivalente de interrupção por unidade consumidora) e FEC (Freqüência equivalente de interrupção por unidade consumidora).

Além dessas conseqüências, tem-se o reflexo dos surtos de tensão ocorridos na rede primária refletidos na rede secundária pelos transformadores. Estes surtos refletidos apontam como uma das principais fontes de danos em equipamentos eletro-eletrônicos dos consumidores, impondo em diversos casos multas e indenizações à concessionária.

De fato, em sistemas de distribuição, os surtos provocados pelas descargas atmosféricas se configuram como sendo uma das principais causas de falhas em equipamentos, incluindo os transformadores. Essa constatação tem motivado diversos pesquisadores buscarem soluções cada vez mais eficazes no sentido de diminuir os efeitos dessas descargas nos sistemas elétricos, 
levando-se em conta a sofisticação do mercado consumidor, que a cada dia necessita de índices de desempenho cada vez mais elevados.

Nesse sentido, a proteção efetiva dos equipamentos e também dos transformadores de distribuição frente às descargas atmosféricas torna-se uma missão prioritária para qualquer concessionária de energia elétrica, uma vez que a troca de transformadores e a diminuição da vida útil dos mesmos implicam em custos operacionais e financeiros para a empresa.

Diante deste cenário, fica então evidente que otimizar a coordenação da proteção dos equipamentos de modo a reduzir os desligamentos das redes de distribuição devido às descargas atmosféricas, será um desafio constante para as empresas concessionárias de energia elétrica, uma vez que cada empresa possui critérios e filosofias de proteção diferenciada para cada sistema.

\subsection{JUSTIFICATIVAS E OBJETIVOS DA DISSERTAÇÃO}

Atualmente, diversos pesquisadores têm abordado a necessidade de integrar as inovações tecnológicas, relacionadas à proteção efetiva dos transformadores, a um ferramental computacional capaz de realizar simulações digitais das descargas atmosféricas examinadas em laboratório de alta tensão. A tônica apresentada nesses estudos é identificar as falhas provenientes de solicitações em pontos característicos dos enrolamentos, causadas pela distribuição não linear da tensão, levando-se em consideração características construtivas, distribuição das descargas e modelagem dos enrolamentos.

Outro tipo de estudo também muito difundido é o desenvolvimento de circuitos para modelagem de pára-raios em ensaios em escala reduzida, visando-se o estudo das tensões induzidas em linhas aéreas de distribuição frente às descargas atmosféricas e seus efeitos nos transformadores de distribuição e outros equipamentos. O principal objetivo desses estudos é verificar a possibilidade de redução da amplitude dessas descargas induzidas, considerando diversos aspectos relacionados ao valor do aterramento, à topologia da rede e ao tipo de páraraios utilizados no sistema.

Simulações digitais utilizando o programa ATP (Alternative Transient Program) ou TLM (Transmission Line Modelling) têm sido também utilizadas por pesquisadores no cálculo de sobretensões atmosféricas, principalmente os transitórios eletromagnéticos e seus efeitos nos transformadores. 
Diante deste quadro, existe uma unanimidade entre os pesquisadores que a influência das descargas atmosféricas na proteção dos transformadores não pode ser abordada levando em consideração apenas modelos analíticos, numéricos ou experimentais. Na verdade, os resultados mais convincentes são aqueles desenvolvidos no laboratório e no campo, e que são auxiliados por ferramentas computacionais. Desta forma, o desempenho dos sistemas de proteção pode ser avaliado com maior confiabilidade. Neste sentido, percebe-se a necessidade de realização de estudos de coordenação da proteção dos transformadores por intermédio dos diversos tipos de abordagens existentes.

A partir destas constatações sobre a importância de coordenar adequadamente os sistemas de proteção dos transformadores é que foi fundamentada a proposta desta pesquisa, onde se parte da premissa que o estabelecimento de critérios mais rígidos relacionados à proteção dos transformadores diminuirá significativamente as taxas de falhas nos sistemas de distribuição. Essa coordenação será formulada em função de aspectos técnico-operacionais e na análise e melhoria de modelos matemáticos já existentes.

Assim, o objetivo deste trabalho consiste em apresentar um sistema especialista que visa auxiliar nos procedimentos envolvidos com a especificação da proteção de transformadores frente às descargas atmosféricas, bem como permitir que a análise do comportamento dos surtos de tensão de origem atmosférica que incidem em determinada na área de concessão possa ser executada de forma detalhada e sistemática. Para tanto, o sistema especialista desenvolvido faz a integração eficiente de abordagens e técnicas que levam em consideração os aspectos característicos das descargas atmosféricas, as análises experimentais representativas do fenômeno e os modelos matemáticos que permitam mapear todo o processo de desencadeamento das descargas atmosféricas.

A primeira fase da pesquisa objetivou a execução de atividades de investigação científica a respeito de modelos matemáticos que representam as sobretensões oriundas de descargas atmosféricas.

A segunda fase destinou à implementação dos procedimentos computacionais referentes aos modelos desenvolvidos para a simulação de surtos de tensão. A partir destas implementações foi possível simular diversas situações envolvendo os efeitos das sobretensões sobre um alimentador da rede de distribuição. Como resultado desta fase, o sistema computacional denominado "SimSurto" foi implementado visando à simulação de surtos de tensão de origem atmosférica, permitindo analisar os mesmos em diversas configurações envolvendo a disposição e características das linhas de distribuição em relação às descargas atmosféricas. 
Já a terceira fase da pesquisa consistiu principalmente na elaboração e definição de critérios técnicos que permitiram a especificação correta do tipo de proteção mais adequado para os transformadores, baseando-se nas implementações computacionais que possibilitaram calcular os valores de tensões induzidas oriundas de descargas atmosféricas. Assim sendo, levando-se em consideração o conhecimento prévio sobre as características das descargas atmosféricas que incidem na região de atuação da concessionária, tornou-se possível estruturar diversos critérios que possibilitaram incrementar a proteção de transformadores frente às sobretensões ocasionadas pelas descargas atmosféricas. Ressalta-se também que a plataforma de simulação de surtos de tensão “SimSurto" permitiu simular com bastante realismo o comportamento das tensões induzidas decorrentes de descargas atmosféricas indiretas, visto que as constatações observadas estão de acordo com diversos relatos descritos na literatura técnica-científica, e também com alguns resultados práticos reais que são disponibilizados pela comunidade científica envolvida com a área.

Finalmente, a quarta fase de desenvolvimento do projeto objetivou a implementação de um sistema computacional (Protection Plus) que auxilia nos procedimentos de especificação dos equipamentos de proteção do transformador, levando-se em consideração a seletividade requerida entre os seus dispositivos de proteção. Os procedimentos que foram envolvidos com a implementação deste sistema especialista têm promovido a integração sistemática das três abordagens (Métodos Computacionais, Critérios Técnicos, Aspectos das Descargas Atmosféricas) que têm sido investigadas neste projeto de pesquisa.

\subsection{ORGANIZAÇÃO DA DISSERTAÇÃO}

A organização dos capítulos desta dissertação está como se segue.

O Capítulo 2 descreve as atividades de investigação científica a respeito de modelos matemáticos que representam as sobretensões oriundas de descargas atmosféricas.

O Capítulo 3 fornece os aspectos envolvidos com a implementação dos procedimentos computacionais referentes aos modelos desenvolvidos para a simulação de surtos de tensão, os quais resultaram na confecção do sistema SimSurto.

O Capítulo 4 descreve os aspectos envolvidos com a elaboração e especificação de critérios técnicos que permitem definir o tipo de proteção mais adequado para os transformadores. 
O Capítulo 5 mostra os principais procedimentos relacionados com a confecção do sistema especialista, o qual resultou no desenvolvimento do sistema Protection Plus.

Finalmente, o Capítulo 6 descreve as conclusões referentes ao trabalho desenvolvido, assim como tece algumas proposições sobre a continuidade da pesquisa.

Para facilitar a leitura da dissertação, optou-se por apresentar as referências bibliográficas no final de cada capítulo abordado.

Como informação complementar, no decorrer do período de mestrado, os seguintes trabalhos foram publicados em anais de congressos científicos:

- SANTOS, Nerivaldo dos Reis, SILVA, Ivan Nunes, FLAUZINO, Rogério Andrade. “Sistemas Especialistas Para Projeto Otimizado de Sistemas de Aterramento e Proteção Eficiente de Transformadores Frente às Descargas Atmosféricas”, Anais do XIX Seminário Nacional de Distribuição de Energia Elétrica (CD-ROM // Paper No. uuj378 // 12 Páginas), 2010.

- SANTOS, Nerivaldo dos Reis, SILVA, Ivan Nunes, FLAUZINO, Rogério Andrade, SPATTI, Danilo Hernane. "Optimized Selection Approach of Transformer Protection Devices against Atmospheric Discharges Using Expert System”, Proceedings of the 2009 IEEE PES General Meeting (CD-ROM // Paper No. PESGM2009-001472 // 06 Páginas), 2009. 



\section{Capítulo 2}

\section{Aspectos de Investigação Técnico-Científica}

\subsection{INTRODUÇÃO}

Os focos dos estudos aqui constituíram na execução de atividades de investigação científica a respeito de modelos matemáticos que pudessem representar de forma realista as sobretensões oriundas de descargas atmosféricas, bem como os modelos de transformadores que pudessem ser utilizados na simulação do fenômeno. Conforme descrito no capítulo anterior, as atividades que foram desenvolvidas nesta fase foram de suma importância para a execução da pesquisa, pois a partir da investigação destes modelos e de suas respectivas implementações computacionais é que foi possível realizar as adequações necessárias nos mesmos de forma que pudessem ser simuladas diversas situações envolvendo os efeitos das sobretensões sobre uma rede de distribuição.

Mais especificamente, no que diz respeito aos modelos matemáticos de surtos de tensões provenientes de descargas atmosféricas, a investigação foi dividida em duas etapas principais, ou seja, o estudo de sobretensões devidas às descargas diretas e o estudo de sobretensões oriundas de descargas indiretas. Essa sistemática adotada contribuiu favoravelmente para a elaboração e confecção das etapas pertinentes ao projeto do sistema especialista.

Em relação ao estudo dos modelos de transformadores utilizados para representar as sobretensões oriundas de descargas atmosféricas, os mesmos foram de suma importância para verificar quais são os eventuais efeitos das sobretensões residuais que serão transferidas para o lado da baixa tensão, no qual provavelmente está a maior parte dos clientes das concessionárias de distribuição.

Conforme analisado nas investigações científicas realizadas, as descargas atmosféricas é a principal causa de interrupções não-planejadas nos sistemas de energia elétrica, incluindo 
linhas de transmissão e de distribuição. Estes fenômenos também se constituem como as principais fontes de danos em equipamentos instalados na rede de distribuição de energia. A especificação e projeto da proteção do sistema de distribuição contra os efeitos do fenômeno requerem a caracterização dos seus respectivos parâmetros condicionantes. O conhecimento de parâmetros locais típicos associados com as descargas atmosféricas, tais como os níveis de tensão, as correntes das descargas, os tipos de onda, as polaridades, a densidade de descargas locais e seus períodos críticos, contribuem para a melhoria da proteção dos equipamentos. As descargas atmosféricas que afetam os sistemas de distribuição podem ser caracterizadas em dois tipos básicos, ou seja, as descargas diretas e as descargas indiretas.

Em função dos níveis de tensão relativamente baixos das redes de baixa (127-440 V) e média tensão (13,8-34,5 kV), as incidências de descargas diretas em qualquer parte destas redes geram descargas disruptivas que são responsáveis pelo rompimento da isolação da rede e/ou de seus equipamentos. Além disso, as descargas diretas podem causar incêndios, explosões, danos e destruição de equipamentos que se encontram nas imediações do ponto de incidência.

Em relação às descargas indiretas, as quais ocorrem entre a nuvem e a terra, ou em estruturas localizadas próximas da rede de distribuição, estas provocam sobretensões induzidas nas linhas que podem ser maiores que os seus níveis de isolação. Diferentemente das descargas diretas, a presença de condutores neutros ou cabos guardas podem ter uma grande influência na sobretensão que foi gerada.

Outro fato relevante é que os sistemas de distribuição de energia elétrica, devidos às suas próprias configurações e aos seus níveis de exposição, estão mais propensos a serem afetados por descargas indiretas. Desta forma, as sobretensões que são oriundas destas descargas indiretas são na maioria dos casos as principais causadoras de danos aos equipamentos instalados na rede de distribuição. Assim sendo, devido à sua importância, as próximas seções deste capítulo dará maior ênfase à análise dos modelos matemáticos de tensões induzidas que foram investigados visando às respectivas adequações aos sistemas de distribuição de energia elétrica. Os principais fundamentos relacionados à metodologia de Rusck, a qual foi utilizada para a estimação das tensões induzidas em linhas de distribuição ocasionadas por descargas atmosféricas, serão então apresentados. 


\subsection{ESTIMAÇÃO DE TENSÕES INDUZIDAS UTILIZANDO O MÉTODO DE RUSCK}

A metodologia desenvolvida por Rusck em [1] é amplamente utilizada na estimação da tensão induzida em linhas de distribuição e transmissão aéreas ocasionadas por descargas atmosféricas indiretas nas vizinhanças da linha em questão.

O método de estimação da tensão induzida apresentado por Rusck tem como ponto de partida a modelagem da corrente de retorno imposta pela descarga atmosférica à linha de distribuição. Rusck calcula o campo elétrico originado por esta corrente de retorno na superfície do solo e, a partir deste campo elétrico e da configuração da linha multifilar, fornece os valores das tensões resultantes ao longo do trecho da linha de distribuição.

Em [2] é demonstrado formalmente que o desenvolvimento apresentado em [1] para o cálculo do campo elétrico resultante da corrente de retorno está correto. Este fato veio a contribuir com uma maior credibilidade ao método desenvolvido.

Um questionamento existente acerca desta teoria é que esta prevê valores de tensão induzida para os condutores de uma linha multifilar apenas em função da localização geométrica do condutor em relação ao ponto de incidência da descarga atmosférica, ou seja, uma linha com vários condutores de mesma altura e com pequeno espaçamento horizontal, como nas linhas de distribuição, tendo valores de tensão induzida iguais em cada condutor. Medições realizadas com a técnica do modelo reduzido [3,4], bem como medições reais realizadas na África do Sul, demonstram que a teoria de Rusck é coerente com os resultados experimentais [5].

Originalmente, Rusck propôs uma corrente para a descarga atmosférica na forma de degrau com amplitude $I$. A tensão induzida por esta descarga em uma linha infinita pode ser calculada por:

$$
\begin{aligned}
& V(x, t)=U(x, t)+U(-x, t) \\
& U(x, t)=30 \operatorname{Ih} \beta \cdot\left[\frac{(c t-x)}{y^{2}+\beta^{2}(c t-x)^{2}}\right]\left[1+\frac{x+\beta^{2}(c t-x)}{\sqrt{(\beta c t)^{2}+\left(1-\beta^{2}\right)\left(x^{2}+y^{2}\right)}}\right] \\
& \beta=\frac{v}{c} \approx \sqrt{\frac{1}{1+\frac{5.10^{5}}{I}}}
\end{aligned}
$$

onde: $V(x, t)$ é a tensão induzida (em volts) em um ponto $x$ da linha (em metros); $t$ é o tempo (em segundos); $c$ é a velocidade da luz no vácuo (em $\mathrm{m} / \mathrm{s}$ ); $I$ é o valor de pico da corrente de retorno (em amperes); $h$ é a altura da linha de distribuição (em metros); $y$ é a menor distância entre a 
linha e o ponto de incidência da descarga (em metros); e $x$ é um ponto ao longo da linha (em metros).

As equações (2.1), (2.2) e (2.3) expressam a base da teoria de Rusck. Em (2.4) tem-se a expressão para a máxima tensão induzida no ponto $x=0 \mathrm{~m}$.

$$
V_{\max } \approx \frac{30 \cdot I \cdot h}{y}
$$

A partir das expressões anteriores é possível identificar que a mesma fornece uma expressão analítica para o cálculo da tensão induzida em uma linha de distribuição, enquanto que as demais teorias existentes fornecem expressões iterativas e de grande custo computacional para desempenharem a mesma estimação.

Na Figura 2.1 é apresentada a tensão induzida no ponto $x=0 \mathrm{~m}$ para uma descarga atmosférica degrau com $I=10 \mathrm{kA}$ em uma linha infinita com 10m de altura e distância da descarga atmosférica à linha de distribuição de 100m. Na Figura 2.2 é apresentada a tensão induzida em diferentes pontos de medição.

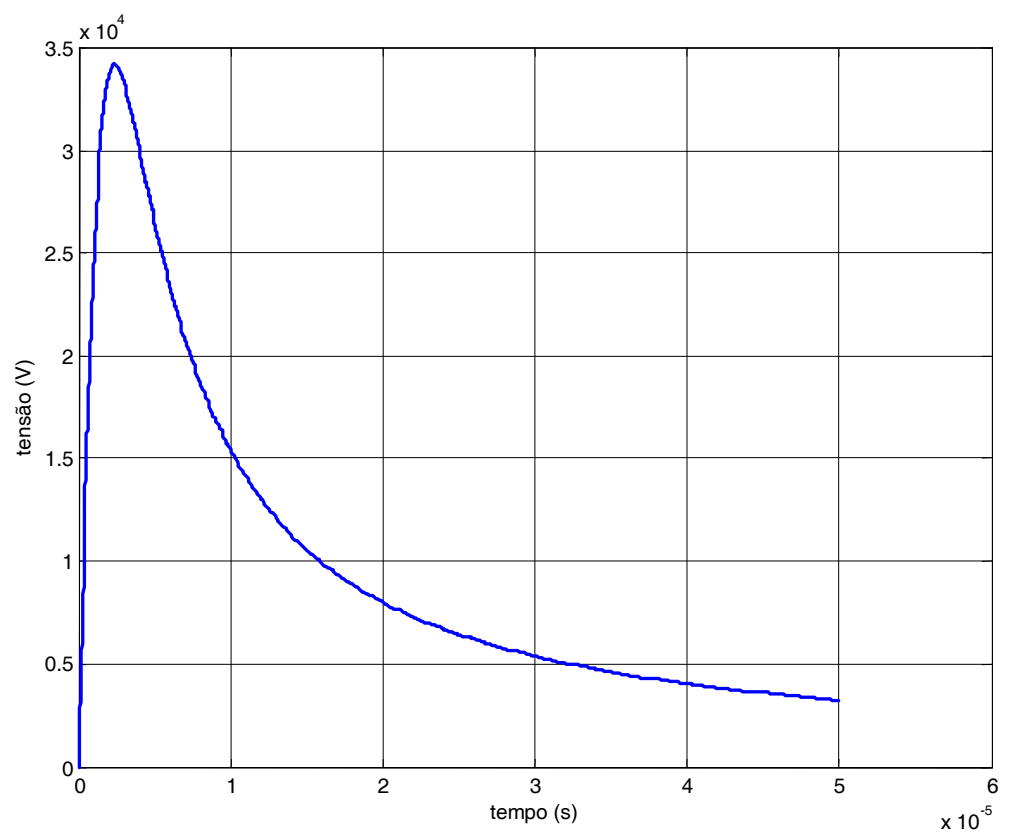

Figura 2.1 - Tensão induzida no ponto de máxima tensão em uma linha infinita com 10m de altura e descarga atmosférica de 10 kA a uma distância perpendicular de $100 \mathrm{~m}$ da linha. 


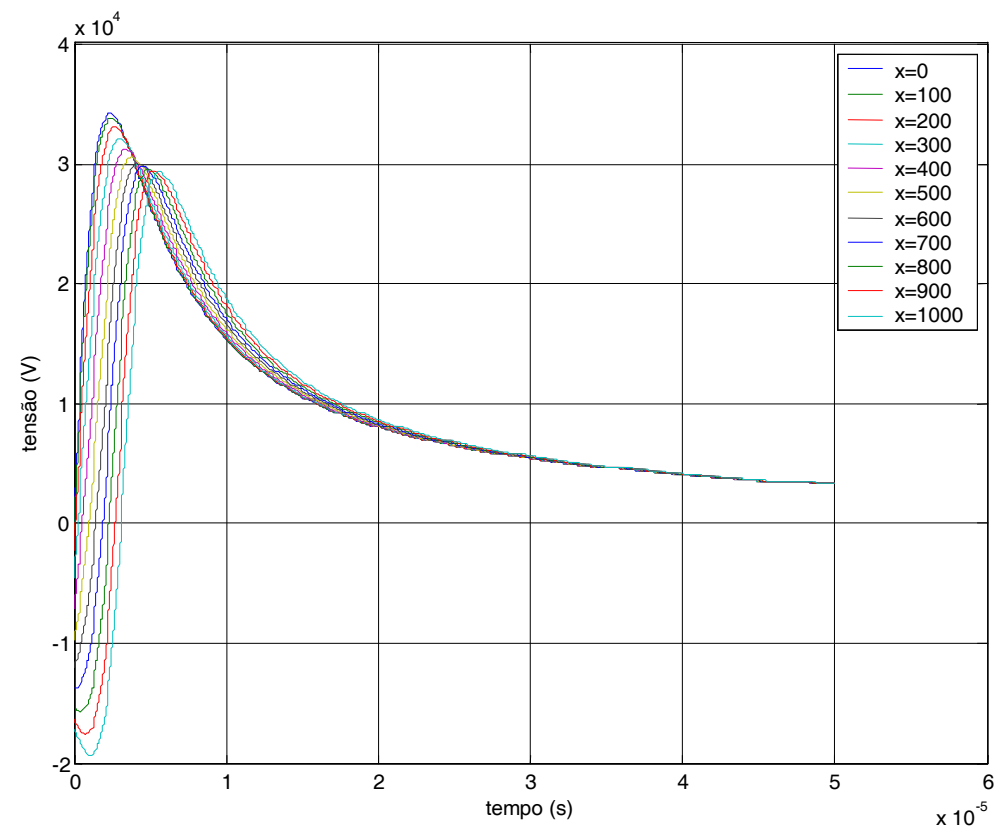

Figura 2.2 - Tensão induzida em uma linha de distribuição infinita com 10m de altura e descarga atmosférica de 10 kA a uma distância perpendicular de 100m da linha em diversos pontos ao longo da linha.

Pode-se observar por meio da Figura 2.2 que o formato de onda de tensão induzida se altera em função da distância entre o ponto de máxima tensão e o ponto de medida. As alterações sofridas ao longo da linha de distribuição na tensão induzida podem ser mais bem verificadas mediante a mensuração de parâmetros como máxima tensão induzida, tempo de subida, tempo de pico e tempo de meia onda. As Figuras 2.3, 2.4, 2.5 e 2.6 apresentam como estes parâmetros se alteram em função da distância entre o ponto de máxima tensão e um ponto ao longo deste condutor.

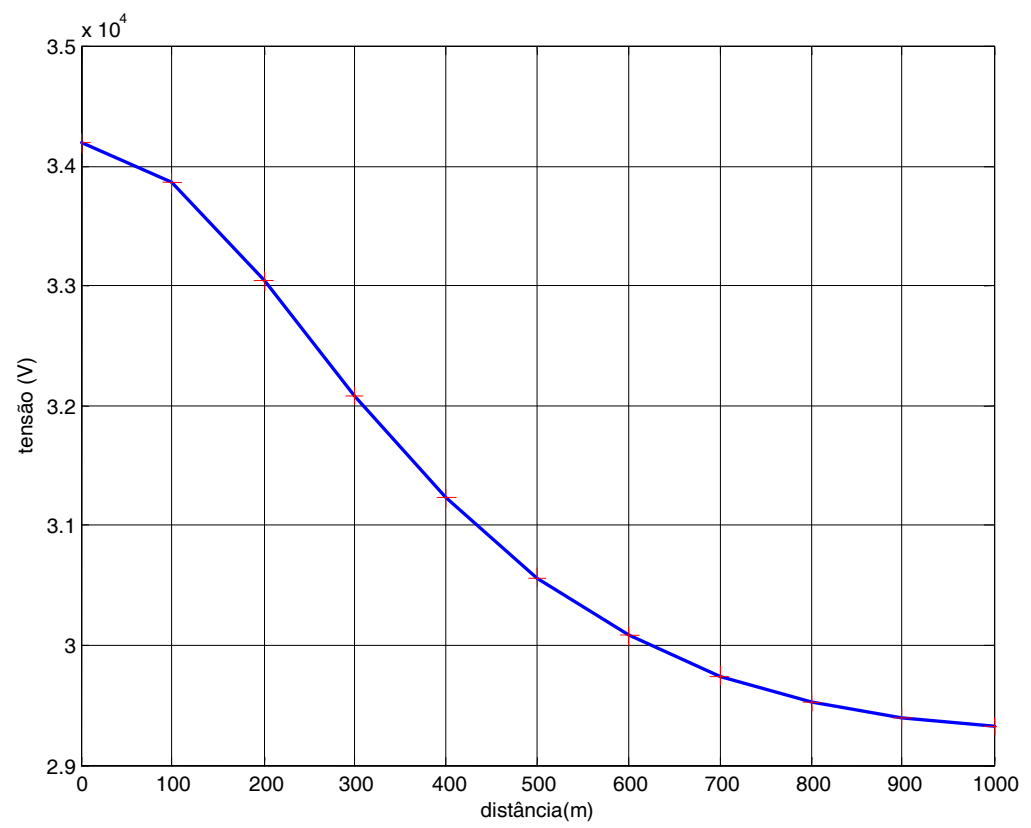

Figura 2.3 - Variação da máxima tensão induzida ao longo da linha de distribuição. 


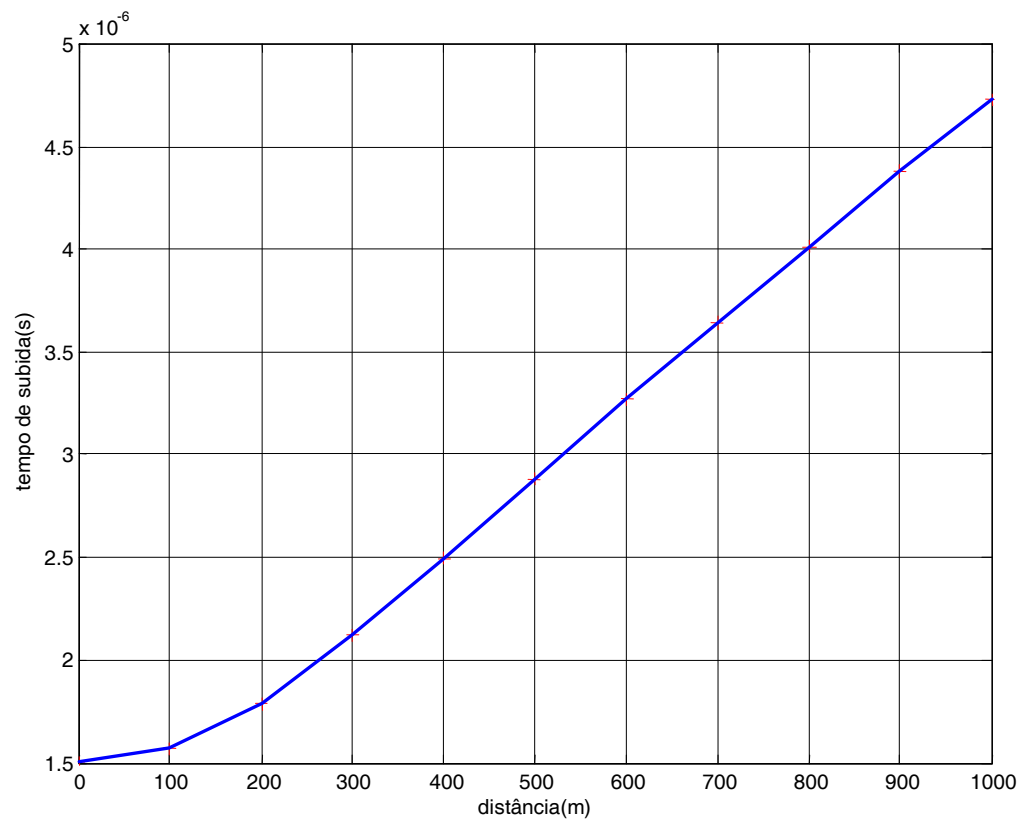

Figura 2.4 - Variação do tempo de subida ao longo da linha de distribuição.

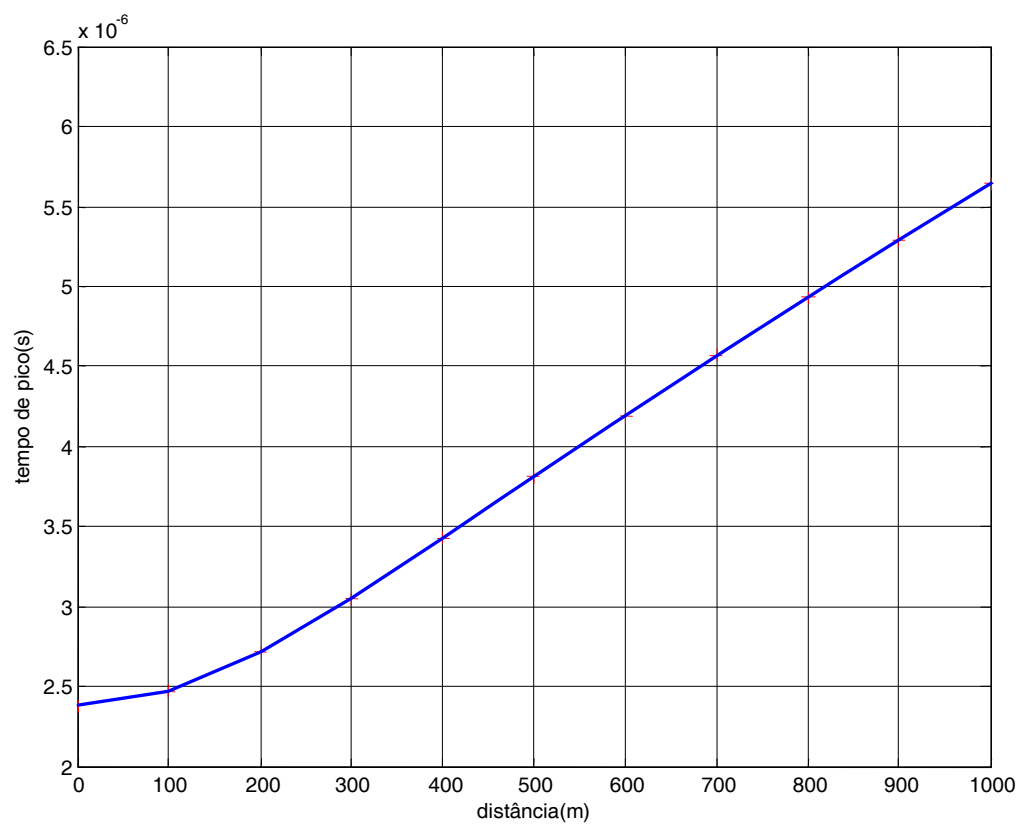

Figura 2.5 - Variação do tempo de pico ao longo da linha de distribuição. 


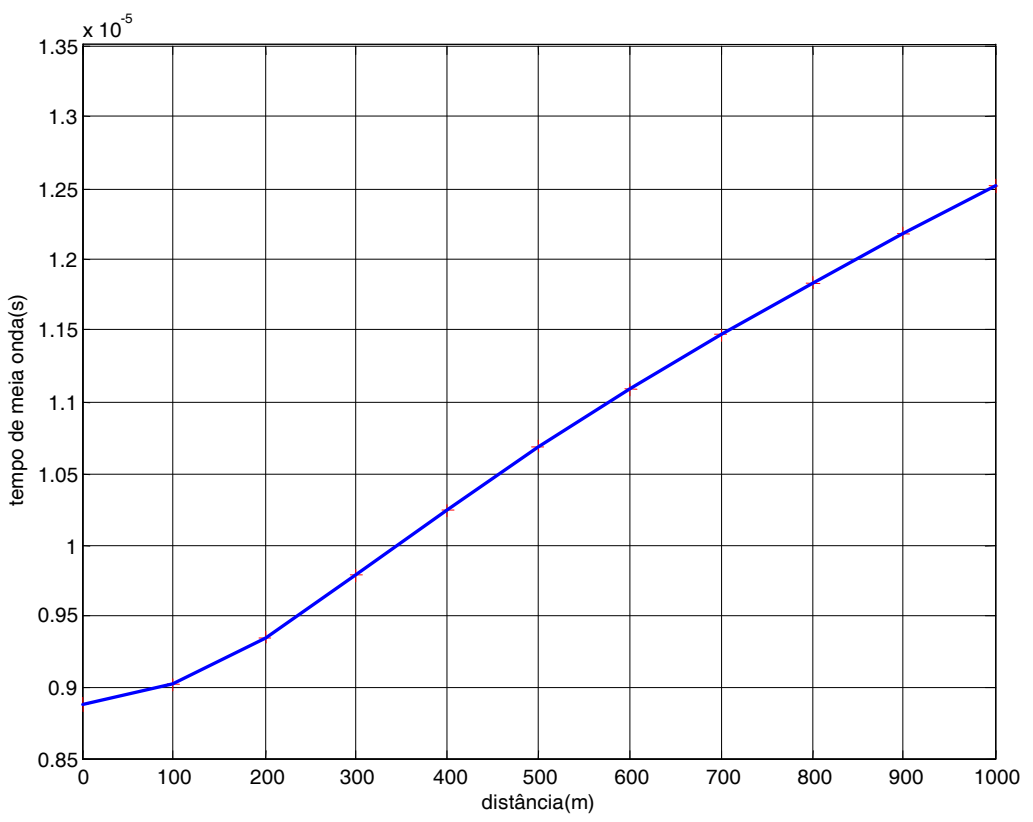

Figura 2.6 - Variação do tempo de meia onda ao longo da linha de distribuição.

Como pode ser observada pela Figura 2.3, a tensão ao longo do comprimento da linha decresce a uma taxa praticamente linear em alguns trechos em função da distância do ponto de ocorrência da descarga atmosférica. Esta observação indica que a onda de tensão ao longo da linha de distribuição sofre uma atenuação decorrente das altas freqüências envolvidas, bem como da dissipação de energia no condutor metálico.

As Figuras 2.4, 2.5 e 2.6 ilustram como o tempo de subida, o tempo de pico e o tempo de meia onda se alteram ao longo da linha de distribuição. Pode-se observar que estes três parâmetros tendem em aumentar a uma taxa praticamente constante ao longo da linha de distribuição. Este fato indica que a onda de tensão perde energia em função da distância ao longo da linha uma vez que, tempo subida, tempo de pico e tempo de meia onda maiores, ocasionam gradientes de tensão mais suaves ao longo da linha.

As simulações realizadas e apresentadas nesta seção com o auxílio da formulação proposta em [1] permite que se verifique a veracidade dos resultados fornecidos com aqueles obtidos por intermédio da experimentação em campo [5] ou mesmo com os resultados mediante a técnica do modelo reduzido [3,4].

No entanto, algumas modificações neste método se fazem necessárias com a finalidade de transpor esta metodologia para situações práticas e de interesse para os sistemas de distribuição [8,9]. Basicamente, é necessária a consideração de formas onda de corrente para a descarga atmosférica semelhantes àquelas encontradas na natureza. Isto se faz necessário devido 
à característica de descarga atmosférica considerada na dedução da metodologia de Rusck. Como apresentado no início desta seção, a forma de onda para a corrente de descarga atmosférica na metodologia de Rusck foi tida como sendo um degrau. A abordagem necessária para a consideração de uma forma de onda de corrente qualquer é apresentada na Seção 2.3. Outro fato relevante é a consideração da linha de distribuição como tendo comprimento infinito, sendo que a formulação matemática para se contornar esta limitação é desenvolvida na Seção 2.4.

\subsection{GENERALIZAÇÃO DA METODOLOGIA DE RUSCK PARA FORMAS DE ONDA DE CORRENTE DE DESCARGA GENÉRICAS}

A formulação de Rusck pressupõe que a descarga atmosférica pode ser representada por uma forma de onda degrau. Porém, medições realizadas em campo evidenciam que as características da forma de onda de corrente influenciam na tensão induzida nas linhas de distribuição próximas ao local de ocorrência da descarga. Mais especificamente, parâmetros como o tempo de subida e tempo de pico da onda de corrente possuem alta correlação no processo de indução de tensão nas linhas de distribuição. Desta maneira, sugere-se que a estimação da tensão induzida nas linhas de distribuição seja realizada considerando-se uma forma de onda para a corrente de descarga próxima àquela encontrada na natureza.

Uma abordagem adotada com freqüência para a modelagem da corrente de descarga atmosférica pode ser fornecida como em (2.5).

$$
i(t)=i_{h 1}(t)+i_{h 2}(t)+i_{d e}(t)
$$

onde:

$$
\begin{aligned}
& i_{h 1}(t)=\frac{I_{01}}{\eta_{1}} \frac{\left(\frac{t}{\tau_{11}}\right)^{n 1}}{1+\left(\frac{t}{\tau_{11}}\right)^{n 1}} \exp \left(-\frac{t}{\tau_{12}}\right) \\
& i_{h 2}(t)=\frac{I_{02}}{\eta_{2}} \frac{\left(\frac{t}{\tau_{21}}\right)^{n 2}}{1+\left(\frac{t}{\tau_{21}}\right)^{n 2}} \exp \left(-\frac{t}{\tau_{22}}\right) \\
& i_{d e}(t)=[(1-\exp (\alpha))-(1-\exp (\beta))]
\end{aligned}
$$

sendo: 


$$
\begin{aligned}
& \eta_{1}=\exp \left[-\left(\frac{\tau_{11}}{\tau_{12}}\right)\left(n 1 \frac{\tau_{12}}{\tau_{11}}\right)^{\frac{1}{n 1}}\right] \\
& \eta_{2}=\exp \left[-\left(\frac{\tau_{21}}{\tau_{22}}\right)\left(n 2 \frac{\tau_{22}}{\tau_{21}}\right)^{\frac{1}{n 2}}\right]
\end{aligned}
$$

As expressões (2.6) e (2.7) são exemplos de funções de Heidler. Uma alternativa freqüentemente empregada na modelagem da descarga atmosférica é a dupla exponencial. No entanto, a modelagem através das duas funções de Heidler, como apresentado em (2.5), fornece uma aproximação mais adequada ao fenômeno real, uma vez que a derivada da corrente no instante $t=0$ s é nula, fato este comprovado em diversos experimentos em campo.

Na Tabela 2.1 são apresentados os valores para as constantes utilizadas nas simulações desta seção.

Tabela 2.1 - Valor de constantes usadas para a simulação da corrente de descarga.

\begin{tabular}{|c||c|}
\hline Constante & Valor \\
\hline \hline$I_{01}$ & $10,7 \times 10^{3}$ \\
\hline$n 1$ & 2 \\
\hline$\tau_{11}$ & $0,25 \times 10^{-6}$ \\
\hline$\tau_{12}$ & $2,5 \times 10^{-6}$ \\
\hline$I_{02}$ & $6,5 \times 10^{3}$ \\
\hline$n 2$ & 2 \\
\hline$\tau_{21}$ & $2,1 \times 10^{-6}$ \\
\hline$\tau_{22}$ & $230,0 \times 10^{-6}$ \\
\hline$I_{d e}$ & 0 \\
\hline$\alpha$ & $5 \times 10^{4}$ \\
\hline$\beta$ & $3 \times 10^{5}$ \\
\hline
\end{tabular}

Na Figura 2.7 é apresentada a forma de onda de corrente resultante da modelagem apresentada nesta seção. 


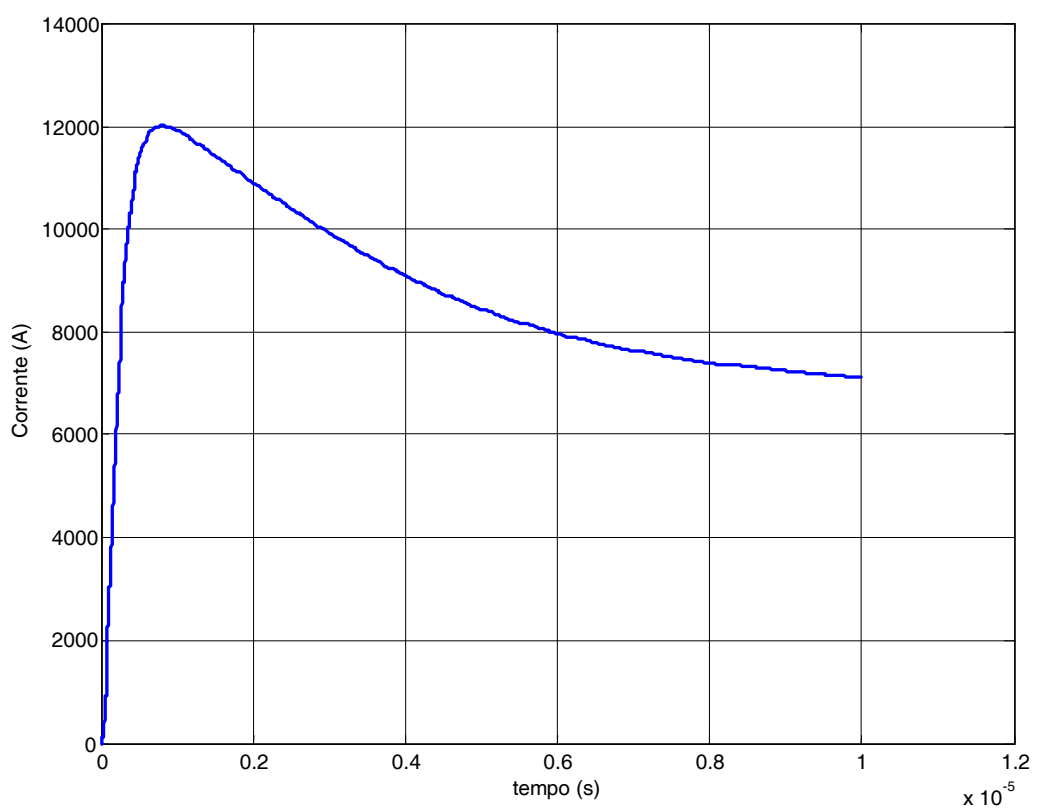

Figura 2.7 - Forma de onda de corrente para modelagem da descarga atmosférica.

A forma de onda de corrente apresentada na Figura 2.7 possui valor de pico de aproximadamente $12 \mathrm{kA}$ e tempo de pico de $0,81 \times 10^{-6} \mathrm{~s}$.

Supondo que o sistema seja linear é então possível o emprego da integral de Duhamel [6] a fim de representar a forma de onda de corrente através de uma série sucessiva de degraus. Desta forma, ao se adotar este procedimento, os valores de cada um dos degraus aos quais representam a forma de onda de corrente da Figura 2.7 podem ser fornecidos como na Figura 2.8 .

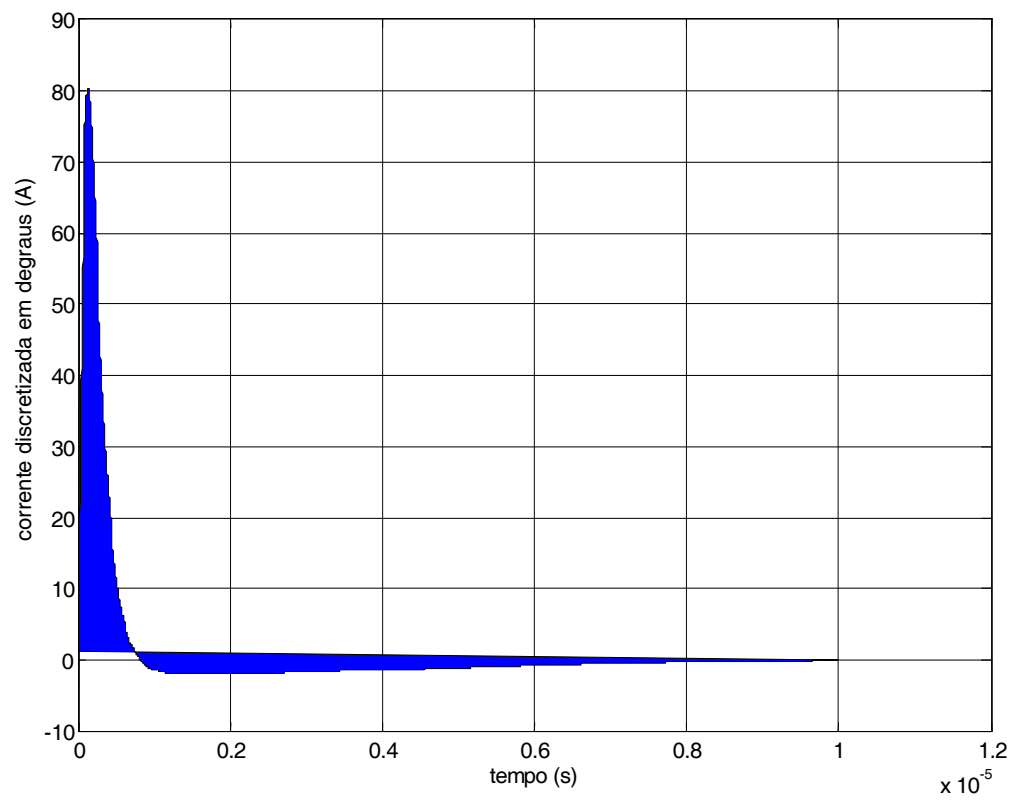

Figura 2.8 - Forma de onda de corrente discretizada em degraus. 
Procedendo desta maneira, a tensão induzida em um ponto $x$ qualquer da linha de distribuição pode ser dada pela somatória das contribuições individuais de cada componente de corrente discretizada.

Supondo uma descarga atmosférica caracterizada como na Figura 2.7, ocorrendo a uma distância de 100 m de uma linha de distribuição infinita instalada a uma altura de 10m, a forma de onda de tensão no ponto $x=0 \mathrm{~m}$ (ponto de máxima tensão) pode ser representada como na Figura 2.9.

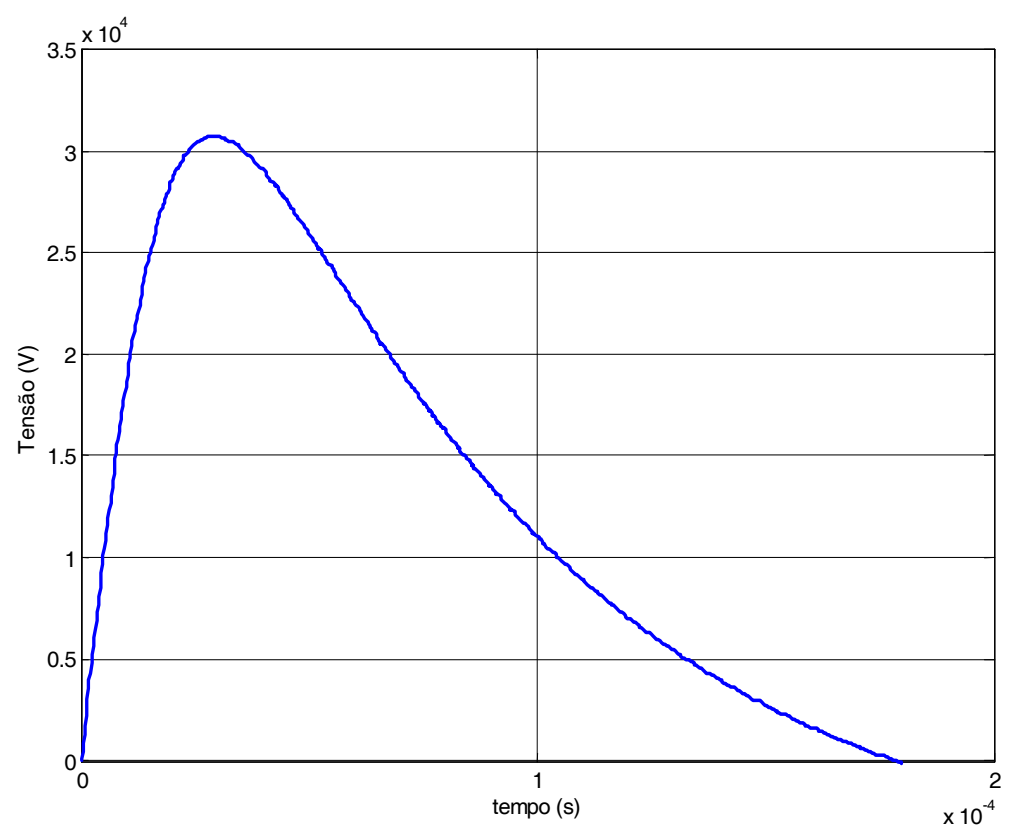

Figura 2.9 - Tensão induzida no ponto de máxima tensão para uma forma de onda de corrente expressa em termos de funções de Heidler.

Como mencionado no início desta seção, esta metodologia pode ser extensível para qualquer forma de onda de corrente. Outros tipos de forma de onda para a corrente de descarga serão apresentados no Capítulo 3 referentes aos estudos de casos.

\subsection{CONSIDERAÇÕES PARA ESTIMAÇÃO DE TENSÕES INDUZIDAS EM LINHAS FINITAS}

A expressão de Rusck para o cálculo da tensão induzida em linhas de distribuição é composta de duas parcelas, como pode ser observado por meio da seguinte expressão:

$$
V\left(x_{0}, t\right)=U\left(x_{0}, t\right)+U\left(-x_{0}, t\right)
$$

onde $V\left(x_{0}, t\right)$ é a tensão induzida no ponto $x_{0}$ da linha; $U\left(x_{0}, t\right)$ é a componente de tensão induzida devido à contribuição das cargas à direita do ponto $x_{0}$; e $U\left(-x_{0}, t\right)$ é a componente de tensão 
induzida devido à contribuição das cargas no trecho de linha à esquerda do ponto $x_{0}$. Na Figura 2.10 tem-se a interpretação da tensão induzida proposta na formulação sugerida por Rusck.

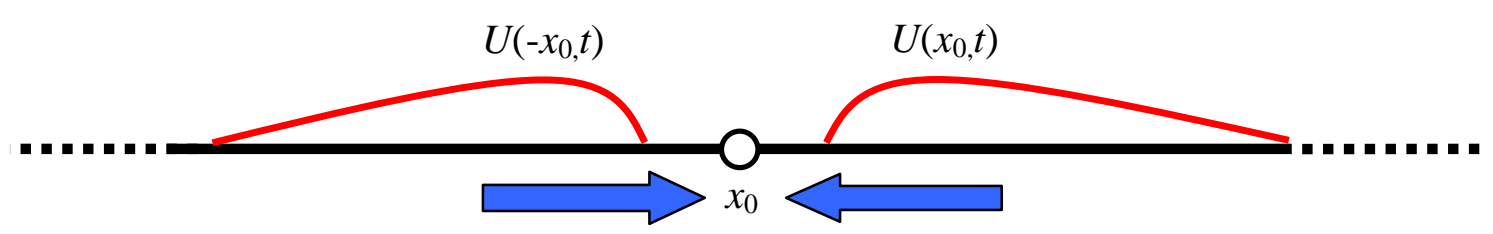

Figura 2.10 - Composição da tensão induzida em um ponto da linha.

No caso de uma linha finita, algumas modificações na teoria de Rusck podem ser incorporadas a fim de possibilitar a estimação da tensão induzida em um ponto qualquer de sua extensão, sendo então esta linha modelada de maneira mais adequada, conforme situações práticas reais. Assim, seja uma linha com terminação em $x_{1}$, com uma impedância de terminação $R_{f}$, conforme indicado na Figura 2.11 .

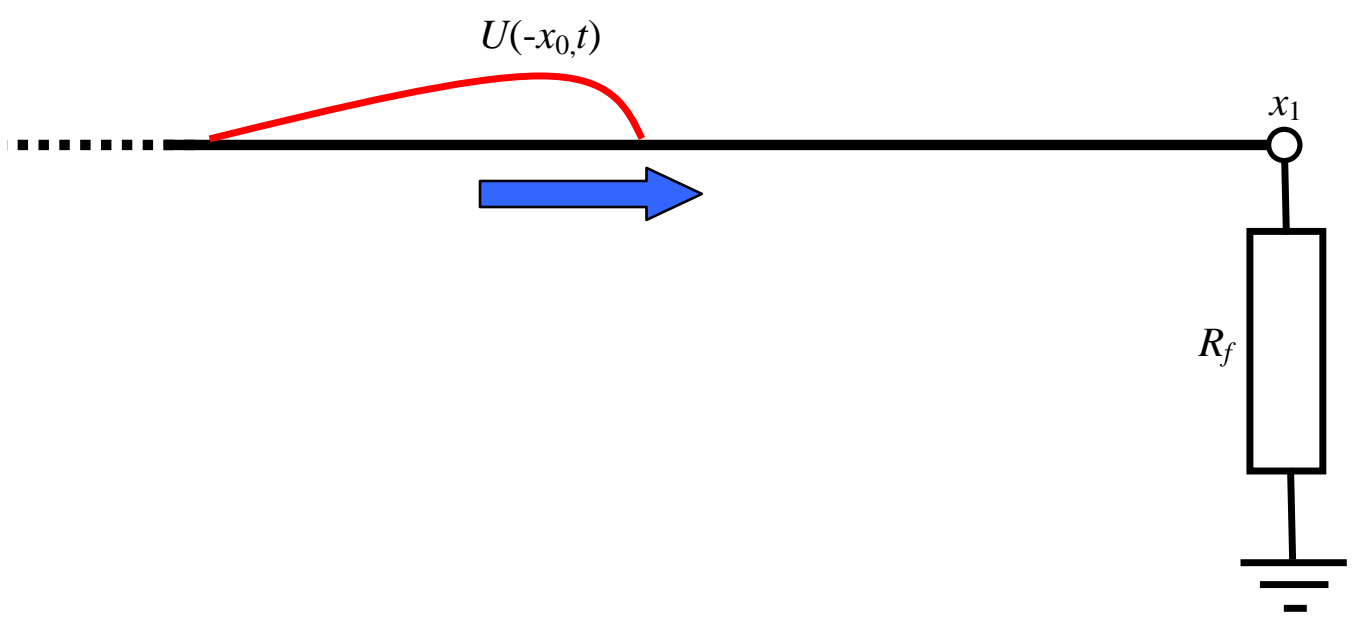

Figura 2.11 - Tensão induzida em uma linha finita.

Se a linha fosse infinita, a tensão no ponto $x_{1}$ seria dada por:

$$
V\left(x_{1}, t\right)=U\left(x_{1}, t\right)+U\left(-x_{1}, t\right)
$$

Como não existe linha à direita do ponto $x_{1}$, não se tem então a contribuição das cargas à direita de $x_{1}$, ou seja, a contribuição da tensão $U\left(x_{1}, t\right)$. Como a linha possui uma impedância de terminação, a tensão no ponto $x_{1}$ pode ser calculada como:

$$
V\left(x_{1}, t\right)=U\left(-x_{1}, t\right)+\Gamma U\left(-x_{1}, t\right)
$$

onde $\Gamma$ é denominado de coeficiente de reflexão. A expressão para o cálculo de $\Gamma$ é dada por: 


$$
\Gamma=\frac{R_{f}-\left|Z_{L}\right|}{R_{f}+\left|Z_{L}\right|}
$$

onde $Z_{L}$ é a impedância característica da linha de distribuição, sendo este definido por:

$$
Z_{L}=138 \log \left(2 \frac{h}{r}\right)
$$

onde $h$ é a altura da linha de distribuição e $r$ é o diâmetro do seu condutor.

Supondo-se que a descontinuidade no ponto $x_{1}$ seja substituída por uma fonte de compensação, o valor desta fonte pode ser calculado conforme o desenvolvimento a seguir.

$$
\begin{aligned}
& V\left(x_{1}, t\right)+\Delta V=U\left(-x_{1}, t\right)+\Gamma U\left(-x_{1}, t\right) \\
& U\left(x_{1}, t\right)+U\left(-x_{1}, t\right)+\Delta V=U\left(-x_{1}, t\right)+\Gamma U\left(-x_{1}, t\right) \\
& \Delta V=\Gamma U\left(-x_{1}, t\right)-U\left(x_{1}, t\right)
\end{aligned}
$$

A fonte de compensação de valor $\Delta V$ é aplicada no ponto $x_{1}$, mas o seu efeito deve ser propagado para toda a linha, uma vez que a não existência de linha à direita de $x_{1}$ altera os valores de tensão induzida ao longo de toda a linha.

Desejando-se calcular a tensão em um ponto $x$ qualquer, pode-se somar a tensão induzida calculada para o ponto $x$ (supondo linha infinita) ao valor da fonte de compensação aplicada em $x_{1}$. Deve-se observar, no entanto, que a tensão da fonte de compensação localizada em $x_{1}$ sofre um atraso de tempo no percurso entre $x$ e $x_{1}$, ou seja:

$$
V(x, t)=U(x, t)+U(-x, t)+\left[\Gamma U\left(-x_{1}, t\right)-U\left(x_{1}, t\right)\right] u\left(t-t_{f}\right)
$$

A parcela $u\left(t-t_{f}\right)$ é a função degrau unitário, isto é:

$$
u\left(t-t_{f}\right)= \begin{cases}0, & \text { se } t<t_{f} \\ 1, & \text { se } t \geq t_{f}\end{cases}
$$

onde $t_{f}$ é o valor do tempo de trânsito entre o ponto $x$ e o ponto $x_{1}$, ou seja:

$$
t_{f}=\frac{\left|x-x_{1}\right|}{v_{0}}
$$

onde $v_{0}$ é a velocidade de propagação, que para as simulações em questão serão tomadas como sendo igual à velocidade da luz, como também foi assumido em [7,10].

O mesmo procedimento pode ser realizado supondo-se uma descontinuidade à esquerda de $x$. Assim, supondo-se uma linha finita, com início no ponto $x_{0}$ e terminação em $x_{f}$, a tensão 
induzida em um ponto $x$ ao longo da linha de distribuição poderá ser estimada segundo a seguinte expressão:

$$
\begin{aligned}
& V(x, t)=U(x, t)+U(-x, t)+\left[\Gamma U\left(-x_{f}, t\right)-U\left(x_{f}, t\right)\right] u\left(t-t_{f}\right)+\ldots \\
& \ldots+\left[\Gamma U\left(x_{0}, t\right)-U\left(-x_{0}, t\right)\right] u\left(t-t_{0}\right)
\end{aligned}
$$

A substituição do efeito de uma descontinuidade por uma fonte de tensão de compensação é um procedimento eficiente, principalmente quando se deseja escrever algoritmos computacionais.

\subsection{CONSIDERAÇÕES PARCIAIS}

Neste capítulo foram apresentados os principais aspectos relacionados à metodologia de Rusck para a estimação da tensão induzida em linhas de distribuição. As modificações necessárias para a aplicação desta metodologia às situações reais foram desenvolvidas e apresentadas, cabendo-se aqui ressaltar que não foram consideradas as diferentes características dos solos. Desta maneira, muitos dos aspectos que na teoria original não seriam considerados foram acrescidos neste trabalho, possibilitando assim a aplicação deste método na estimação da tensão induzida junto a casos práticos e freqüentemente encontrados junto às redes de distribuição das concessionárias.

\subsection{REFERÊNCIAS BIBLIOGRÁFICAS}

[1] S. Rusck, Induced Lightning Over-voltage on Power Transmission Lines with Special Reference to Over-voltage Protection of Low Voltage Networks. Stockholm, Royal Institute of Technology, Ph.D. Thesis, 1957.

[2] M. Rubinstein, M. A. Uman, "Methods for calculating the electromagnetic fields from a know source distribution: Application to lightning”. IEEE Transactions on Electromagnetic Compatibility, vol. 31, no. 2, pp. 183-189, May 1989.

[3] S. C. M. de Paula, R. G. Mendonça, L. M. Neto, C. A. G. Medeiros, R. V. R. Silva, "Evaluation of performance of groundings electrics in conditions of lightning current". Canadian Conference on Electrical and Computer Engineering, Toronto, Canada, 2001, 737-742. 
[4] J. C. Salari, C. Portela, "A methodology for electromagnetic transients calculation - an application for the calculation of lightning propagation in transmission lines”. IEEE Transactions on Power Delivery, vol. 22, no. 1, pp. 527-536, 2007.

[5] A.J. Eriksson, M.F. Stringfellow, M.F. Meal, “Lightning induced overvoltages on overhead transmission lines”. IEEE Transaction on Power Apparatus and Systems, vol. 101, no. 4, pp. 960-968, April 1982.

[6] A. Greenwood, Electrical Transients in Power Systems. John Wiley \& Sons Inc., New York, 1992.

[7] S. R. Naidu, Transitórios Eletromagnéticos em Sistemas de Potência”. Co-edição EletrobrásUFPB, 1985.

[8] M. Darveniza, “A practical extension of Rusck’s formula for maximum lightning-induced voltages that accounts for ground resistivity”. IEEE Transactions on Power Delivery, vol. 22, no.1, pp. 605-612, 2007.

[9] A. Borghetti, C. A. Nucci, M. Paolone, “An improved procedure for the assessment of overhead line indirect lightning performance and its comparison with the IEEE Std. 1410 method”, IEEE Transactions on Power Delivery, vol. 22, no.1, pp. 684-692, 2007.

[10] G. V. Cooray, The Lightning Flash. IEE Power \& Energy Series, London, 2003. 



\section{Capítulo 3}

\section{Aspectos da Implementação Computacional}

\subsection{INTRODUÇÃO}

Os procedimentos computacionais desenvolvidos foram baseados naquelas atividades de investigação científica apresentadas no capítulo anterior, as quais consistiram da avaliação e da melhoria de modelos matemáticos que pudessem ser aplicados no mapeamento de surtos de tensão, e que levariam também em consideração os principais aspectos das descargas atmosféricas incidentes em determinada área de concessão da distribuidora.

Para a confecção desta plataforma computacional para simulação de surtos de tensão foi necessária a utilização de ferramentas de suporte computacional (software) que apresentassem uma série de características importantes, tais como eficiência, confiabilidade e facilidade de implementação/interação usuário-máquina.

Além das simulações efetuadas por meio do programa ATP (Alternative Transients Program), tem-se também confirmado a validade das implementações que foram realizadas através do software científico MATLAB. Assim sendo, tiveram-se garantias adicionais que as implementações desenvolvidas fornecessem resultados condizentes com a realidade, estando também em sintonia com os valores reportados na literatura técnica-científica. Uma característica adicional do MATLAB é que este é bastante interativo e possui uma interface usuário-máquina com um bom nível de interação, o que facilita a elaboração de gráficos e figuras.

No capítulo anterior foram apresentados os principais aspectos relacionados à metodologia de Rusck para a estimação da tensão induzida em linha de distribuição. No entanto, algumas das características da teoria original não permitiam o seu correto emprego em situações práticas, as quais são próprias de sistemas de distribuição real. Desta maneira, desenvolvimentos subseqüentes se fizeram necessários. As principais modificações realizadas sob a teoria original 
versavam, basicamente, sobre a consideração de uma forma de onda de descarga genérica e sobre a consideração de uma linha finita. Assim, com os devidos aprimoramentos incorporados à teoria original, o processo de estimação da tensão induzida decorrente de descargas atmosféricas em uma linha de distribuição foi realizado com mais precisão, não acarretando em erros significativos quando comparado com mensurações realizadas em campo. Os resultados apresentados pela metodologia desenvolvida condizem com os resultados mensurados em campo e descritos na bibliografia correlata.

A qualidade dos dados obtidos em simulações computacionais prévias, bem como as análises dos mesmos, forneceu uma contribuição acentuada para o desenvolvimento de um programa computacional para a estimação da tensão induzida em linha de distribuição, o qual foi denominado "SimSurto".

\subsection{DESCRIÇÃO FUNCIONAL DA PLATAFORMA COMPUTACIONAL PARA ESTIMAÇÃO DE TENSÕES INDUZIDAS OCASIONADAS POR DESCARGAS ATMOSFÉRICAS EM LINHAS DE DISTRIBUIÇÃO}

Todo o desenvolvimento realizado para a correta estimação das tensões induzidas em linhas de distribuição ocasionadas por descargas atmosféricas indiretas foi implementado computacionalmente na forma de uma plataforma computacional. A principal vantagem em se implementar este estudo em uma plataforma computacional é a disponibilidade de uma ferramenta adequada para a realização rápida e eficiente de estudos relacionados à natureza deste fenômeno.

O desenvolvimento desta plataforma computacional foi previamente planejado, sendo que o planejamento funcional de sua implementação pode ser representado por meio do fluxograma apresentado na Figura 3.1. 


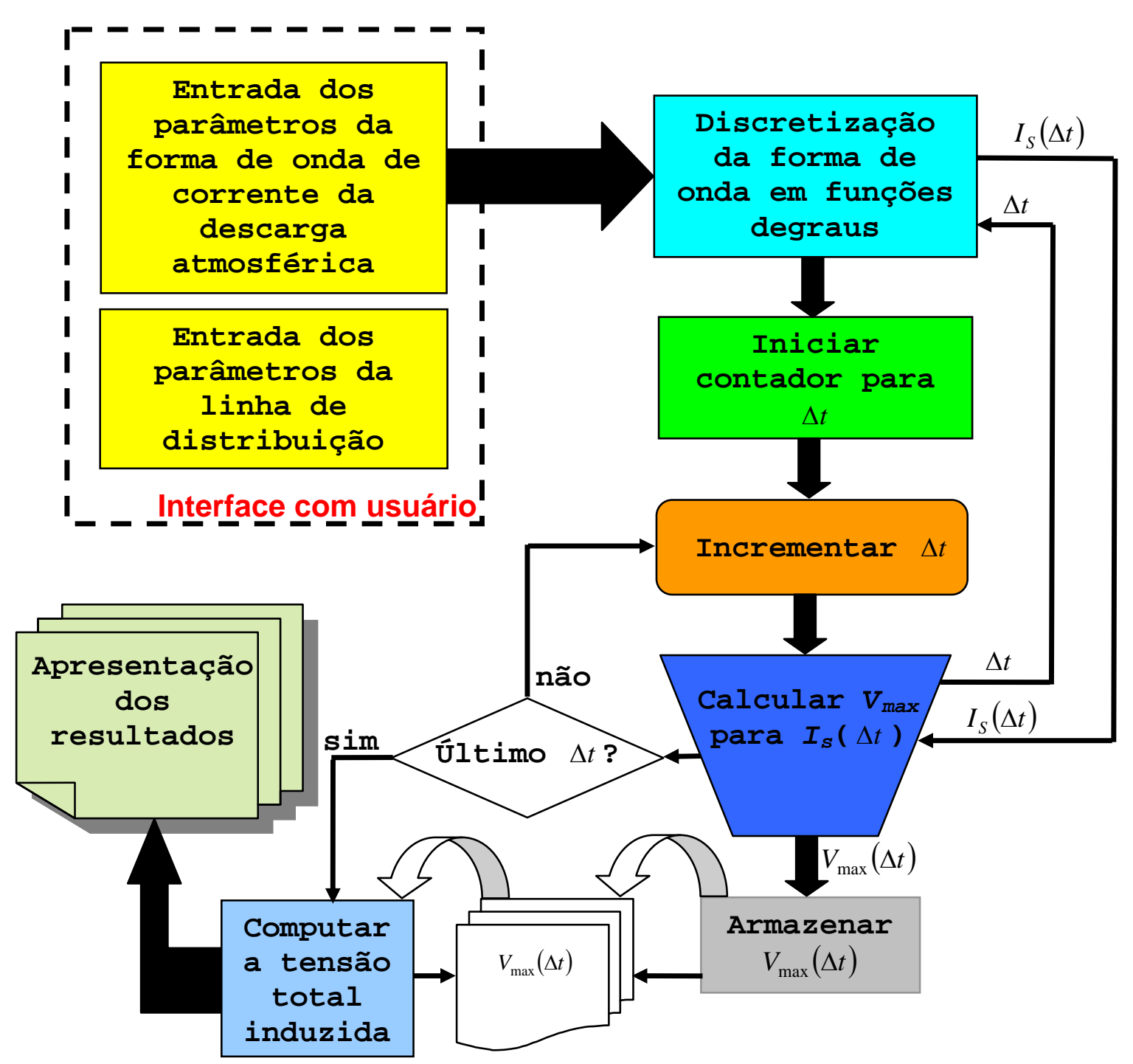

Figura 3.1 - Fluxograma do cálculo da tensão induzida através da metodologia de Rusck.

Desta forma, nas seções subseqüentes será apresentado detalhadamente o funcionamento da plataforma computacional desenvolvida. A implementação do algoritmo de estimação de tensão induzida torna-se transparente para o usuário, assim, o foco principal deste capítulo será a explicação das funcionalidades implementadas na plataforma computacional.

\subsection{INICIANDO UM NOVO PROJETO DE ESTIMAÇÃO DE TENSÃO INDUZIDA}

A tela inicial da plataforma computacional desenvolvida é apresentada na Figura 3.2. 


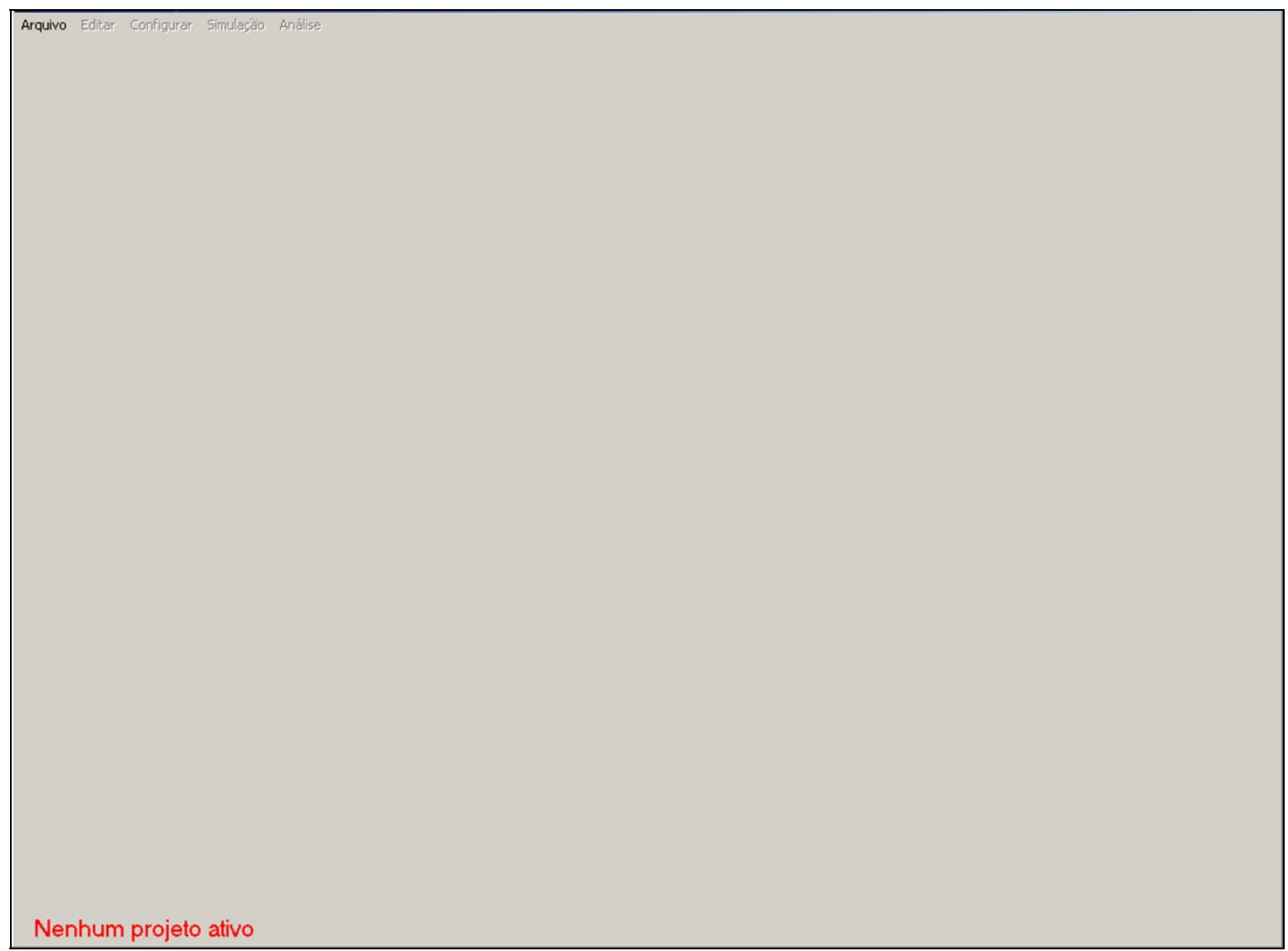

Figura 3.2 - Tela principal e área de trabalho da plataforma computacional.

Na parte inferior da tela principal tem-se uma barra de status indicando ao usuário a descrição do projeto ativo, ou ainda, como no caso apresentado na Figura 3.2, indicando que não há nenhum projeto ativo.

Com a finalidade de facilitar o uso e tornar este mais amigável ao usuário, implementaram-se praticamente todas as funcionalidades nesta tela principal. Esta tela será denominada de área de trabalho.

Na seção seguinte os passos necessários para a criação de um novo projeto serão descritos.

\subsection{CRIAÇÃO DE UM NOVO PROJETO DE ESTIMAÇÃO DE TENSÃO INDUZIDA EM LINHA DE DISTRIBUIÇÃO}

O primeiro passo para se criar um novo projeto de estimação de tensão induzida em linhas de distribuição é entrar no menu Arquivo e escolher a opção Novo. O menu Arquivo encontra-se parte superior esquerda da Área de Trabalho. Este procedimento é apresentado nas Figuras 3.3 e 3.4 . 


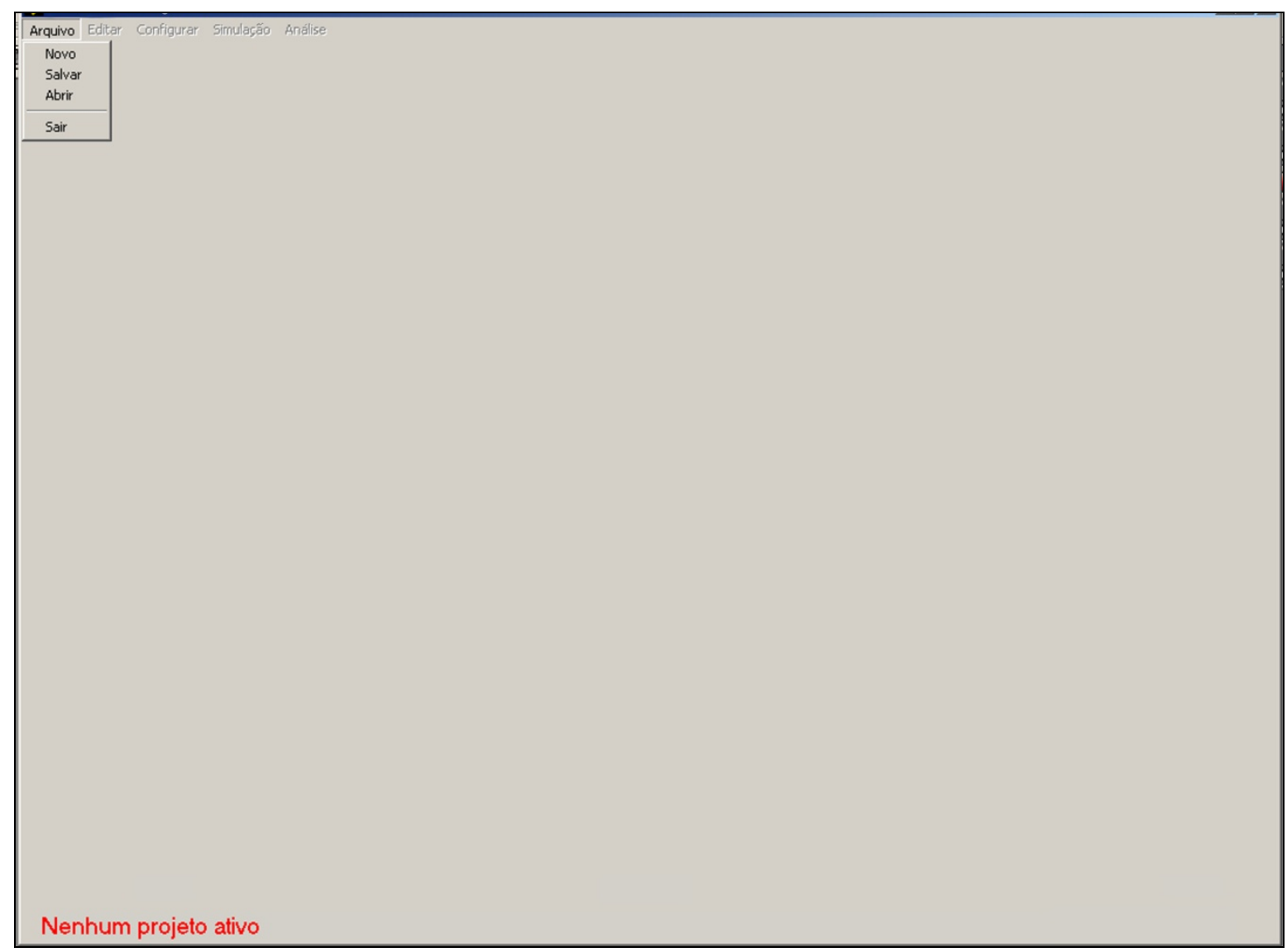

Figura 3.3 - Menu “Arquivo” e opção “Novo”.

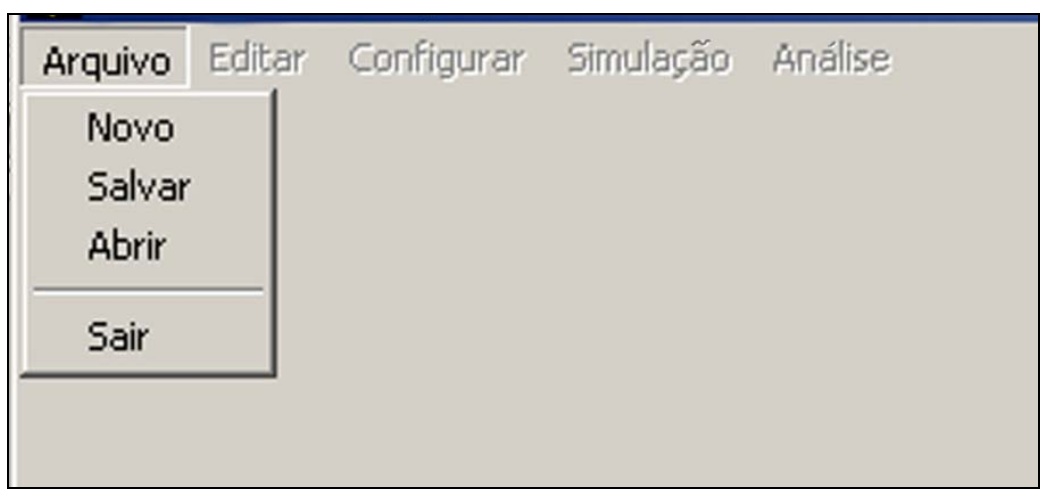

Figura 3.4 - Detalhes da barra de menu, item “Arquivo” e opção “Novo”.

Escolhendo-se a opção Novo, será então apresentado ao usuário a Tela de Iniciação de Novo Projeto, conforme apresentado na Figura 3.5. 


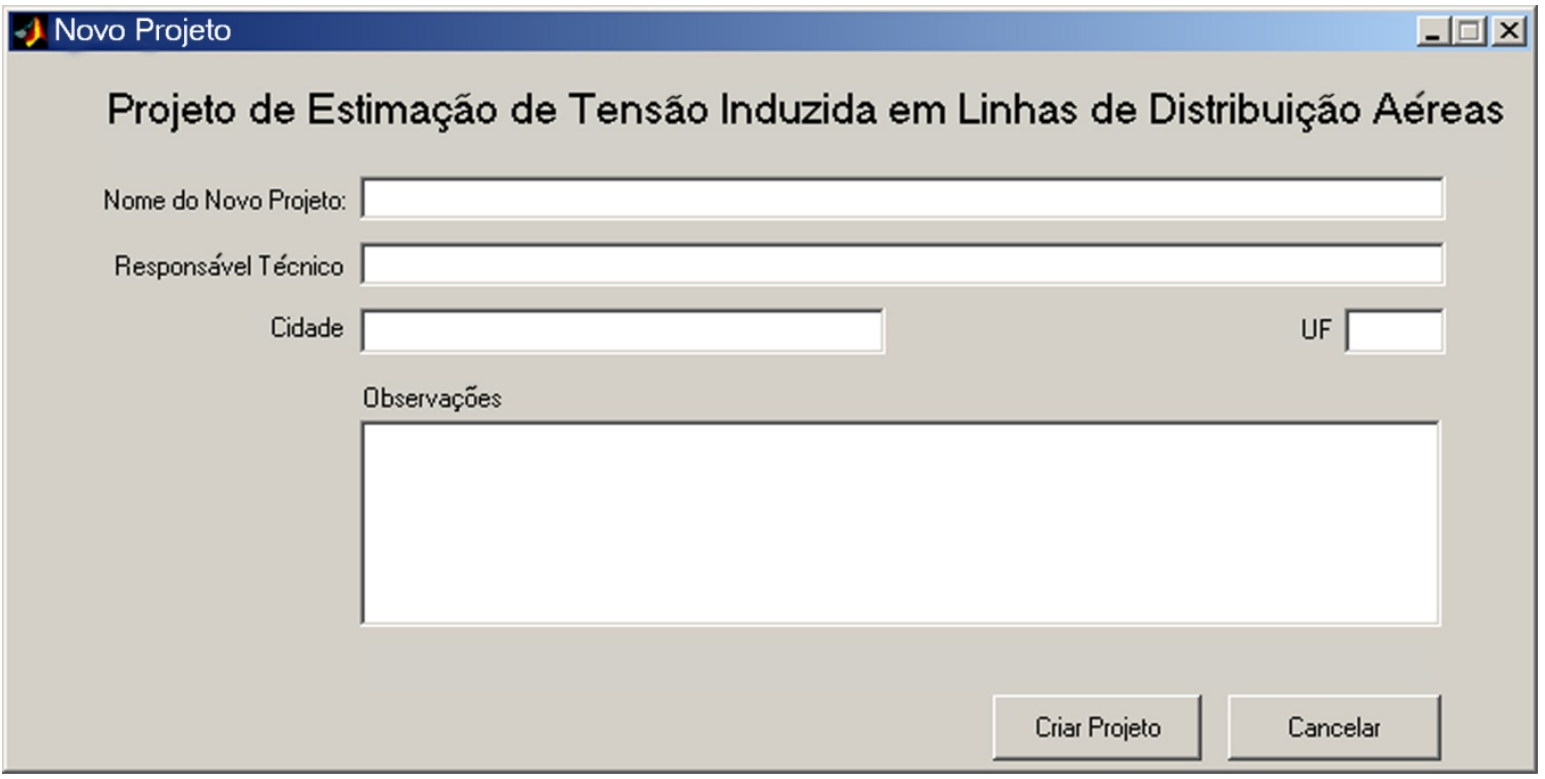

Figura 3.5 - Tela de iniciação de novo projeto.

A tela de iniciação de novo projeto apresenta ao usuário os seguintes campos:

๑ Nome do Novo Projeto: Campo de preenchimento obrigatório. O usuário deve especificar um nome para o projeto de estimação de tensão induzida que ele deseja criar.

\ Responsável Técnico: Nome do responsável técnico pelo estudo de tensão induzida.

a Cidade: Quando se deseja realizar o estudo de tensão induzida para uma linha de distribuição em específico é conveniente que a cidade seja especificada.

\ UF: Sigla do Estado da cidade especificada no campo Cidade.

๑ Observações: Este campo está reservado para que o responsável técnico pelo estudo de tensão induzida realize alguma observação necessária ao projeto em questão.

Na Figura 3.6 é apresentada uma Tela de Iniciação de Novo Projeto devidamente preenchida. 


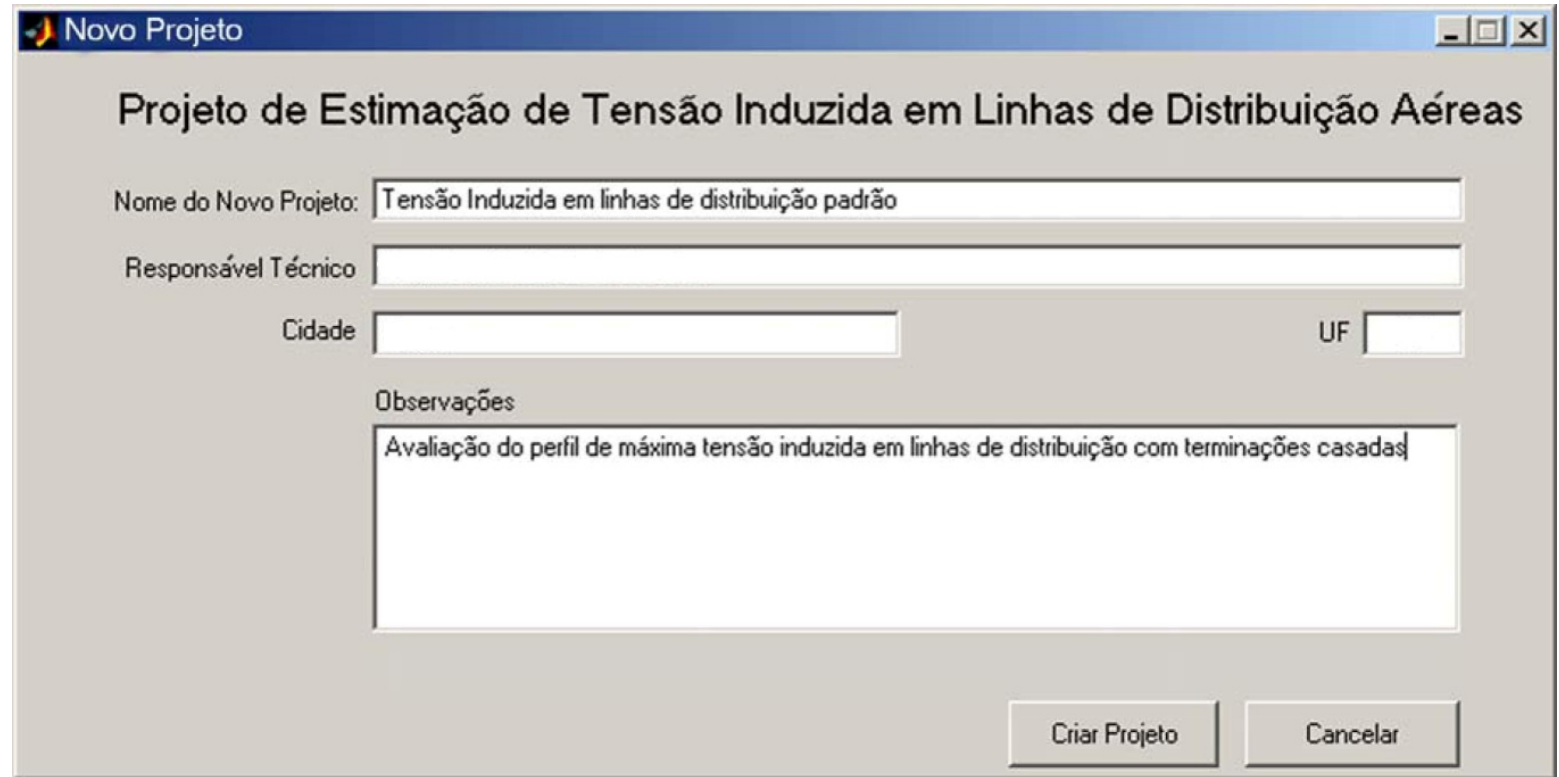

Figura 3.6 - Tela de iniciação de novo projeto devidamente preenchida.

A criação do novo projeto é efetuada pressionando o botão “Criar Projeto”, localizado no canto inferior direito da Tela de Iniciação de Novo Projeto.

Uma mensagem com informações a respeito da criação no novo projeto deve aparecer na Tela de Iniciação de Novo Projeto, como apresentado na Figura 3.7.

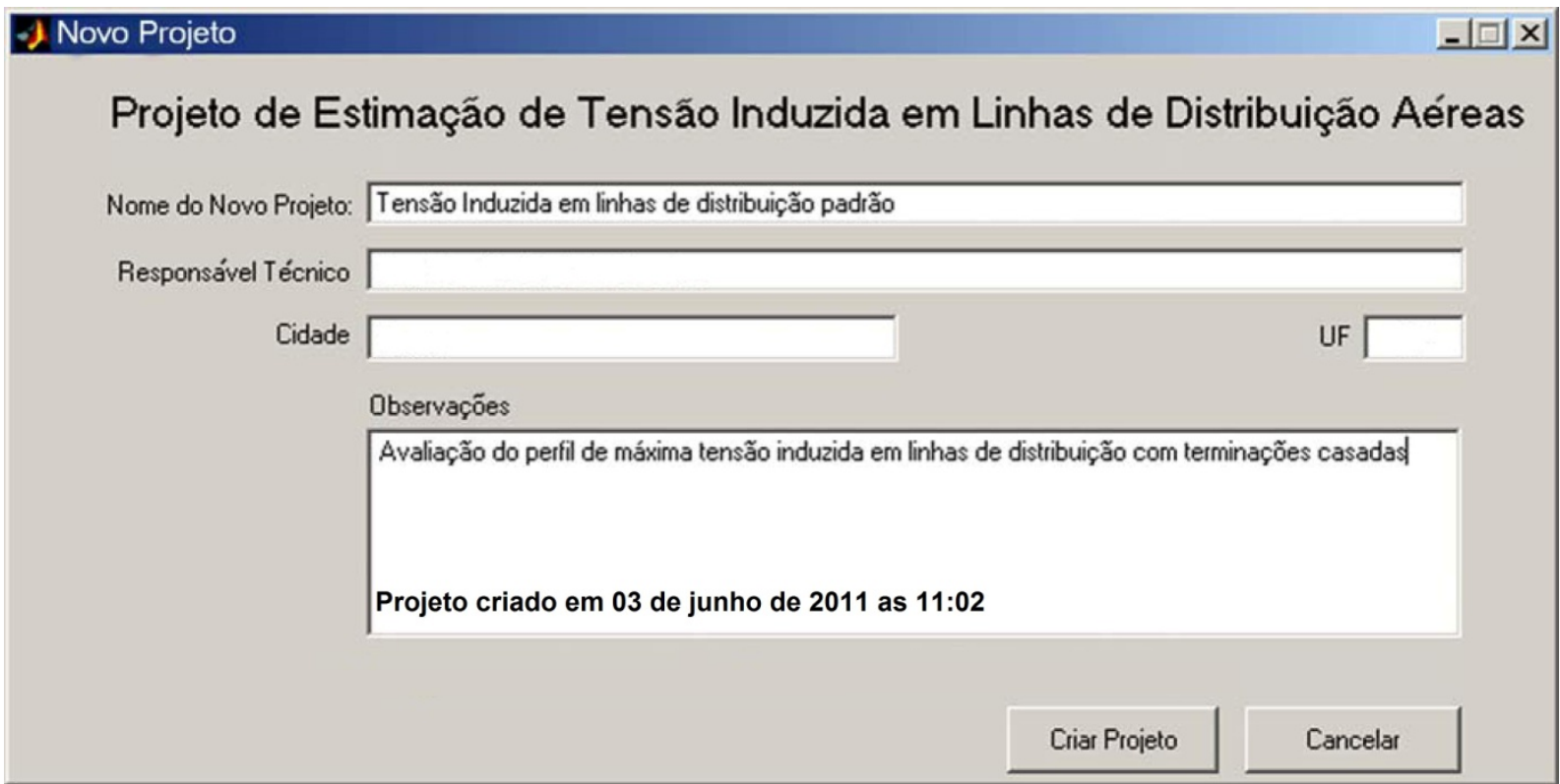

Figura 3.7 - Mensagem de criação do novo projeto.

A configuração dos parâmetros do projeto criado é apresentada na Seção 3.5. 


\subsection{CONFIGURAÇÃO DOS PARÂMETROS DE UM NOVO PROJETO}

Após a criação de um novo projeto, a Área de Trabalho então apresentará ao usuário as informações inseridas na Tela de Iniciação de Novo Projeto através da Barra de Status. Além disso, será também apresentado a Tela de Configuração Interativa de Projeto. A Tela de Configuração Interativa de Projeto tem por finalidade auxiliar o usuário na configuração de todos os parâmetros necessários para o estudo de tensões induzidas em linhas de distribuição. Na Figura 3.8 é mostrada a Área de Trabalho que é apresentada ao usuário logo após a criação de um novo projeto.

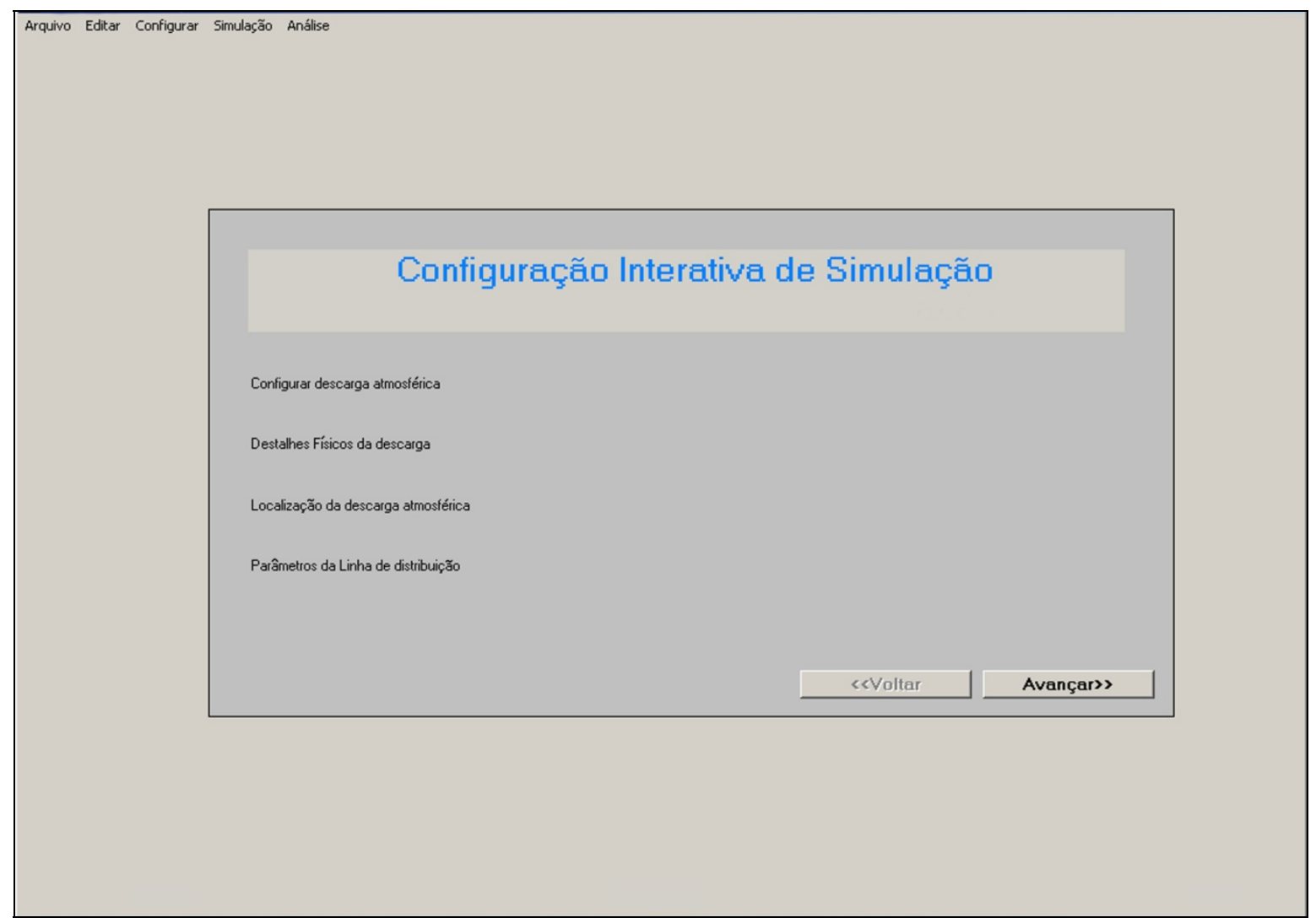

Figura 3.8 - Área de trabalho após a criação de um novo projeto.

A Área de Trabalho indica ao usuário quais os parâmetros que devem ser configurados, ou sejam:

\ Configuração da descarga atmosférica.

๑ Parâmetros físicos da descarga atmosférica.

๑ Localização da descarga atmosférica.

๑ Parâmetros da linha de distribuição.

Pressionando o botão “Avançar”, a Tela de Configuração de Descarga Atmosférica será então apresentada, conforme ilustração da Figura 3.9. 


\section{Descarga Atmosférica: Configuração Padrão}

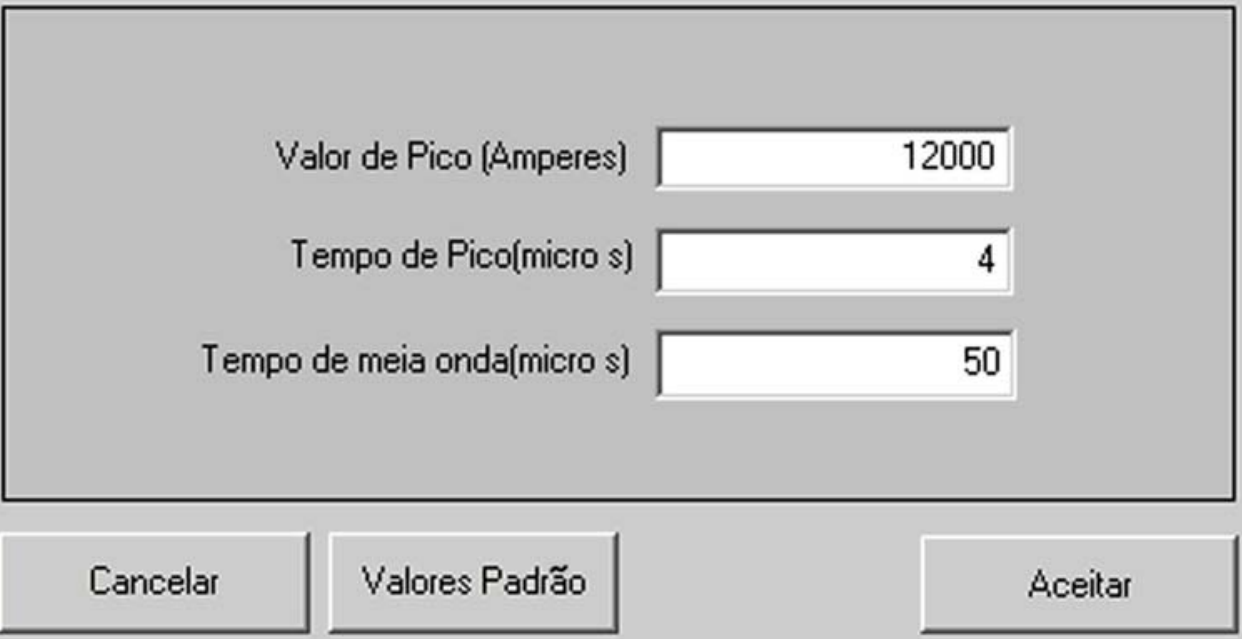

Figura 3.9 - Tela de configuração de descarga atmosférica.

Na Figura 3.9 tem-se que a descarga atmosférica utilizada nas simulações a serem efetuadas terá um valor de pico de $12 \mathrm{kA}$, um tempo de subida de $4 \mu \mathrm{s}$ e um tempo de meia onda de $50 \mu$ s. Pressionando-se o botão “Aceitar”, estes valores são armazenados e a configuração da descarga atmosférica é validada. A validação de qualquer configuração efetuada é indicada na Área de Trabalho por meio da alteração do índice da configuração efetuada.

Estando a configuração validada, a Tela de Configuração Interativa ficará da maneira como apresentada na Figura 3.10. 


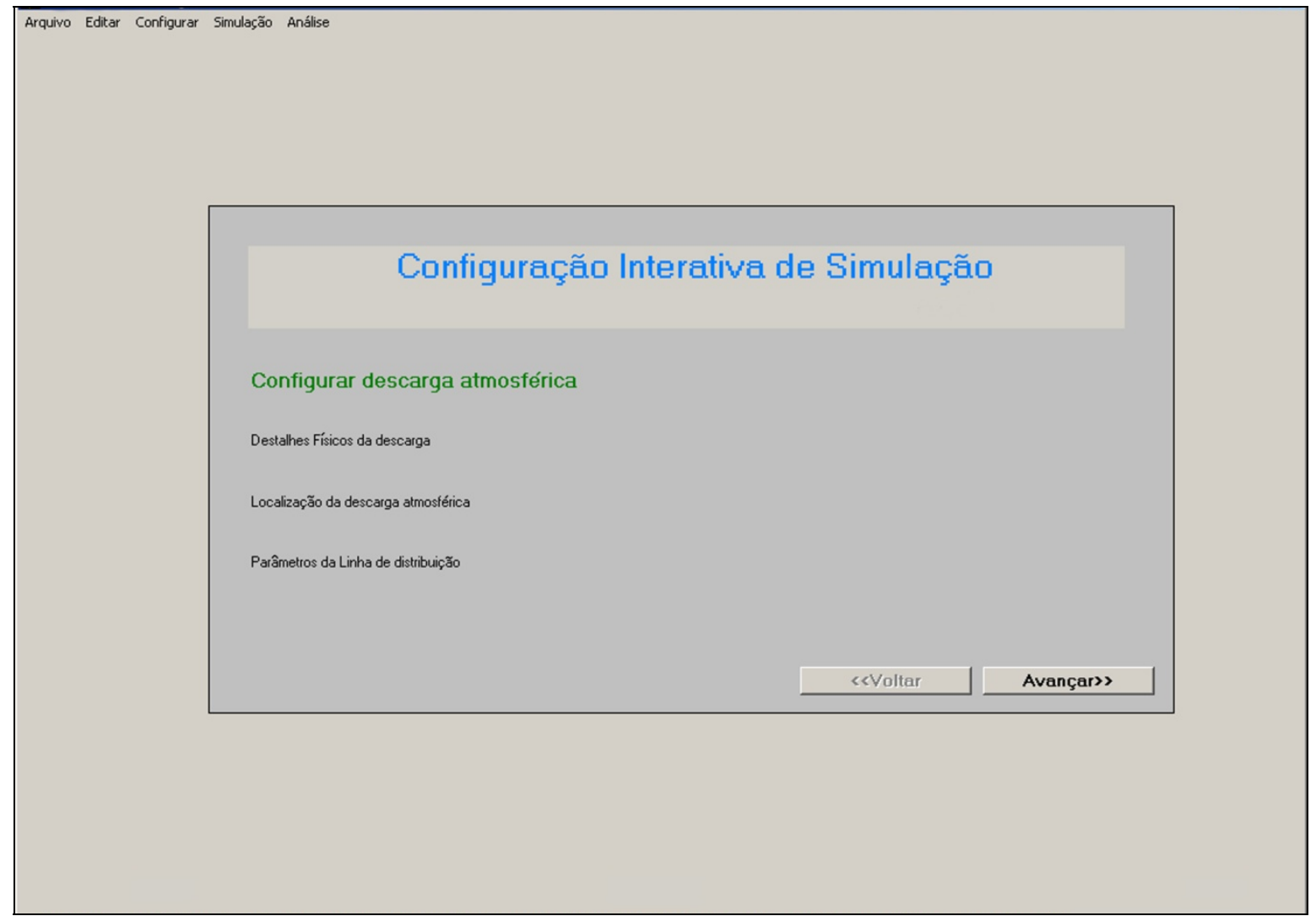

Figura 3.10 - Tela de configuração interativa indicando a validação da configuração da descarga atmosférica.

Pressionando novamente o botão “Avançar”, a próxima tela de configuração será então apresentada. Neste caso, a tela de configuração a ser apresentada será a Tela de Configuração dos Detalhes Físicos da Descarga Atmosférica, conforme ilustrada na Figura 3.11. 


\section{Descarga Atmosférica: Parâmetros Físicos}

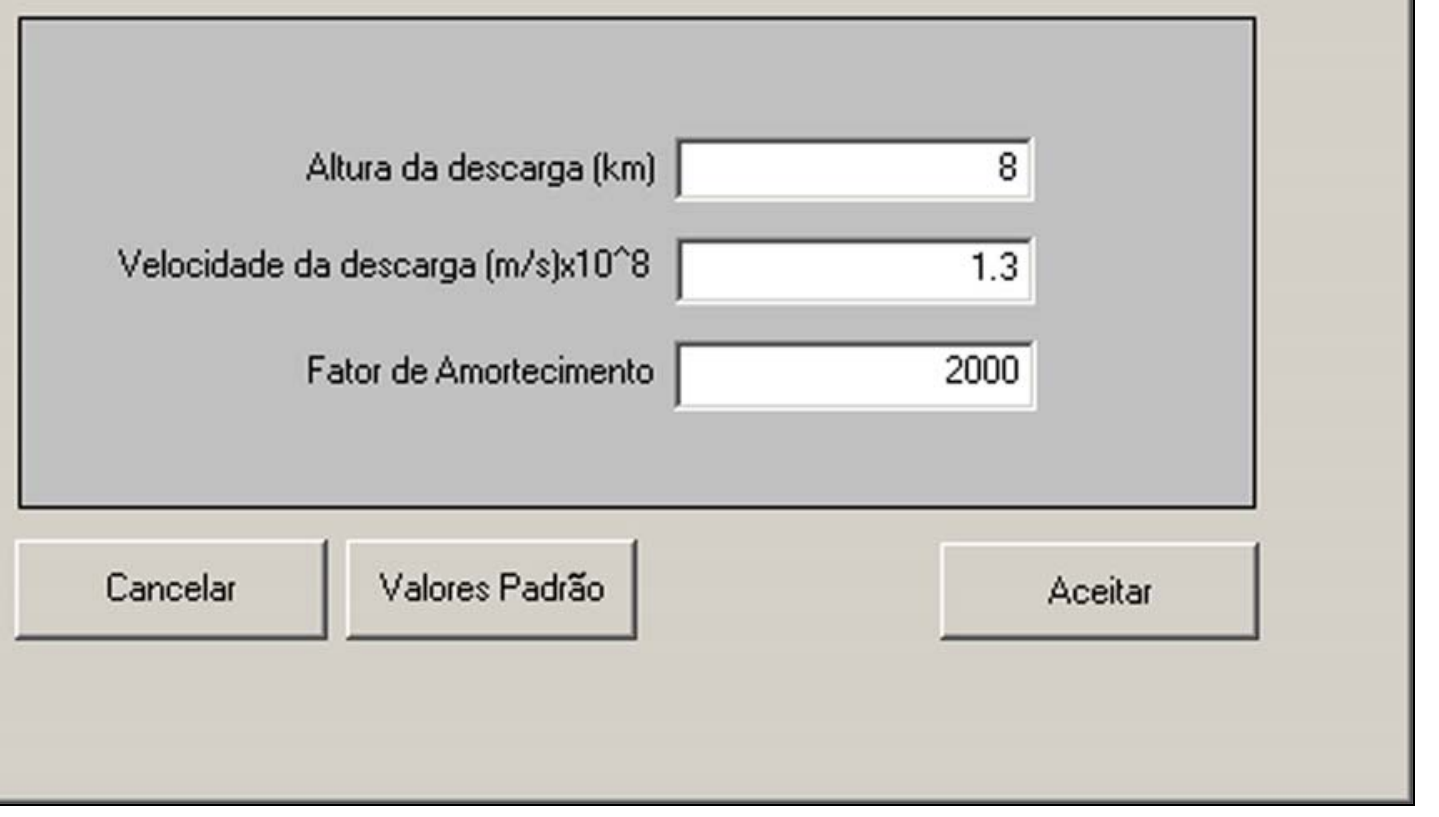

Figura 3.11 - Tela de configuração dos detalhes físicos da descarga atmosférica.

Como apresentado na Figura 3.11, nesta Tela de Configuração dos Detalhes Físicos da Descarga Atmosférica, os valores para altura da descarga atmosférica, velocidade da descarga e o fator de amortecimento da descarga são especificados (dados que podem ser obtidos junto ao INPE - Instituto Nacional de Pesquisas Espaciais).

Pressionando-se o botão “Aceitar”, os valores indicados pelo usuário são então validados e o ele se torna habilitado em prosseguir com as configurações.

Ao pressionar o botão “Aceitar”, além de validar os valores dos parâmetros indicados, o usuário retornará à Área de Trabalho. Pressionando o botão “Avançar”, a próxima tela de configuração será apresentada ao usuário, ou seja, a Tela de Configuração da Localização da Descarga Atmosférica, conforme mostra a Figura 3.12. 


\section{Localização da Descarga Atmosférica}

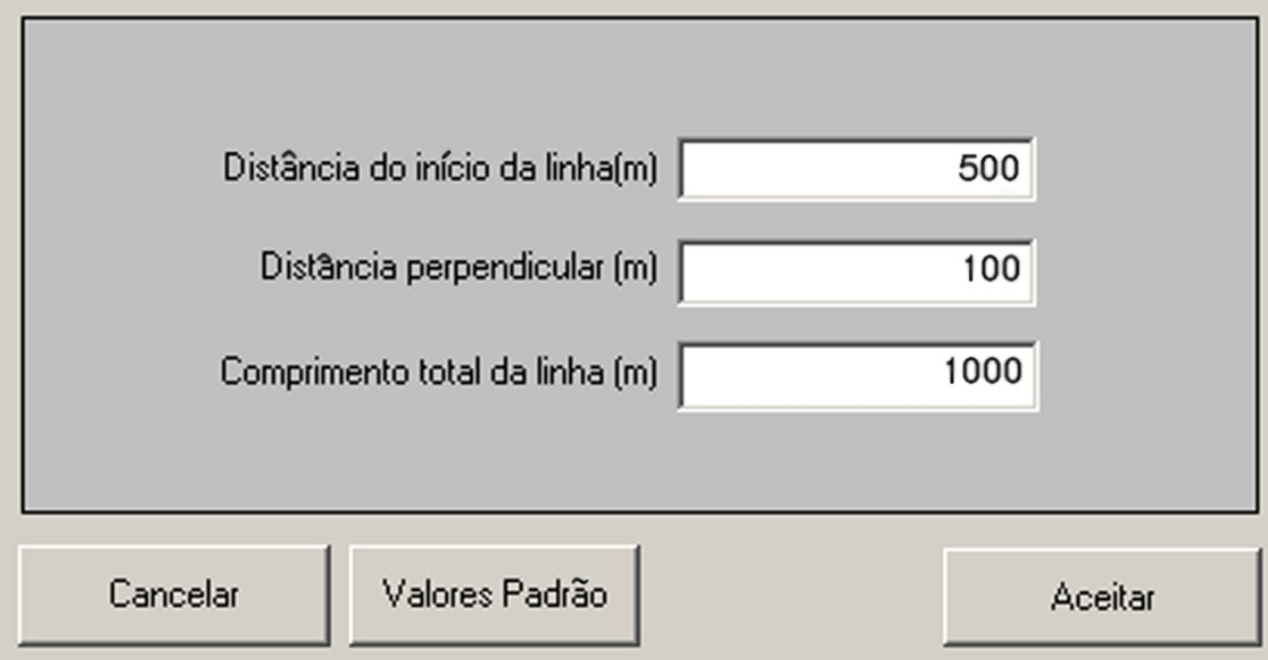

Figura 3.12 - Tela de configuração da localização da descarga atmosférica.

Como apresentado na Figura 3.12, o usuário está informando que o comprimento total da linha de distribuição é de 1000m, sendo que a descarga atmosférica ocorrerá a uma distância perpendicular de 100m, com uma distância do início da linha de 500m.

Uma representação esquemática destas distâncias é apresentada na Figura 3.13 com a finalidade de auxiliar o usuário na correta configuração destes parâmetros.

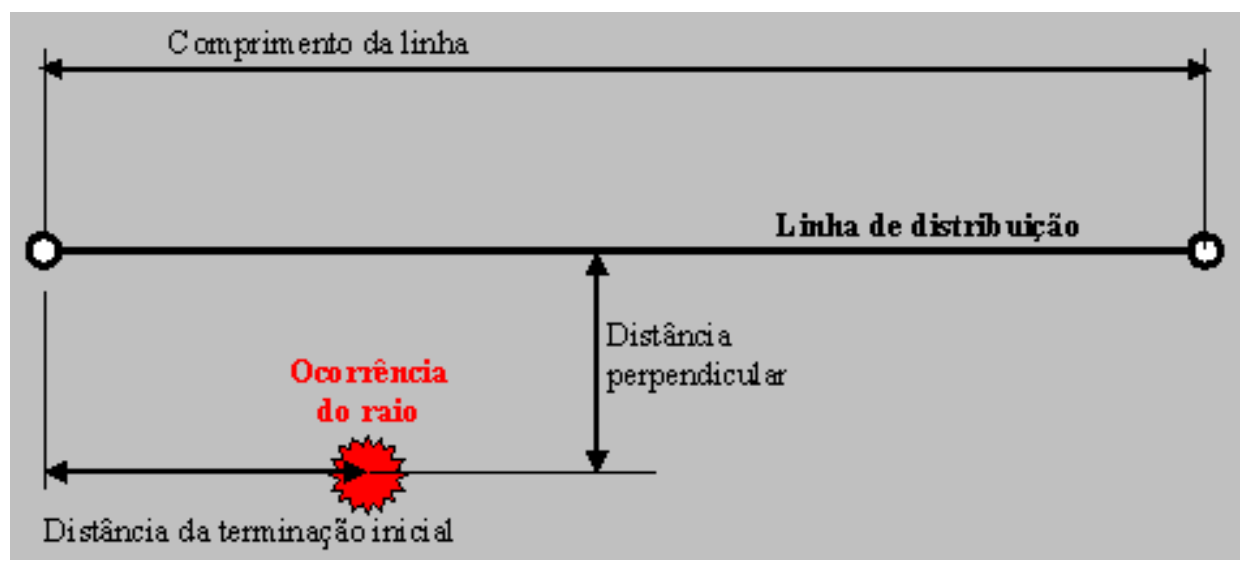

Figura 3.13 - Representação esquemática dos parâmetros necessários para a configuração da localização da descarga atmosférica.

Pressionando-se o botão “Aceitar”, os valores indicados pelo usuário são validados e o ele se torna habilitado para prosseguir com as configurações. 
Ao pressionar o botão “Aceitar”, além de validar os valores dos parâmetros indicados, o usuário retorna à Área de Trabalho. Pressionando o botão “Avançar”, a próxima tela de configuração será então apresentada ao usuário, ou seja, a Tela de Configuração dos Parâmetros da Linha de Distribuição, conforme apresentada na Figura 3.14.

\section{Parâmetros da Linha de Distribuição}

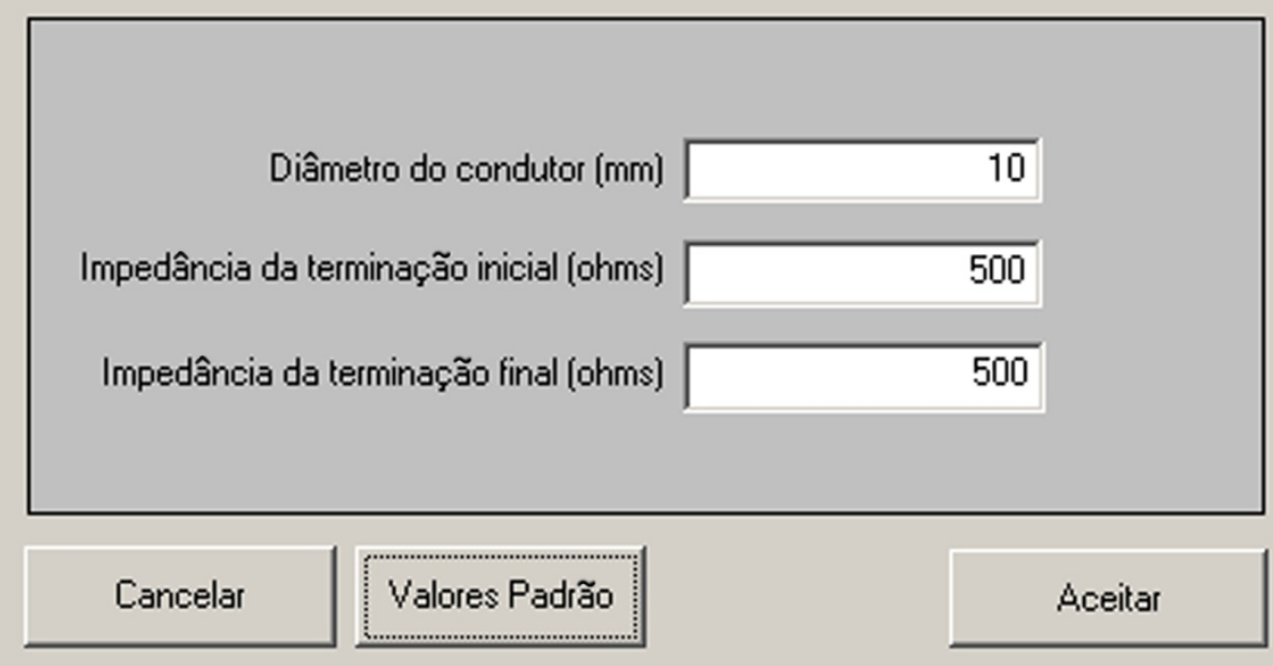

Figura 3.14 - Tela de configuração dos parâmetros da linha de distribuição.

Pressionando-se a botão “Aceitar”, os valores indicados pelo usuário são validados e o usuário se torna habilitado para prosseguir com o estudo das tensões induzidas em linhas de distribuição.

Estando todos os parâmetros configurados, a Área de Trabalho se mostrará ao usuário conforme indicado na Figura 3.15. 


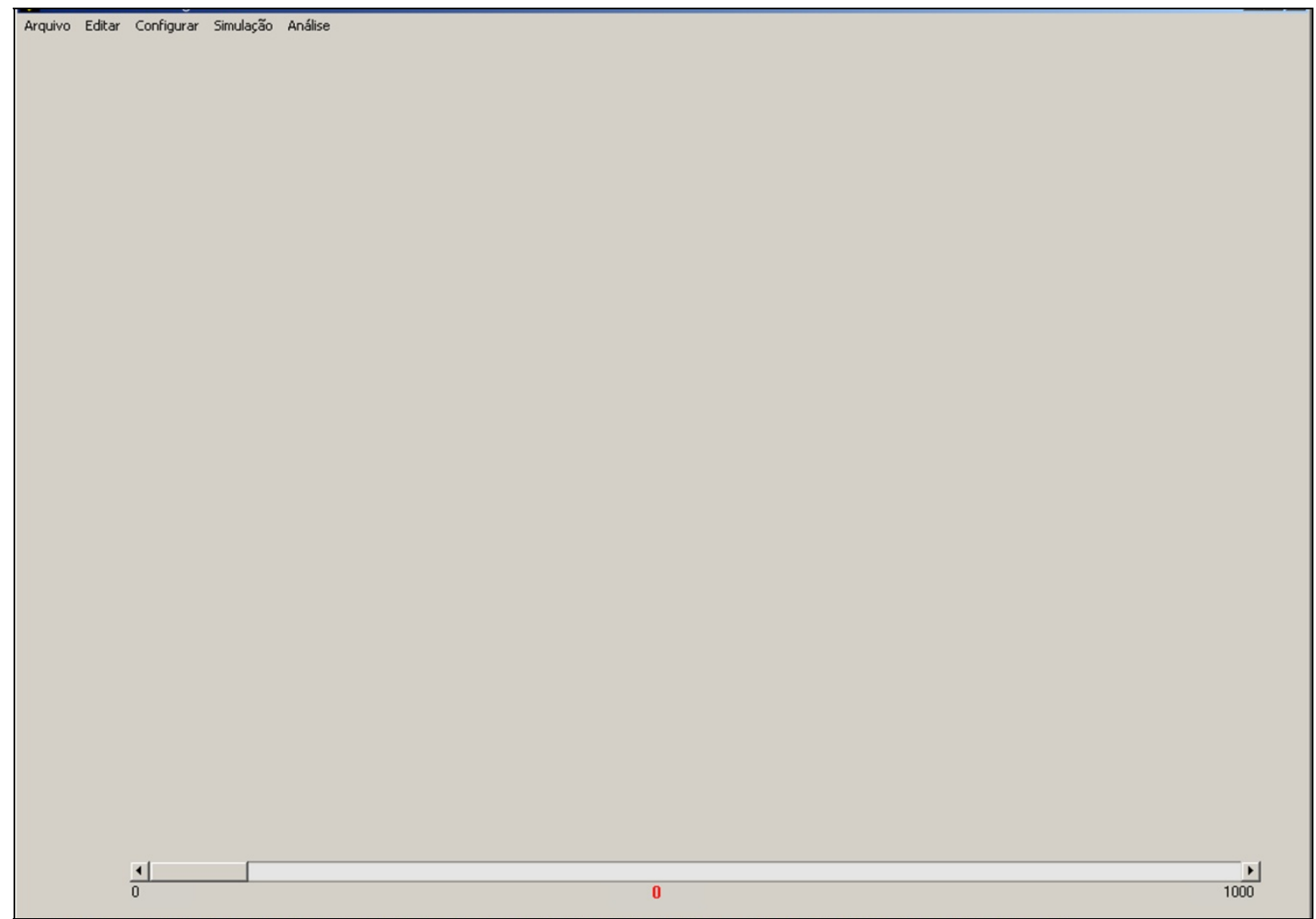

Figura 3.15 - Área de trabalho após a configuração de todos os parâmetros.

Estando então todos os parâmetros configurados, o usuário pode assim iniciar a execução das simulações desejadas. Na Seção 3.6 serão discutidas as simulações possíveis de serem efetuadas por meio da plataforma computacional desenvolvida.

\subsection{SIMULAÇÕES PONTUAIS PARA O ESTUDO DE TENSÕES INDUZIDAS EM LINHAS DE DISTRIBUIÇÃO}

A plataforma computacional desenvolvida possibilita a execução de dois tipos de simulação. Nesta seção será discutida e apresentada as Simulações Pontuais. As Simulações Pontuais realizam a simulação da tensão induzida em um ponto ao longo da linha de distribuição e apresentam graficamente a tensão induzida em função do tempo. O cálculo do valor de pico, tempo de pico, tempo de subida e tempo de meia onda é realizado automaticamente e são também apresentados ao usuário.

O usuário especifica o ponto de interesse para o estudo através da barra de rolagem localizada logo abaixo da Barra de Status da plataforma computacional. Na Figura 3.16 são apresentados os detalhes da Barra Posicional na qual o usuário indica a posição de interesse. 


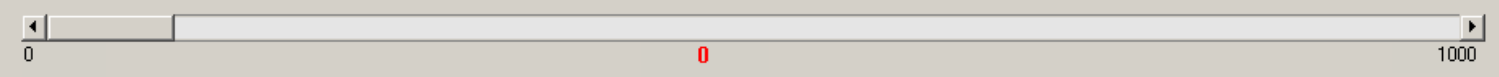

Figura 3.16 - Detalhes da barra posicional.

No centro da Barra Posicional é indicado o ponto considerado para se realizar a simulação.

A execução da simulação pontual é iniciada selecionando-se o menu Simulação e escolhendo-se a opção Simulação Pontual. Este procedimento é indicado na Figura 3.17.

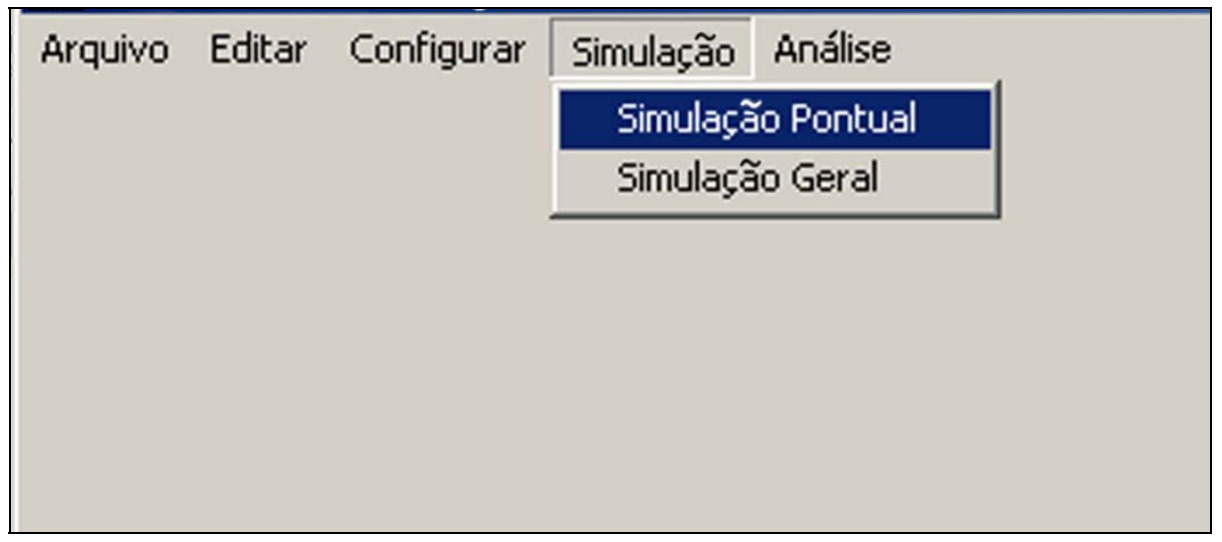

Figura 3.17 - Detalhes do procedimento para iniciação da simulação pontual.

Selecionando a Simulação Pontual no menu Simulação, a plataforma computacional desenvolvida inicia os cálculos necessários para a estimação da tensão induzida e, na seqüência, apresenta na Área de Trabalho o gráfico da tensão induzida em função do tempo, bem como as quantias para valor de pico, tempo de pico, tempo de subida e tempo de meia onda. Na Figura 3.18 é apresentado o resultado calculado para o ponto de início da linha de distribuição. 


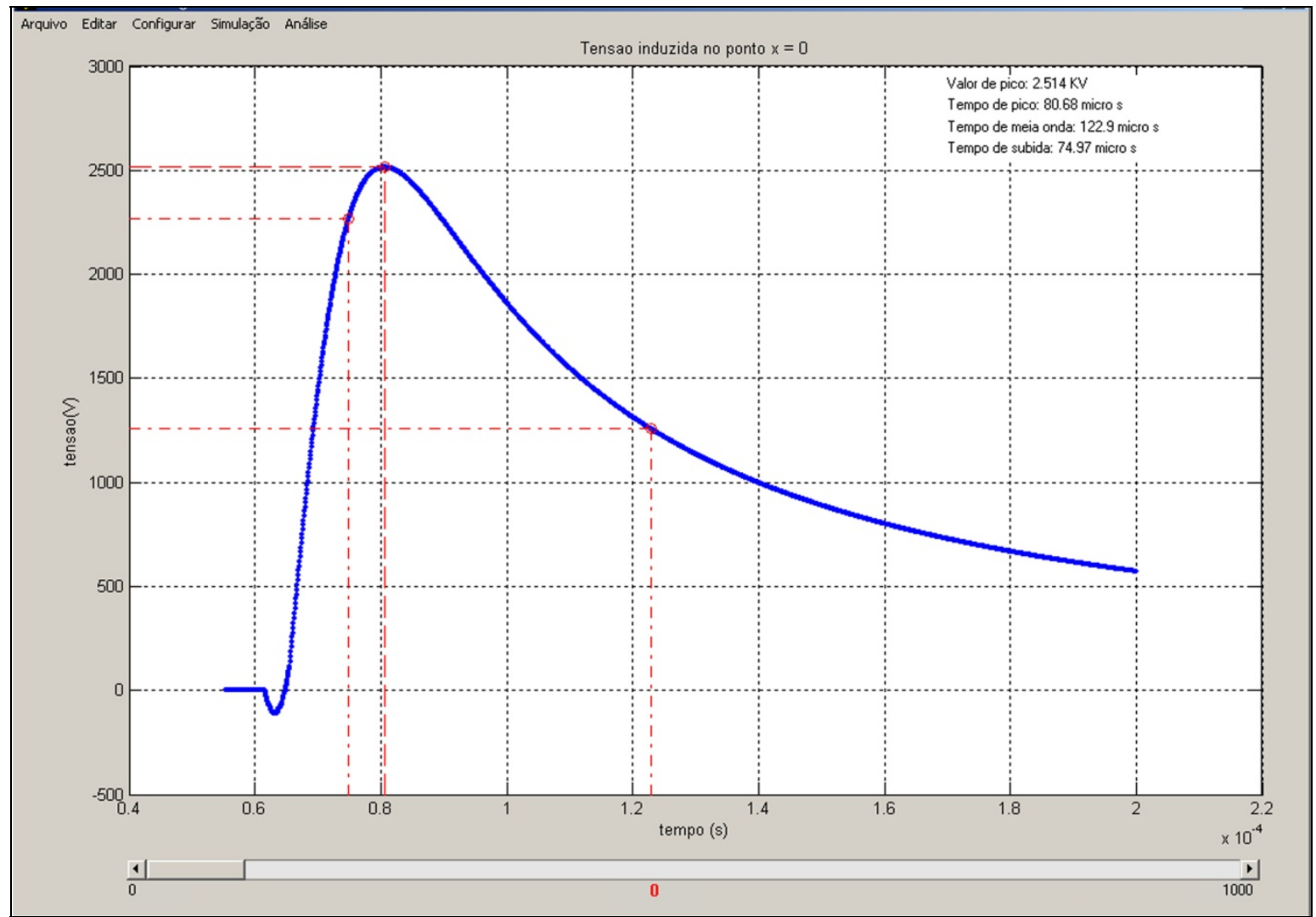

Figura 3.18 - Apresentação dos resultados para o início da linha de distribuição.

Como pode ser observado pela Figura 3.18, as quantias dos parâmetros para valor de pico, tempo de pico, tempo de subida e tempo de meia onda são apresentadas no canto superior direito do gráfico de tensão em relação ao tempo. Na Figura 3.19 estes resultados são apresentados com mais detalhes.

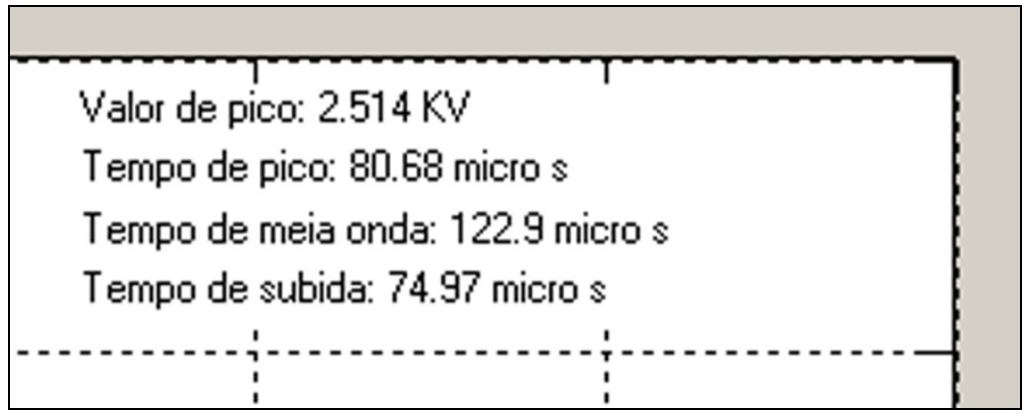

Figura 3.19 - Detalhes da tela de resultados de simulação.

Modificando-se a posição do marcador da Barra Posicional e, selecionando-se a opção Simulação Pontual no menu Simulação, uma nova simulação será efetuada. Nas Figuras 3.20, 3.21 e 3.22 são apresentadas as simulações para as posições de $250 \mathrm{~m}, 500 \mathrm{~m}$ e $1000 \mathrm{~m}$ da linha de distribuição, respectivamente. 


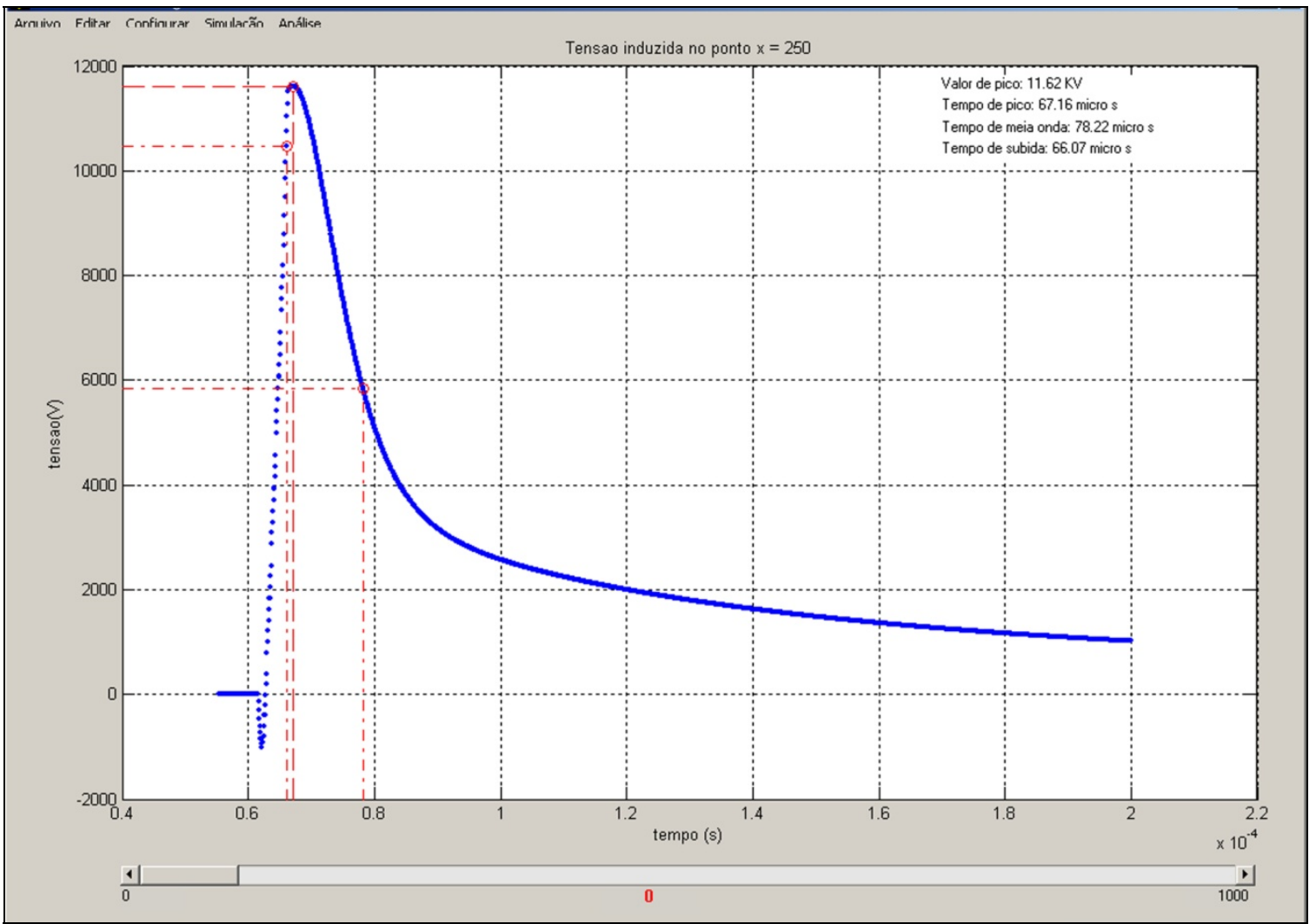

Figura 3.20 - Simulação da tensão induzida para uma distância de 250m do início da linha.

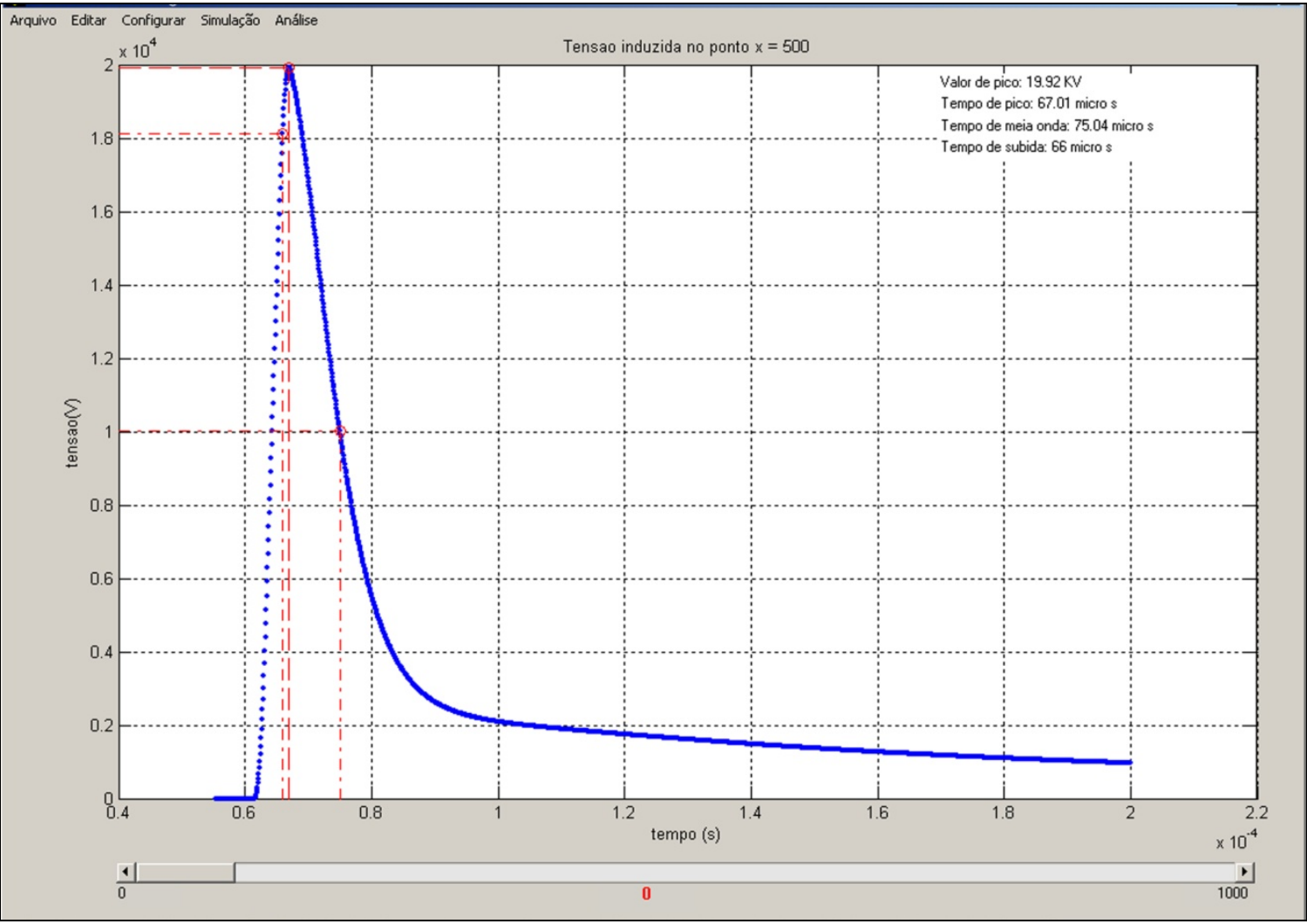

Figura 3.21 - Simulação da tensão induzida para uma distância de 500m do início da linha. 


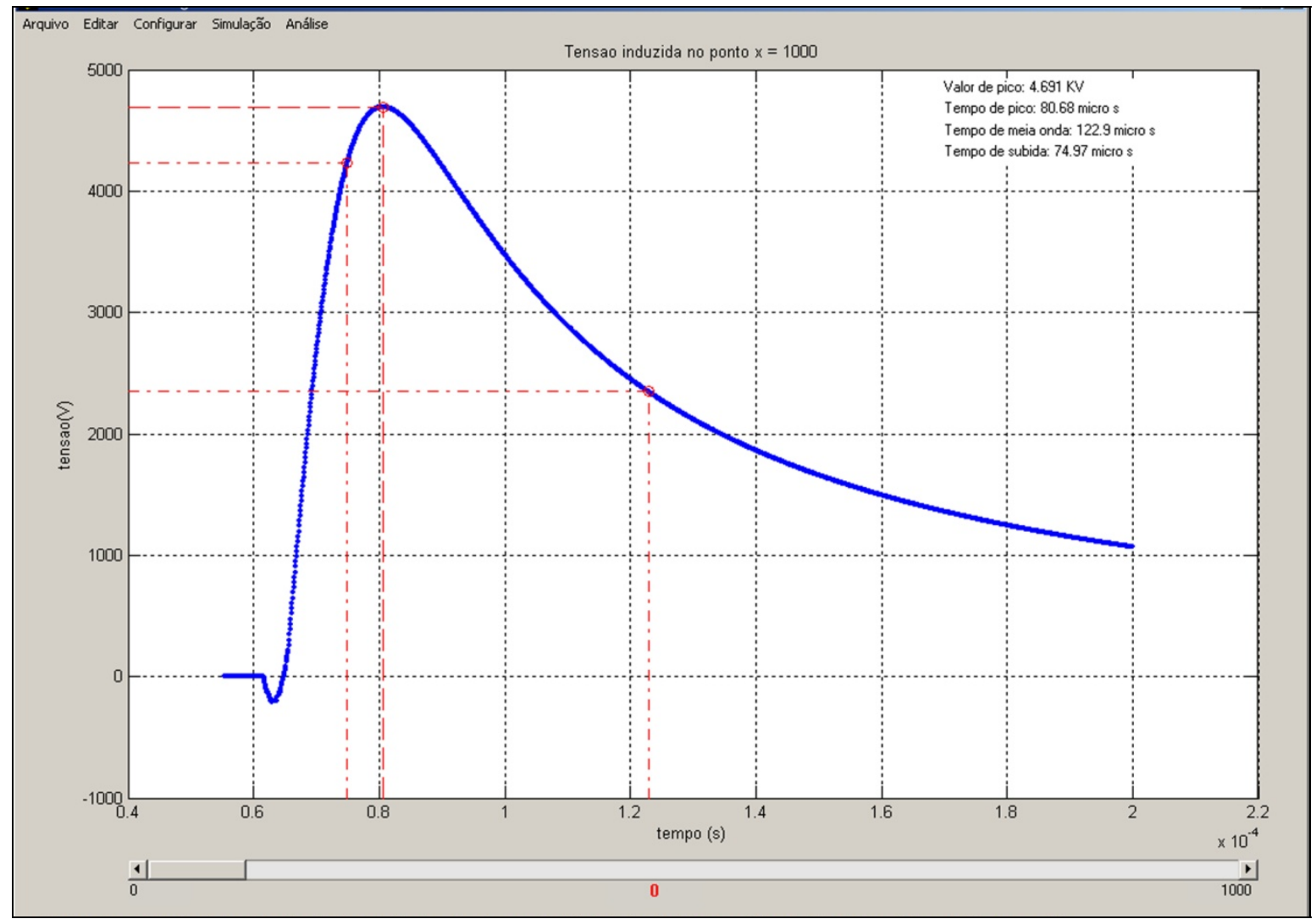

Figura 3.22 - Simulação da tensão induzida para uma distância de 1000m do início da linha.

Todas as simulações realizadas são armazenadas na estrutura da plataforma computacional de forma que se o usuário desejar voltar a um ponto, cuja tensão induzida já tenha sido calculada, não será então necessário que se execute a procedimento de cálculo novamente.

\subsection{SIMULAÇÃO GERAL PARA O ESTUDO DE TENSÕES INDUZIDAS EM LINHAS DE DISTRIBUIÇÃO}

$\mathrm{Na}$ plataforma computacional desenvolvida foi também incluído o módulo de Simulação Geral. O módulo de Simulação Geral tem por objetivo levantar os perfis de máxima tensão induzida, tempo de pico e tempo de meia onda para toda a extensão da linha de distribuição.

Selecionando-se o menu Simulação e a opção Simulação Geral, os perfis de máxima tensão induzida, tempo de pico e tempo de meia onda para toda a extensão da linha de distribuição são então apresentados na Área de Trabalho. Na Figura 3.23, o procedimento para execução da Simulação Geral é apresentado. 


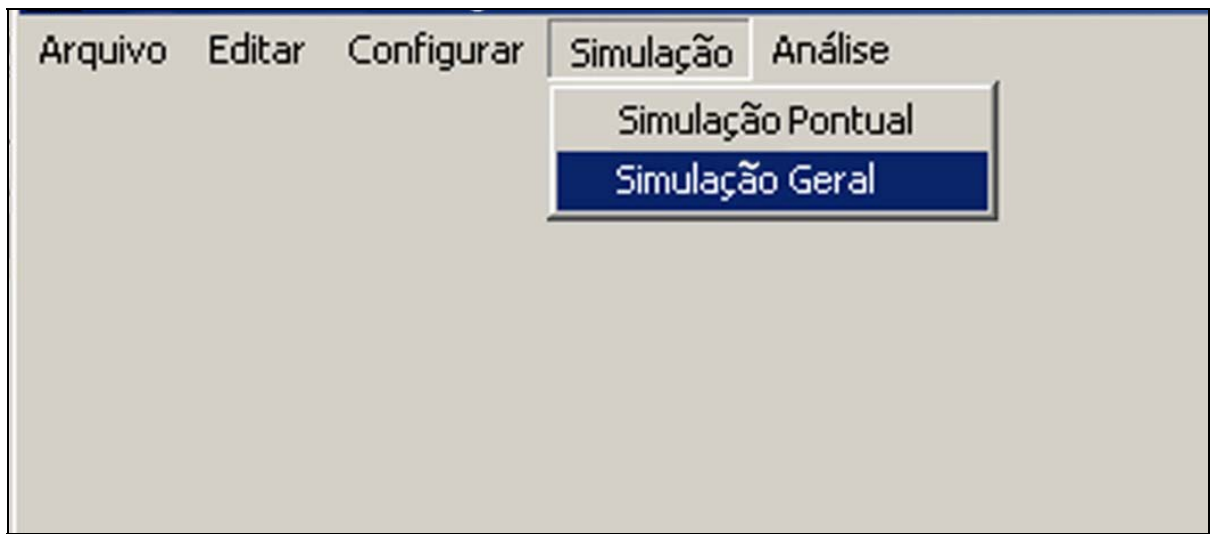

Figura 3.23 - Procedimento para execução da simulação geral.

Na Figura 3.24 são apresentados os perfis de máxima tensão induzida, tempo de pico e tempo de meia onda para toda a extensão da linha de distribuição, calculados pela plataforma computacional.

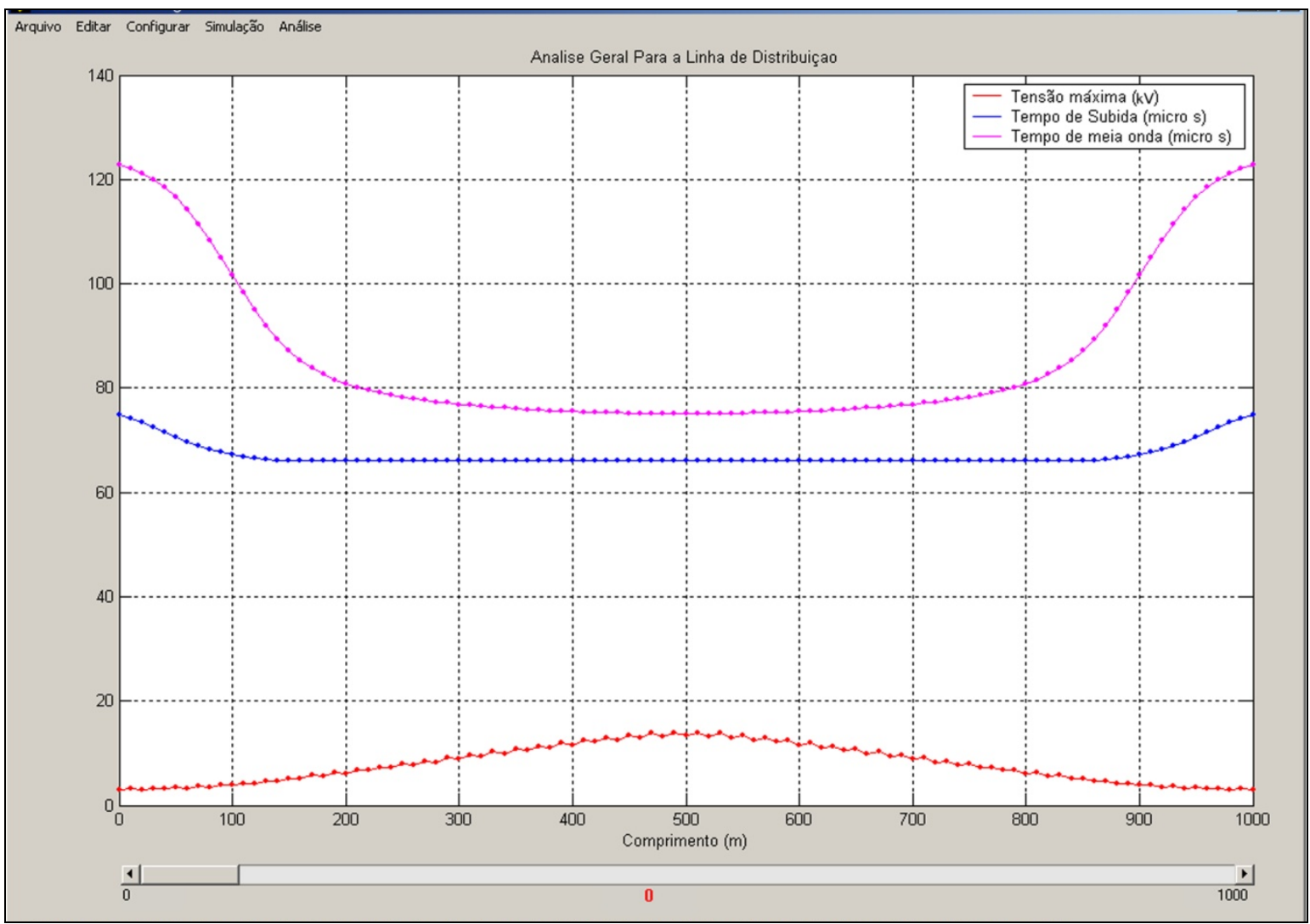

Figura 3.24 - Perfis de máxima tensão induzida, tempo de pico e tempo de meia onda para toda a extensão da linha de distribuição.

O conhecimento dos perfis de máxima tensão induzida, tempo de pico e tempo de meia onda para toda a extensão da linha de distribuição é interessante para o correto projeto de sistemas de proteção para linhas aéreas de distribuição. 


\subsection{SALVANDO O PROJETO DE ESTUDO DE TENSÕES INDUZIDAS EM LINHAS DE DISTRIBUIÇÃO}

A plataforma computacional desenvolvida permite que o projeto de estudo de tensões induzidas em linhas de distribuição, bem como todas as suas simulações, possa ser salvas para avaliações futuras.

Selecionando-se o menu Arquivo e a opção Salvar o projeto será salvo em local desejado pelo usuário. A Figura 3.25 apresenta o procedimento para se salvar o projeto de estudo de tensões induzidas em linhas de distribuição.

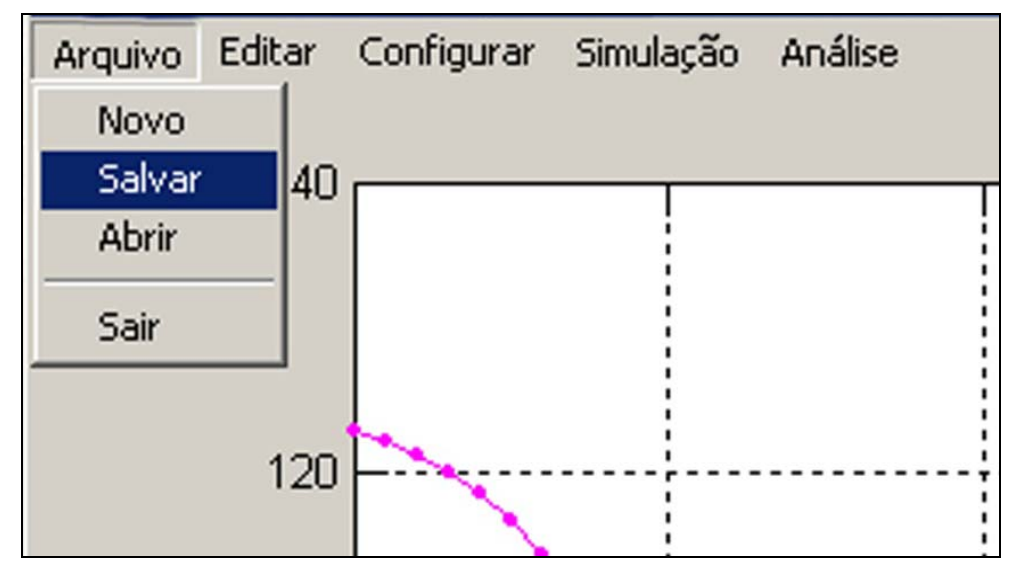

Figura 3.25 - Procedimento para salvar o projeto de estudo de tensões induzidas em linhas de distribuição.

Selecionando-se o menu Arquivo e a opção Salvar, a tela mostrada na Figura 3.26 será então apresentada ao usuário. Através desta tela o usuário indicará o local e o nome do arquivo desejado para armazenar o projeto ativo. 


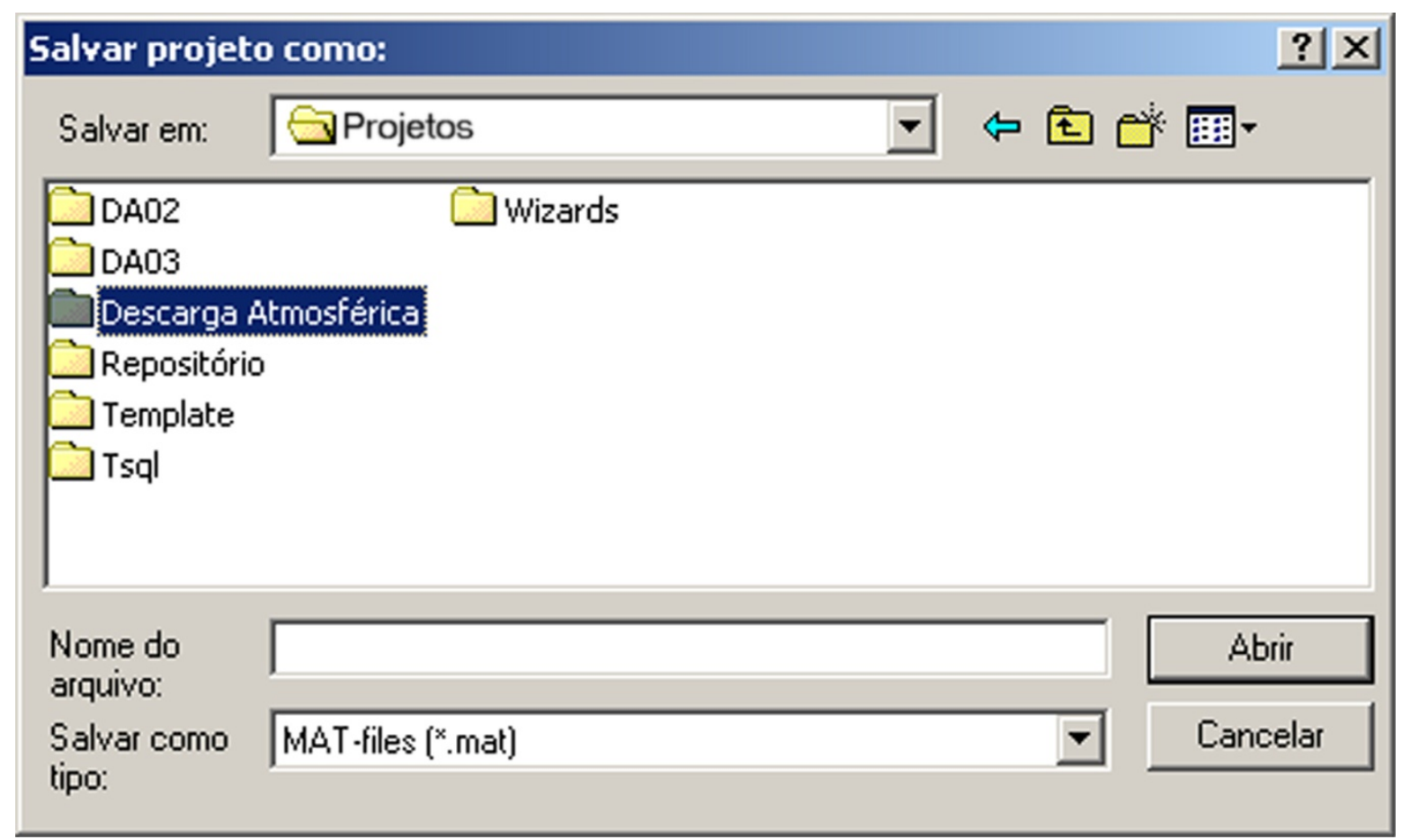

Figura 3.26 - Interface para salvar o projeto de estudo de tensões induzidas em linhas de distribuição.

\subsection{RESTAURANDO O PROJETO DE ESTUDO DE TENSÕES INDUZIDAS EM LINHAS DE DISTRIBUIÇÃO}

Estando um projeto de estudo de tensões induzidas em linhas de distribuição armazenado em arquivo, este pode ser então recuperado pelo usuário.

Selecionando-se o menu Arquivo e a opção Abrir, o projeto será recuperado do local e arquivo especificado pelo usuário. A Figura 3.27 apresenta o procedimento para se recuperar o projeto de estudo de tensões induzidas em linhas de distribuição.

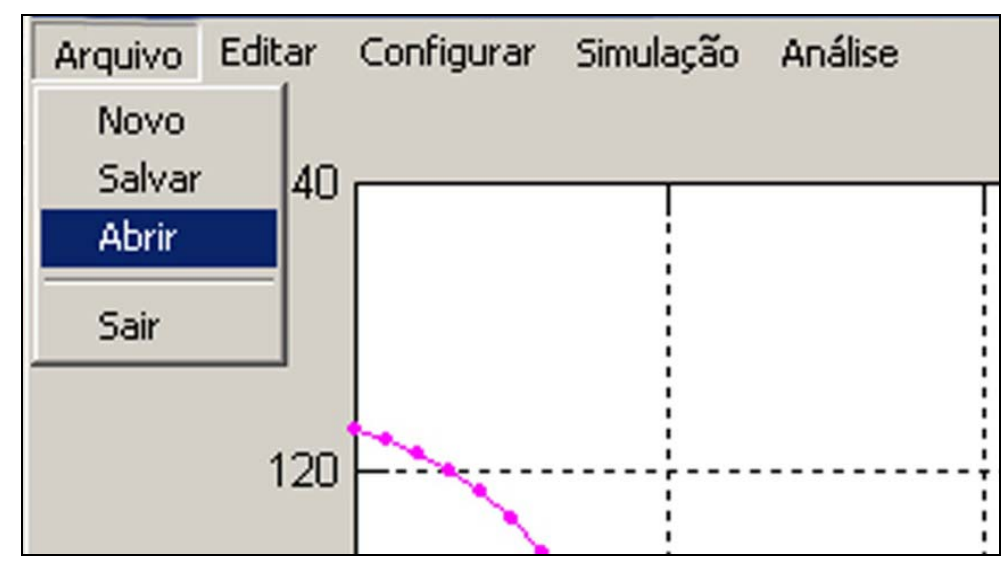

Figura 3.27 - Procedimento para recuperar o projeto de estudo de tensões induzidas em linhas de distribuição. 
Selecionando-se então o menu Arquivo e a opção Abrir, a tela apresentada na Figura 3.28 será apresentada ao usuário. Por meio desta tela, o usuário indicará assim o local e o nome do arquivo onde se encontra o projeto a ser recuperado.

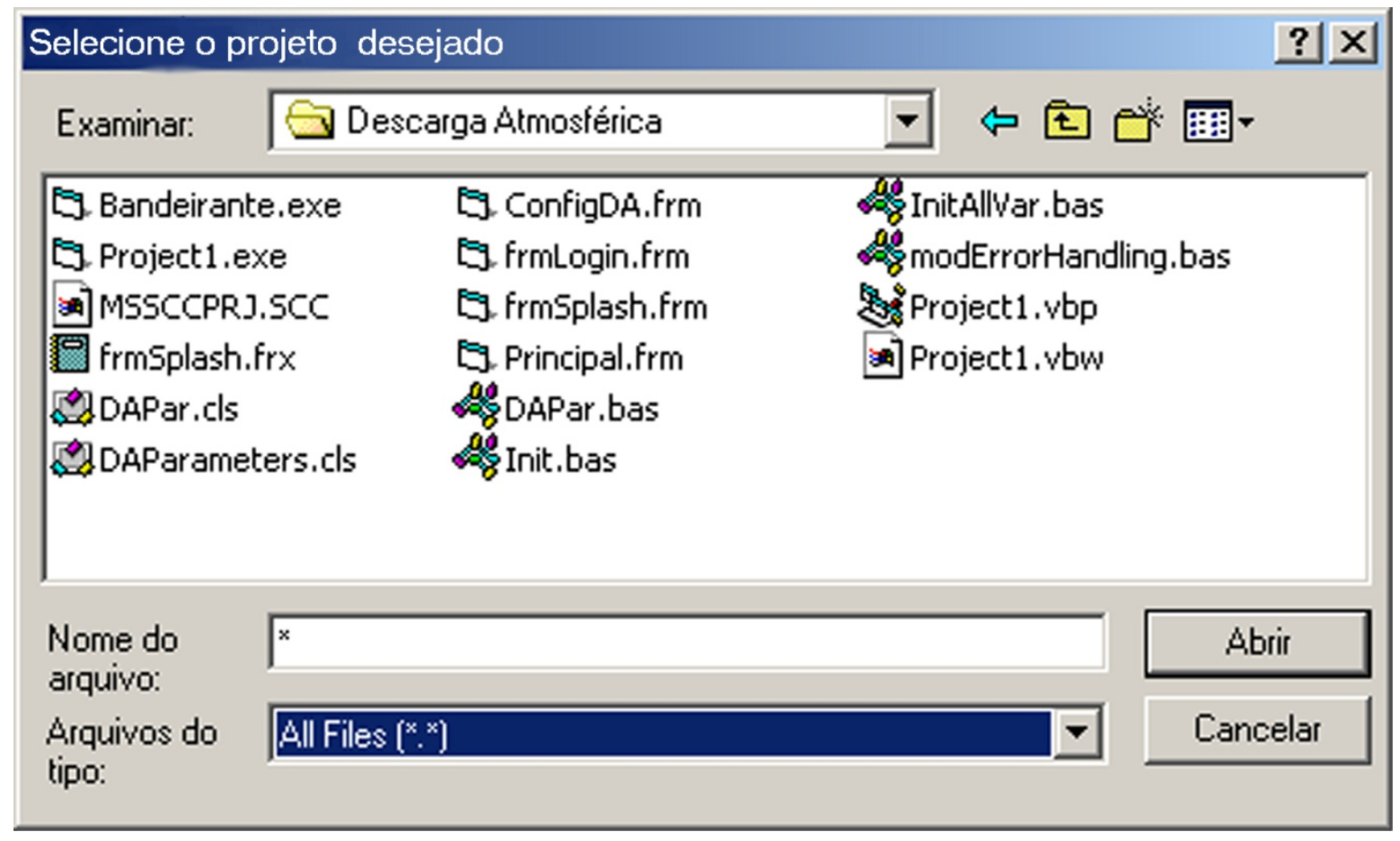

Figura 3.28 - Interface para recuperar o projeto de estudo de tensões induzidas em linhas de distribuição.

\subsection{SAINDO DA PLATAFORMA COMPUTACIONAL}

Ao se selecionar o menu Arquivo e a opção Sair, conforme apresentado na Figura 3.29, o usuário será então solicitado a salvar o projeto ativo antes de finalizar a execução da plataforma computacional, sendo que esta solicitação não aparecerá se o projeto já estiver salvo.

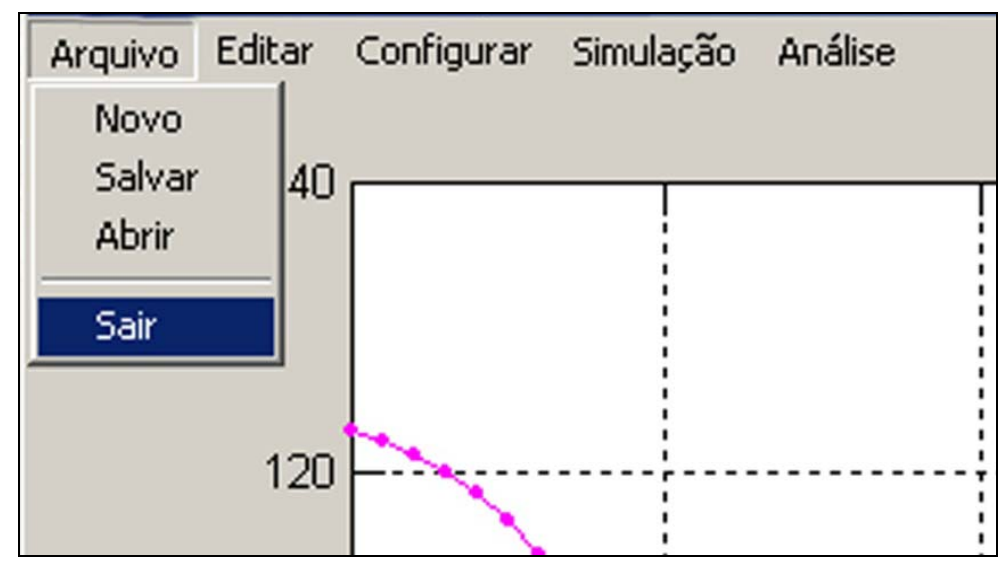

Figura 3.29 - Procedimento para encerrar a execução da plataforma computacional para o cálculo de tensões induzidas em linhas de distribuição. 


\subsection{CONSIDERAÇÕES PARCIAIS}

A realização de exaustivas simulações computacionais demonstrou a eficiência da ferramenta desenvolvida quando comparada com as técnicas usuais. Porém, a grande contribuição dos resultados apresentados neste capítulo foi a de permitir inferências sobre as características físicas da linha de distribuição e da tensão induzida devido às descargas atmosféricas. Assim, por intermédio de um estudo sistemático sobre estas características físicas e seu inter-relacionamento com as tensões induzidas ao longo da linha de distribuição, deseja-se aumentar o grau de confiabilidade nos projetos de sistemas de proteção para linhas de distribuição, bem como o próprio projeto de linhas de distribuição.

A plataforma computacional desenvolvida e apresentada neste capítulo tem por finalidade realizar estudos relacionados às tensões induzidas nas linhas de distribuição aérea. A plataforma incorporou em sua estrutura algorítmica todos os refinamentos desenvolvidos no Capítulo 2, possibilitando-se assim a obtenção de resultados confiáveis para as finalidades propostas. 



\section{Capítulo 4}

\section{Aspectos da Elaboração de Critérios Técnicos}

\subsection{INTRODUÇÃO}

Esta etapa da pesquisa consistiu principalmente da investigação e definição de critérios técnicos que permitiriam a especificação correta do tipo de proteção mais adequado para os transformadores, baseando-se para tanto nas implementações computacionais que possibilitam calcular os valores de tensões induzidas oriundas de descargas atmosféricas.

Levando-se em consideração o conhecimento prévio sobre as características das descargas atmosféricas que incidem na região de atuação da concessionária, torna-se então possível estruturar diversos critérios que viabilizam incrementar a proteção de transformadores frente às sobretensões ocasionadas pelas descargas atmosféricas.

\subsection{NÍVEL DE EXPOSIÇÃO DAS LINHAS DE DISTRIBUIÇÃO}

A confiabilidade de uma linha de distribuição é dependente do nível de sua exposição em relação às descargas atmosféricas. Para determinar o nível de exposição é necessário conhecer o número anual de raios por unidade de área e por unidade de tempo [1]. Assim sendo, a densidade de raios de uma determinada região, a qual exprime o nível de exposição das linhas de distribuição na respectiva área, é definida por:

$$
N_{g}=0.04 \cdot T_{d}^{1.25}
$$

onde $N_{g}$ é a densidade de raios e $T_{d}$ é o número estimado de dias com temporais por ano.

Outra forma de estimar a densidade de raios é por meio de registros de horas de temporais [2], ou seja:

$$
N_{g}=0.054 \cdot T_{h}^{1.1}
$$


Outras estimações dos valores de densidades de raios podem ser obtidas diretamente de informações proveniente de estações de detecção de raios.

\subsection{CARACTERÍSTICAS ELÉTRICAS DAS DESCARGAS}

A partir de estudos realizados sobre os parâmetros das descargas [3], a variação da corrente de pico $I_{0}$ da descarga pode ser aproximada por uma distribuição log-normal. A função distribuição de probabilidade dos valores de corrente de pico é definida pela seguinte expressão [4]:

$$
P\left(I_{0} \geq i_{0}\right)=\frac{1}{1+\left(i_{0} / 31\right)^{2.6}}
$$

onde se exprime a probabilidade de a corrente de pico $I_{0}$ ser maior ou igual a um dado valor $i_{0}$ (kA).

Para exemplificação da forma de onda da corrente de descarga ao longo de tempo, apresentam-se na Figura 4.1 os principais parâmetros envolvidos com as respectivas formas de onda, tomando-se como unidade o valor de pico da corrente.

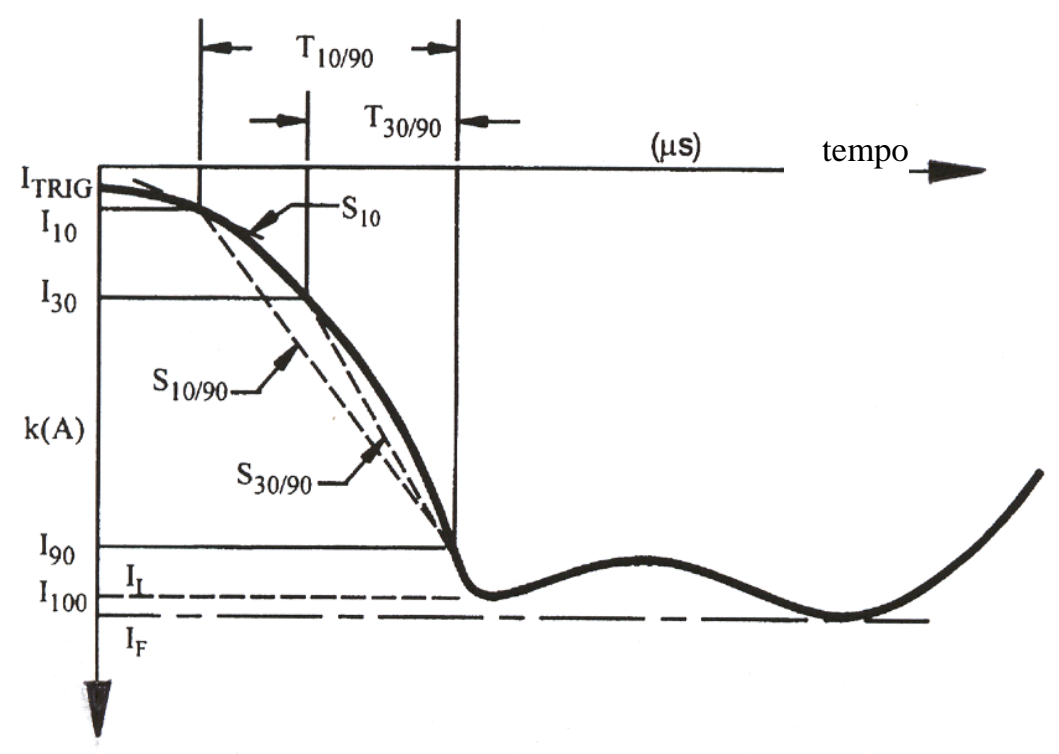

Figura 4.1 - Descrição dos parâmetros da forma de onda da corrente de descarga.

A Tabela 4.1 mostra alguns parâmetros usados na distribuição log-normal para correntes produzidas por descargas com polaridade negativa. 
Tabela 4.1 - Parâmetros da corrente de descarga (polaridade negativa).

\begin{tabular}{|c|c|c|c|c|}
\hline \multirow{2}{*}{ Parâmetro } & \multicolumn{2}{|c|}{ Primeira descarga } & \multicolumn{2}{c|}{ Descarga subseqüente } \\
\cline { 2 - 5 } & Média & Desvio padrão & Média & Desvio padrão \\
\hline Frente de Onda $(\mu \mathrm{s})$ & ----- & ----- & ----- & ----- \\
\hline $\mathrm{T}_{\mathrm{d} 10 / 90}=\mathrm{T}_{10 / 90} / 0,8$ & 5,63 & 0,576 & 0,750 & 0,921 \\
\hline $\mathrm{T}_{\mathrm{d} 30 / 90}=\mathrm{T}_{30 / 90} / 0,6$ & 3,83 & 0,553 & 0,670 & 1,013 \\
\hline $\mathrm{T}_{\mathrm{m}}=\mathrm{I}_{\mathrm{f}} / \mathrm{S}_{\mathrm{m}}$ & 1,28 & 0,611 & 0,308 & 0,708 \\
\hline Derivadas da Corrente $(\mathrm{kA} / \mu \mathrm{s})$ & ----- & ----- & ----- & ----- \\
\hline $\mathrm{S}_{\mathrm{m}}($ máxima) & 24,3 & 0,599 & 39,9 & 0,852 \\
\hline $\mathrm{S}_{10}\left(\right.$ em $10 \%$ de $\left.\mathrm{I}_{\max }\right)$ & 2,60 & 0,921 & 18,9 & 1,404 \\
\hline $\mathrm{S}_{10 / 90}\left(\right.$ entre $10 \%$ e $90 \%$ de $\left.\mathrm{I}_{\max }\right)$ & 5,00 & 0,645 & 15,4 & 0,944 \\
\hline $\mathrm{S}_{10 / 90}\left(\right.$ entre 30\% e 90\% de $\left.\mathrm{I}_{\max }\right)$ & 7,20 & 0,622 & 20,1 & 0,967 \\
\hline Corrente de Crista $(\mathrm{kA})$ & ----- & ----- & ----- & ----- \\
\hline $\mathrm{I}_{\mathrm{I}}($ corrente inicial) & 27,7 & 0,461 & 11,8 & 0,530 \\
\hline $\mathrm{I}_{\mathrm{F}}($ corrente final) & 31,1 & 0,484 & 12,3 & 0,530 \\
\hline $\mathrm{I}_{\mathrm{I}} / \mathrm{I}_{\mathrm{F}}$ & 0,90 & 0,230 & 0,90 & 0,207 \\
\hline Tempo de Cauda $(\mu \mathrm{s})$ & 77,5 & 0,577 & 30,2 & 0,933 \\
\hline Carga $(\mathrm{C})$ & 4,65 & 0,882 & 0,938 & 0,882 \\
\hline
\end{tabular}

É importante observar na Figura 4.1 que existem dois diferentes picos, sendo que como ocorre usualmente, o segundo pico é maior e surge num intervalo de tempo de 5 a $10 \mu$ s após o primeiro. Os demais parâmetros desta figura são os seguintes:

\section{Amplitudes Máximas (kA)}

- $\mathrm{I}_{\mathrm{I}} \rightarrow$ É o primeiro pico da corrente de descarga.

- $\mathrm{I}_{\mathrm{F}} \rightarrow$ É o segundo pico da corrente de descarga.

- $\mathrm{I}_{10} \rightarrow$ É o ponto onde o módulo da corrente alcança 10\% de seu valor de pico.

- $\mathrm{I}_{30} \rightarrow$ É o ponto onde o módulo da corrente alcança 30\% de seu valor de pico.

- $\mathrm{I}_{90} \rightarrow$ É o ponto onde o módulo da corrente alcança 90\% de seu valor de pico.

\section{Tempos de Frente de Onda ( $\mu \mathrm{s})$}

- $\mathrm{T}_{10 / 90} \rightarrow$ Significa o intervalo de tempo entre os pontos em que o módulo da corrente vale respectivamente $10 \%$ e $90 \%$ do seu primeiro pico.

- $\mathrm{T}_{30 / 90} \rightarrow$ Significa o intervalo de tempo entre os pontos em que o módulo da corrente vale respectivamente $30 \%$ e $90 \%$ do seu primeiro pico. 


\section{Derivadas da Corrente em Relação ao Tempo}

- $\mathrm{S}_{10} \rightarrow$ É a derivada da corrente no ponto em que o seu módulo vale $10 \%$ do primeiro pico.

- $\mathrm{S}_{10 / 90} \rightarrow$ É a derivada média da corrente entre os pontos em que o seu módulo vale $10 \%$ e $90 \%$ do primeiro pico.

- $\mathrm{S}_{30 / 90} \rightarrow$ É a derivada média da corrente entre os pontos em que o seu módulo vale $30 \%$ e $90 \%$ do primeiro pico.

- $\mathrm{S}_{\mathrm{m}} \rightarrow$ É a derivada máxima da corrente durante o tempo de frente de onda.

\subsection{DESEMPENHO DAS LINHAS DE DISTRIBUIÇÃO FRENTE ÀS DESCARGAS ATMOSFÉRICAS}

O desempenho das linhas de distribuição frente às descargas atmosféricas depende de diversos fatores que envolvem as características estruturais das linhas, assim como as características das descargas que as atingem.

Em relação às características das descargas, as tensões disruptivas nos circuitos de distribuição podem ser devidas tanto às descargas que atingem diretamente as linhas, ou então, às descargas indiretas, as quais ocorrem nas proximidades das linhas, ocasionando-se aqui sobretensões de natureza induzida.

As descargas que atingem diretamente as linhas de distribuição causam quebra da isolação na grande maioria dos casos. Por exemplo, uma descarga de 10 kA produziria uma sobretensão por volta de $2.000 \mathrm{kV}$. Este valor ultrapassa bastante os níveis de isolação de linhas de distribuição operando até $69 \mathrm{kV}$.

Entretanto, diversas experiências e observações mostram que muitas das interrupções provocadas por descargas atmosféricas em linhas de baixa isolação são devidas às descargas que ocorrem nas proximidades da linha.

A maioria das tensões induzidas provocadas por descargas indiretas em uma linha de distribuição é menor que 300 kV. Além disso, os níveis de exposição das linhas de distribuição são influenciados por objetos, tais como edifícios e árvores, localizados nas proximidades da linha. 


\subsubsection{A Influência da Altura da Linha}

As descargas atmosféricas podem ter um efeito significante na confiabilidade da linha, especialmente se seus postes são mais altos que os objetos que estão em sua volta.

A taxa de incidência de raios $N$, em um terreno aberto (sem árvores ou edifícios nas redondezas), é estimada pela equação de Eriksson [5], ou seja:

$$
N=N_{g} \cdot\left(\frac{28 \cdot h^{0.6}+b}{10}\right)
$$

onde $h$ é a altura do poste em metros e $b$ é a largura da estrutura em metros. $N_{g}$ é a densidade de descarga do ambiente em (raios/ $\mathrm{km}^{2} / \mathrm{anno}$ ) e $N$ é o nível de incidência em (raios/100km/ano). Para a maioria das linhas de distribuição, a largura da estrutura é negligenciada, ou seja, o parâmetro $b$ torna-se igual a zero.

A partir da equação (4.4) observa-se que se a altura do poste é incrementada de $20 \%$, então o nível de incidência de raios no poste aumenta em $12 \%$.

\subsubsection{A Influência de Estruturas Próximas às Linhas}

Os edifícios, construções, torres e árvores possuem um papel fundamental para o desempenho das linhas de distribuição frente às descargas atmosféricas, pois estes podem naturalmente interceptar muitas descargas que atingiriam diretamente as linhas.

O fator de proteção $S_{F}$ é definido como a porção (por unidade) da linha de distribuição que está sujeita à proteção por intermédio de objetos localizados em suas proximidades. O número estimado $N_{S}$ de descargas diretas que podem atingir a linha é determinado por:

$$
N_{S}=N \cdot\left(1-S_{F}\right)
$$

Um fator de proteção $S_{F}=0$ indica que a linha de distribuição está totalmente exposta (ambiente aberto), não tendo nenhuma estrutura ou objeto ao seu redor. Para um fator de proteção $S_{F}=1$ significa que a linha de distribuição está completamente protegida contra descargas diretas.

A Figura 4.2 fornece os valores do fator de proteção para objetos de diversas alturas em função de suas distâncias em relação a uma linha de distribuição possuindo 10 metros de altura. 


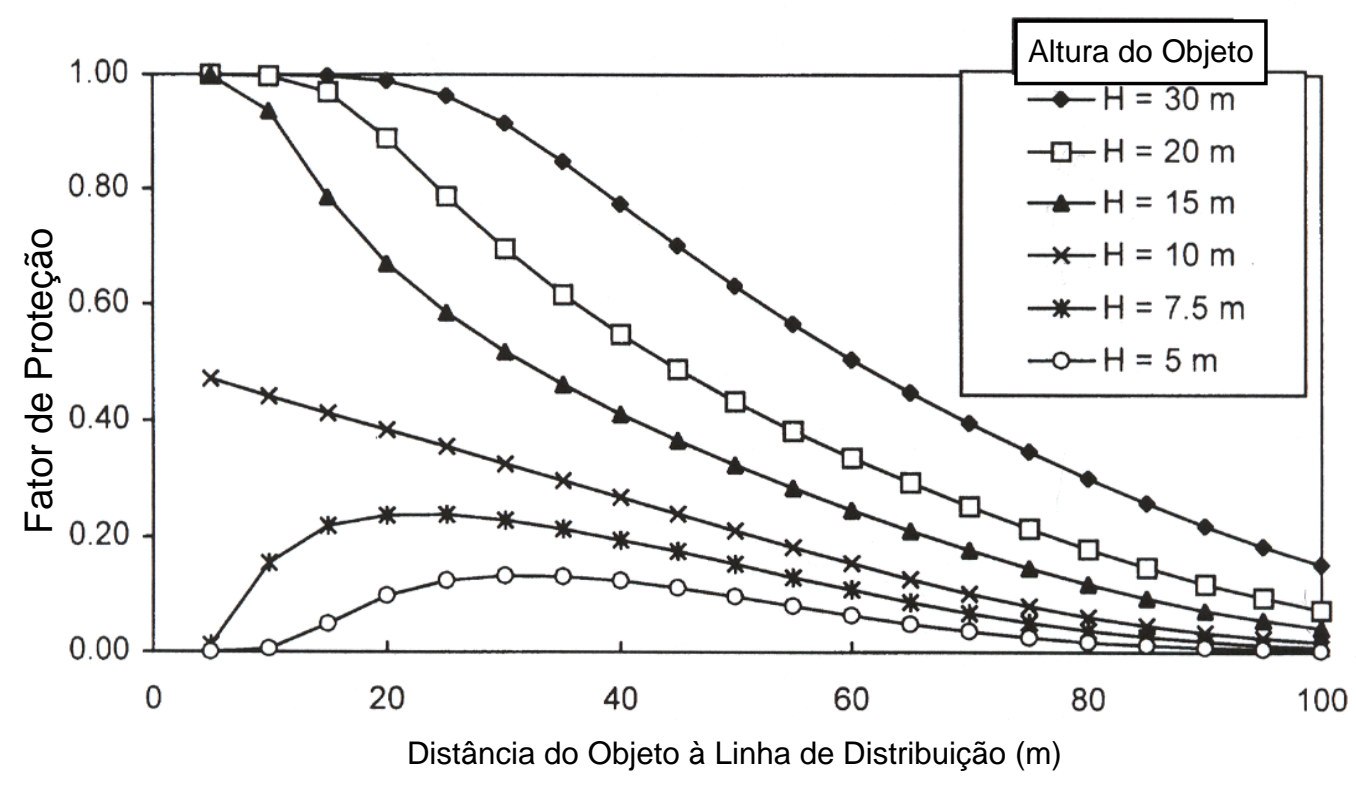

Figura 4.2 - Fatores de proteção devido a objetos próximos da linha de distribuição.

A Figura 4.2 pode ser também usada para objetos localizados em ambos os lados da linha de distribuição. Neste caso, os fatores de proteção do lado esquerdo e direito são somados. Se a soma dos fatores de proteção for maior que um, então o fator de proteção total será também assumido igual a um.

Como um exemplo, considere uma linha de distribuição com altura de 10 metros, tendo os seguintes objetos em cada um de seus lados:

口 Um edifício de 7,5 metros localizado a 30 metros do lado direito da linha.

a Uma torre de 15 metros localizada a 40 metros do lado esquerdo da linha.

Se a densidade de raios nesta região for 1 raio $/ \mathrm{km}^{2} / \mathrm{ano}$, então a partir da equação (4.4) observa-se que o número de descargas diretas na linha de distribuição seria 11,15 raios/100 km/ano. Levando-se em consideração os objetos ao redor da linha, e utilizando os valores obtidos a partir da Figura 4.2, o número de descargas diretas seria reduzido para:

$$
\begin{aligned}
N_{S} & =N \cdot\left[1-\left(S_{E}+S_{D}\right)\right. \\
& =11.15 \cdot[1-(0.23+0.4)] \\
& =4.12 \mathrm{raios} / 100 \mathrm{~km} / \text { ano }
\end{aligned}
$$

onde $S_{E}$ e $S_{D}$ são respectivamente os valores dos fatores de proteção da linha em relação aos objetos localizados à sua esquerda e à sua direita. 
Portanto, para a estimação do número de descargas disruptivas devido às descargas diretas utiliza-se a equação (4.4), ou seja, linha de distribuição em ambiente aberto. Para linhas de distribuição parcialmente protegidas, utilizam-se as equações (4.4) e (4.5).

\subsection{ASPECTOS RELATIVOS À MODELAGEM TÉCNICA}

Apresentam-se nesta seção alguns pontos teóricos relativos aos aspectos técnicos envolvidos com a modelagem da proteção de linhas de distribuição e de seus equipamentos.

\subsubsection{Modelagem do Fator de Proteção}

O modelo eletro-geométrico pode ser usado para estimar o fator de proteção para uma porção específica de uma linha de distribuição. Um modelo eletro-geométrico é baseado na idéia de que uma linha de distribuição ou outro objeto tem certo raio atrativo que aumenta com a altura, sendo este dependente da magnitude de corrente da descarga.

Embora diversos modelos tenham sido propostos, a equação usada para o cálculo das distâncias de incidências das descargas é aquela proposta pelo IEEE [6], a qual é definida por:

$$
\begin{aligned}
& r_{s}=10 \cdot I_{0}^{0.65} \\
& r_{g}=0.9 \cdot r_{s}
\end{aligned}
$$

onde: $r_{s}$ é a distância (em metros) entre o ponto de incidência da descarga e o condutor; $r_{g}$ é a distância (em metros) entre o ponto de incidência da descarga e o solo; e $I_{0}$ é a corrente de pico da descarga. Uma ilustração para os parâmetros $r_{s}$ e $r_{g}$ e mostrada na Figura 4.3.

Este modelo eletro-geométrico é usado para os cálculos do fator de proteção mostrados na Figura 4.2 e também para a estimação do número de disrupções causadas por tensões induzidas. O modelo eletro-geométrico pode também ser usado para estimar o número de raios que atingem diretamente a linha de distribuição, sendo esta uma alternativa à equação de Eriksson dada em (4.4). O modelo eletro-geométrico fornece resultados para descargas diretas que são próximos àqueles dados pela fórmula de Eriksson, o qual pode ser aplicado para linha de distribuição com altura menor que 15 metros. 


\subsubsection{Freqüências de Disrupções Devidas às Tensões Induzidas}

O cálculo teórico do número de disrupções em linhas de distribuição produzidas por descargas que ocorrem próximas às linhas tem sido descrito em [7], sendo baseado nas investigações realizadas por Chowdhuri [8].

Levando-se em consideração a natureza aleatória das descargas, qualquer cálculo tem que ser baseado em distribuições probabilísticas envolvendo os parâmetros a serem usados. Nesta pesquisa utiliza-se a distribuição adotada pelo CIGRE [3], a qual leva em consideração a corrente de pico da descarga.

De acordo com Rusck [9], a tensão máxima induzida em uma linha pode ser estimada por:

$$
V_{\max }=\frac{Z_{0} \cdot I_{0} \cdot h}{y} \cdot\left(1+\frac{1}{\sqrt{2}} \cdot \frac{v}{v_{0}} \cdot \frac{1}{\sqrt{1-\frac{1}{2}\left(\frac{v}{v_{0}}\right)^{2}}}\right)
$$

onde:

$Z_{0}$ é $1 /(4 \pi) \sqrt{\mu_{0} / \varepsilon_{0}}=30 \Omega$;

$I_{0}$ é a corrente de pico da descarga;

$h$ é a altura média da linha de distribuição em relação ao nível do solo;

$y$ é a distância entre o ponto de incidência da descarga e a linha;

$v$ é a velocidade de retorno da descarga;

$v_{0}$ é a velocidade da luz no ar.

O valor obtido de $Z_{0}$ é $30 \Omega$, sendo que o valor geralmente escolhido para $v$ varia entre 0.3 e $1.5 \times 10^{8} \mathrm{~m} / \mathrm{s}$. Assumindo-se o valor de $v$ igual a $1.2 \times 10^{8} \mathrm{~m} / \mathrm{s}$, a equação (4.9) torna-se:

$$
V_{\max }=38.8 \frac{I_{0} \cdot h}{y}
$$

Para estimar a freqüência de disrupções em razão das descargas indiretas, os procedimentos descritos em [7] e em [10] são considerados. O domínio compreendendo os valores de corrente de pico da descarga, o qual está entre 1 e $200 \mathrm{kA}$, é dividido em intervalos de $1 \mathrm{kA}$, e a probabilidade de picos de corrente estar dentro de um determinado intervalo é calculado a partir da equação (4.3). 
A distância máxima $y_{\max }$ para todo intervalo de pico de corrente no qual a descarga pode produzir uma disrupção na linha de distribuição pode ser então calculada. Para a obtenção de $y_{\max }$ basta aplicar a equação (4.10), tomando-se aqui o menor limite de corrente do intervalo em que $V_{\max }$ é 1,5 vezes maior que a tensão crítica. O termo Tensão Crítica (TC) de isolamento refere-se também ao parâmetro denominado de $V_{50 \%}$, o qual corresponde ao valor de tensão que, quando aplicado um grande número de vezes ao isolamento, resulta em ocorrência de falha em $50 \%$ das aplicações e em sua não ocorrência nos outros 50\%. O fator 1,5 é usado para cálculo de tensões induzidas de cabos guardas e de espaçamento de pára-raios, isto é:

$$
V_{\max }=1,5 \cdot T C
$$

A distância mínima $y_{\min }$ para o qual a descarga não desvia da linha é calculada a partir da equação (4.5), como proposto em [7]. Para este propósito, $r_{s}$ e $r_{g}$ são calculados tomando-se o limite superior do intervalo de corrente. A Figura 4.3 ilustra graficamente as distâncias $y_{\min } \mathrm{e}$ $y_{\max }$, as quais são calculadas pelas seguintes expressões:

$$
\begin{aligned}
& y_{\text {min }}=\sqrt{r_{s}^{2}-\left(r_{g}-h\right)^{2}} \\
& y_{\text {max }}=38.8 \frac{I_{0} \cdot h}{1.5 \cdot T C}
\end{aligned}
$$

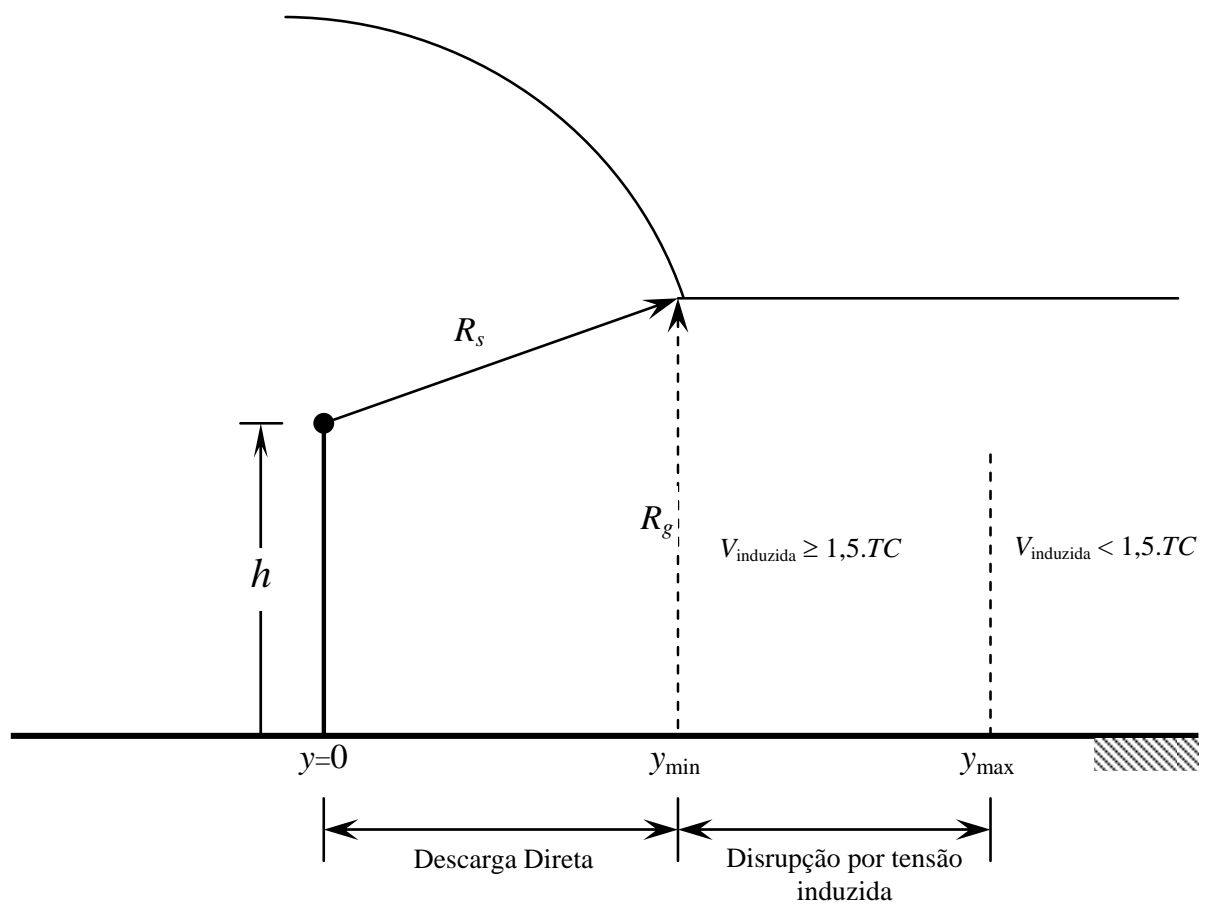

Figura 4.3 - Modelo eletro-geométrico para determinar disrupções por descargas diretas e indiretas. 
Como exemplo da aplicação deste procedimento, aplicando-se então as equações (4.11) e (4.12), para uma linha de distribuição de 10 metros de altura com $T C=150 \mathrm{kV}$, cuja corrente de descarga está no intervalo de $49 \mathrm{kA}$ a $50 \mathrm{kA}$, obtém-se $y_{\min }=72,5$ metros e $y_{\max }=84,5$ metros. Se assumir que a linha está em um ambiente aberto, então três cenários poderão ser considerados:

i) Se a descarga ocorrer entre $y=0$ metros e $y=y_{\min }=72,5$ metros, a mesma então atingirá diretamente a linha.

ii) Se a descarga ocorrer entre $y=y_{\min }=72,5$ metros e $y=y_{\max }=84,5$ metros, a mesma então atingirá o solo e causará um disrupção por tensão induzida.

iii) Se a descarga ocorrer a uma distância superior a $y=y_{\max }=84,5$ metros, a mesma então atingirá o solo, mas não causará uma disrupção por tensão induzida na linha.

Finalmente, o número de disrupções na linha de distribuição devido às tensões induzidas por km e por ano é obtido por meio da somatória das contribuições advindas de todos os intervalos considerados, ou seja:

$$
F_{p}=2 \cdot \sum_{i=1}^{200}\left(y_{\max }^{i}-y_{\min }^{i}\right) \cdot N_{g} \cdot P_{i}
$$

onde: $F_{p}$ é o número de disrupções/km/ano; $N_{g}$ é a densidade de descarga do ambiente em (raios $/ \mathrm{km}^{2} / \mathrm{ano}$ ); e $P_{i}$ é a probabilidade da corrente de pico $I_{0}$ ser maior ou igual a um determinado valor.

A Figura 4.4 ilustra o número de disrupções devidas às tensões induzidas para um circuito localizado em ambiente aberto e para um circuito protegido por árvores e edifícios, considerando-se uma densidade de raios igual a $1 \mathrm{raio} / \mathrm{km}^{2} / \mathrm{ano}$. 


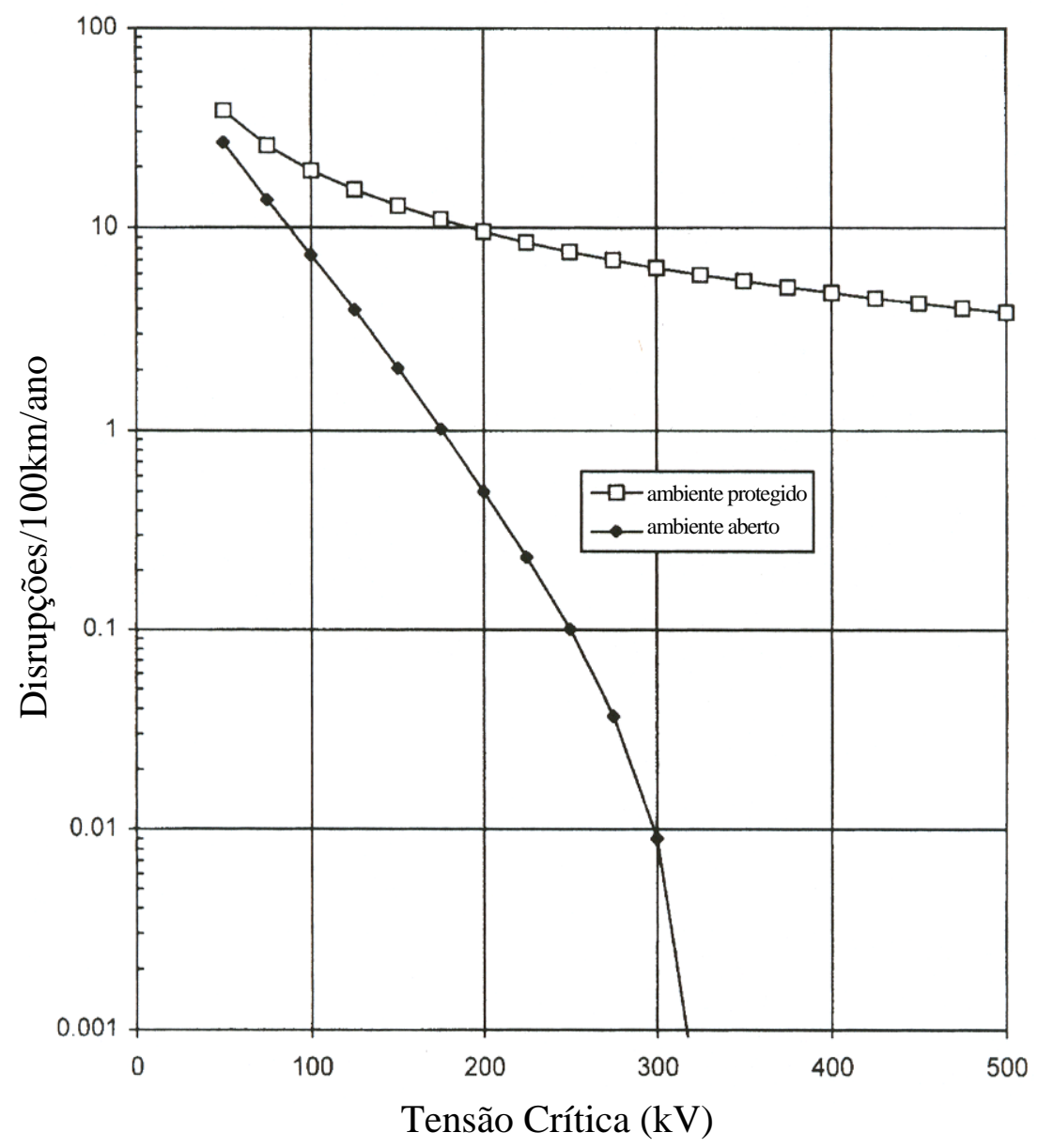

Figura 4.4 - Disrupções devidas às tensões induzidas em ambiente aberto e em ambiente protegido naturalmente.

\subsubsection{Espaçamento entre Pára-Raios Frente às Descargas Diretas}

Se uma descarga direta ocorrer no meio de uma linha de distribuição, onde um poste está com pára-raios e o outro está sem pára-raios, então a tensão que poderá se desenvolver no poste desprotegido é dada por:

$$
V=V_{I R}+\frac{L}{C} \cdot \frac{I \cdot Z_{0}}{2 T_{f}}
$$

onde: $V_{I R}$ é o nível de tensão de descarga do pára-raios, $c$ é a velocidade da onda e $\left(I . Z_{0}\right) / 2 T_{f}$ é a taxa de crescimento da tensão.

A corrente de pico da descarga requerida para causar uma disrupção a partir da meia distância dos postes pode ser obtida fazendo-se $V_{\max }=1,5^{*} T C$, ou seja: 


$$
I_{m d}=\frac{2 \cdot c \cdot T_{f} \cdot\left(1.5 \cdot T C-V_{I R}\right)}{L \cdot Z_{0}}
$$

Assumindo um $T_{f}=2 \mu \mathrm{s}, T C=350 \mathrm{kV}, Z_{0}=10 \Omega, L=75$ metros, e $V_{I R}=40 \mathrm{kV}$, a corrente que poderá então causar disrupção é dada por:

$$
I_{m d}=19,4 \mathrm{kA}
$$

Assim, a probabilidade de que esta corrente seja excedida é calculada por meio da equação (4.3), ou seja:

$$
P_{m d}=77,2 \%
$$

Agora, se uma descarga direta atinge um poste com fases não protegidas por pára-raios, é então assumido que há $100 \%$ de probabilidade de acontecer disrupção. Por outro lado, se uma descarga direta atinge um poste protegido por pára-raios, a probabilidade de uma disrupção ocorrer no próximo poste é então determinada em função da TC do poste desprotegido e pela resistência de aterramento $\left(R_{g}\right)$ do poste com pára-raios. Neste caso, a corrente no poste é dada por:

$$
I_{\text {poste }}=\frac{1.5 \cdot T C-V_{I R}}{R_{g}}
$$

Como exemplo, se $R_{g}=25 \Omega$ e $T C=150 \mathrm{kV}$, então $I_{\text {poste }}=7,4 \mathrm{kA}$ e $P_{\text {poste }}=98 \%$. Entretanto, caso $R_{g}=10 \Omega$ e $T C=350 \mathrm{kV}$, então $I_{\text {poste }}=48,5 \mathrm{kA}$ e $P_{\text {poste }}=24 \%$.

A Tabela 4.2 mostra a porcentagem de disrupções devidas às descargas diretas que ocorrem na linha em função do espaçamento dos pára-raios.

Tabela 4.2 - Disrupções em função do espaçamento dos pára-raios (descargas diretas).

\begin{tabular}{|c|c|c|}
\hline $\begin{array}{c}\text { Espaçamentos Entre } \\
\text { Pára-raios }\end{array}$ & $\begin{array}{c}\text { Porcentagem de Disrupções } \\
R_{g}=25 \Omega, T C=150 \mathrm{kV}\end{array}$ & $\begin{array}{c}\text { Porcentagem de Disrupções } \\
R_{g}=10 \Omega, T C=350 \mathrm{kV}\end{array}$ \\
\hline \hline 75 metros & $0 \%$ & $0 \%$ \\
\hline 150 metros & $100 \%$ & $70 \%$ \\
\hline 225 metros & $100 \%$ & $80 \%$ \\
\hline 300 metros & $100 \%$ & $85 \%$ \\
\hline infinito & $100 \%$ & $100 \%$ \\
\hline
\end{tabular}




\subsubsection{Espaçamento entre Pára-Raios Frente às Descargas Indiretas}

O modelo de Rusck pode ser utilizado para o cálculo do espaçamento entre pára-raios quando se consideram as descargas indiretas. Se uma descarga indireta ocorre perpendicularmente à localização de um poste com pára-raios, então é assumido que nenhuma disrupção ocorrerá. Se a descarga indireta incide perpendicularmente à localização de um poste sem pára-raios, então a tensão que desenvolverá no poste será determinada por:

$$
V=V_{I R}+\frac{2 \cdot L \cdot V_{p k}}{T_{f} \cdot C}
$$

onde: $L$ é a distância até o próximo poste com pára-raios; $V_{I R}$ é o nível de descarga do pára-raios; $c$ é a velocidade da onda; e $V_{p k} / T_{f}$ é a taxa de crescimento da tensão induzida.

A tensão induzida requerida para causar uma disrupção é dada por $V_{\max }=1,5 \cdot T C$. Se utilizarmos $V_{p k} / 1.5$ como uma $T C$ equivalente, então o número de disrupção por ano pode ser estimado para determinado poste. A Tabela 4.3 mostra o espaçamento entre pára-raios em função dos níveis de tensão induzidas que podem causar disrupção. Neste caso, considera-se uma linha de distribuição com $T C=150 \mathrm{kV}, V_{I R}=40 \mathrm{kV}, T_{f}=1 \mu$ s e $L=75 \mathrm{~m}$.

Tabela 4.3 - Número equivalente de disrupções por tensões induzidas.

\begin{tabular}{|c|c|c|}
\hline $\begin{array}{c}\text { Distância Até o } \\
\text { Próximo Pára-raios }\end{array}$ & $\begin{array}{c}\text { Tensão Requerida para } \\
\text { Causar Disrupção }\end{array}$ & $\begin{array}{c}\text { Número Equivalente de } \\
\text { disrupções/100km/ano }\end{array}$ \\
\hline \hline metro & infinita & 0 \\
\hline 75 metros & $220 \mathrm{kV}$ & 0,11 \\
\hline 150 metros & $150 \mathrm{kV}$ & 1,80 \\
\hline 225 metros & $150 \mathrm{kV}$ & 1,80 \\
\hline
\end{tabular}

A Tabela 4.4 mostra o número de disrupções causadas por tensões induzidas para diversos valores de espaçamento de pára-raios.

Tabela 4.4 - Disrupções por tensões induzidas em função do espaçamento entre pára-raios.

\begin{tabular}{|c|c|}
\hline $\begin{array}{c}\text { Espaçamentos Entre } \\
\text { Pára-raios }\end{array}$ & $\begin{array}{c}\text { Número de disrupções } / 100 \mathrm{~km} / \mathrm{ano} \\
\text { (Densidade de Descarga }=1 \mathrm{raio} / \mathrm{km}^{2} / \mathrm{ano} \text { ) }\end{array}$ \\
\hline \hline 75 metros & 0 \\
\hline 150 metros & 0,06 \\
\hline 225 metros & 0,08 \\
\hline 300 metros & 0,51 \\
\hline 375 metros & 0,76 \\
\hline 450 metros & 0,94 \\
\hline Sem pára-raios & 1,79 \\
\hline
\end{tabular}




\subsection{MÉTODOS PARA A COORDENAÇÃO DE ISOLAMENTO EM SISTEMAS DE DISTRIBUIÇÃO}

A coordenação de isolamento compreende a adequação da suportabilidade de um equipamento, ou arranjo isolante, às tensões que podem aparecer no sistema para o qual ele foi projetado. Este procedimento leva em conta as características dos dispositivos de proteção, de modo a reduzir a um nível economicamente e operacionalmente aceitável a probabilidade de que as tensões resultantes impostas causem danos ou afetem a continuidade do serviço.

Para a especificação e análise de desempenho da coordenação de isolamento, alguns aspectos fundamentais devem ser levados em consideração, ou sejam:

\section{a) Solicitações Dielétricas}

Envolve o conhecimento do módulo, duração e probabilidade de ocorrência de sobretensões em sistemas de potência. Essas sobretensões são agrupadas em três categorias [11]:

口 Sobretensões de origem atmosféricas: decorrem de descargas diretas ou indiretas (induzidas) em sistemas de transmissão e distribuição de energia elétrica.

口 Sobretensões de manobra: decorrem da operação (chaveamento) de disjuntores ao longo do sistema elétrico.

• Sobretensões temporárias na freqüência de 60 Hz: resultam de condições normais e anormais do sistema elétrico.

\section{b) Dispositivos e Técnicas de Proteção}

Envolve o conhecimento da natureza e características dos dispositivos de proteção, bem como um entendimento de como o dispositivo de proteção pode controlar a magnitude do surto, incluindo-se a influência na confiabilidade do próprio dispositivo.

\section{c) Esforços Elétricos}

Implica no conhecimento da capacidade das várias partes de um equipamento de resistir à descarga disruptiva sob condições específicas. 


\section{d) Nível de Comportamento}

Denota a avaliação das conseqüências econômicas e operacionais de falha de isolamento.

Desta forma, a coordenação de isolamento envolve a determinação das sobretensões cujas linhas de transmissão e distribuição, bem como os equipamentos, estão submetidas; seguidos então da seleção conveniente das suportabilidades elétricas e das distâncias de isolamento, levando-se também em consideração as características de proteção disponíveis.

Basicamente, existem dois métodos para determinar a coordenação de isolamento em função da sobretensão de origem atmosférica e de manobra [11], ou seja:

- Método Convencional: baseia na seleção de níveis de suportabilidade maiores que as sobretensões esperadas através do uso de uma margem de segurança, julgada adequada por experiência. Esse método é empregado em todas as classes de tensão e para isolação não auto-recuperante, como é o caso de transformadores, dentre outros.

- Método Estatístico: baseia na seleção de níveis de suportabilidade a partir de uma determinada taxa de falha pré-estabelecida, levando-se em consideração a natureza estatística das sobretensões e da suportabilidade do dielétrico. Esse método é empregado para isolação auto-recuperante e, normalmente, para tensão acima de $300 \mathrm{kV}$.

Nos sistemas elétricos de distribuição de energia elétrica emprega-se o método convencional para a especificação e análise da coordenação de isolamento, visto que as tensões máximas de operação são relativamente baixas (até $36 \mathrm{kV}$ ) e que o método estatístico não apresenta vantagem econômica para tensões inferiores a 300 kV [12].

As informações correspondentes à coordenação de isolamento são geralmente traçadas numa curva tensão-tempo similar àquela apresentada na Figura 4.5. Nesse gráfico, representa-se tanto a capacidade de proteção de um pára-raios ou centelhador, bem como a capacidade para as ondas de tempo de crista longo. Essa curva nada mais é que a representação das características físicas do equipamento observadas em testes controlados [11]. 


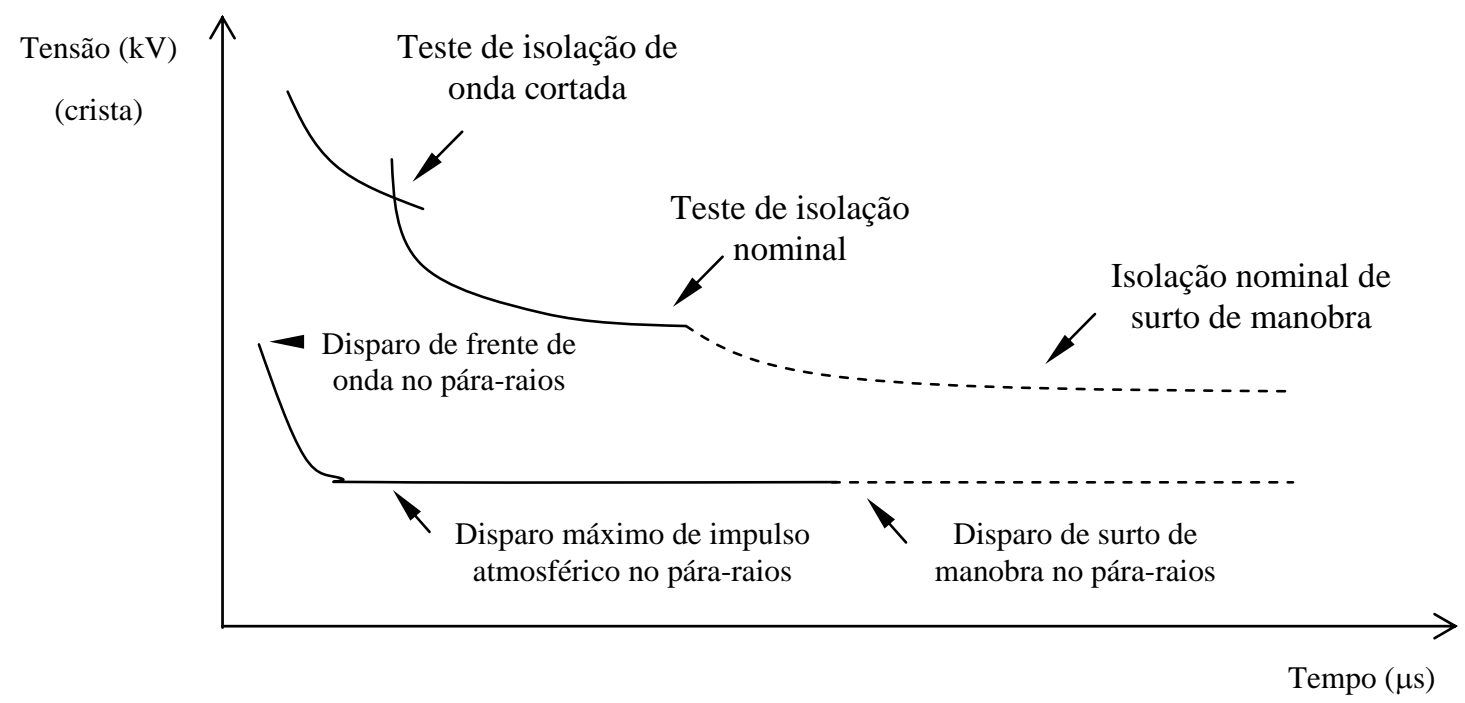

Figura 4.5 - Curva típica de coordenação de isolamento.

Deve-se observar que as linhas de distribuição não são normalmente blindadas, de forma que as sobretensões de origem atmosférica superpõem-se às sobretensões de manobra, sendo que essa última não é considerada no estudo da coordenação de isolação de sistemas de distribuição.

\subsection{ESTRATÉGIAS DE PROTEÇÃO DE SISTEMAS DE DISTRIBUIÇÃO}

O desempenho da proteção de linhas aéreas de distribuição com relação à ocorrência de disrupção (flashover), ao envelhecimento de isolantes não-recuperantes e aos danos permanentes a equipamentos, oriundos de sobretensões de origem atmosférica, pode ser melhorado por meio das seguintes estratégias ou da combinação delas:

\section{a) Instalação de Pára-Raios}

A possibilidade de disrupção (flashover) em linhas de distribuição com ou sem cabo guarda pode ser reduzida com a instalação de pára-raios ao longo de seu comprimento. A localização adequada depende de muitos fatores, tais como a densidade de descargas ao solo, o nível de exposição da linha, a geometria dos condutores, o nível de isolamento, a resistência de aterramento e o nível de desempenho desejado da proteção.

Em geral, quanto maior a densidade de pára-raios na linha, melhor será o desempenho desta no tocante à ocorrência de disrupção e danos aos equipamentos. As Figuras 4.6 e 4.7 apresentam os resultados da variação da distância entre pára-raios em uma linha de distribuição com nível de isolação de 150 kV [13]. 


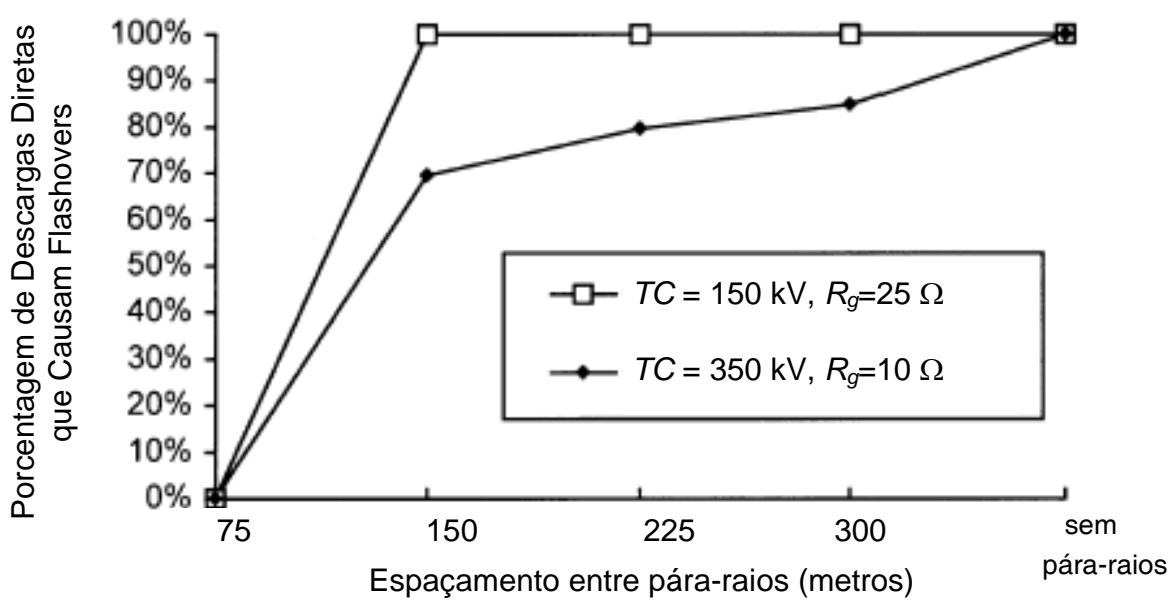

Figura 4.6 - Espaçamento entre pára-raios para descargas diretas.

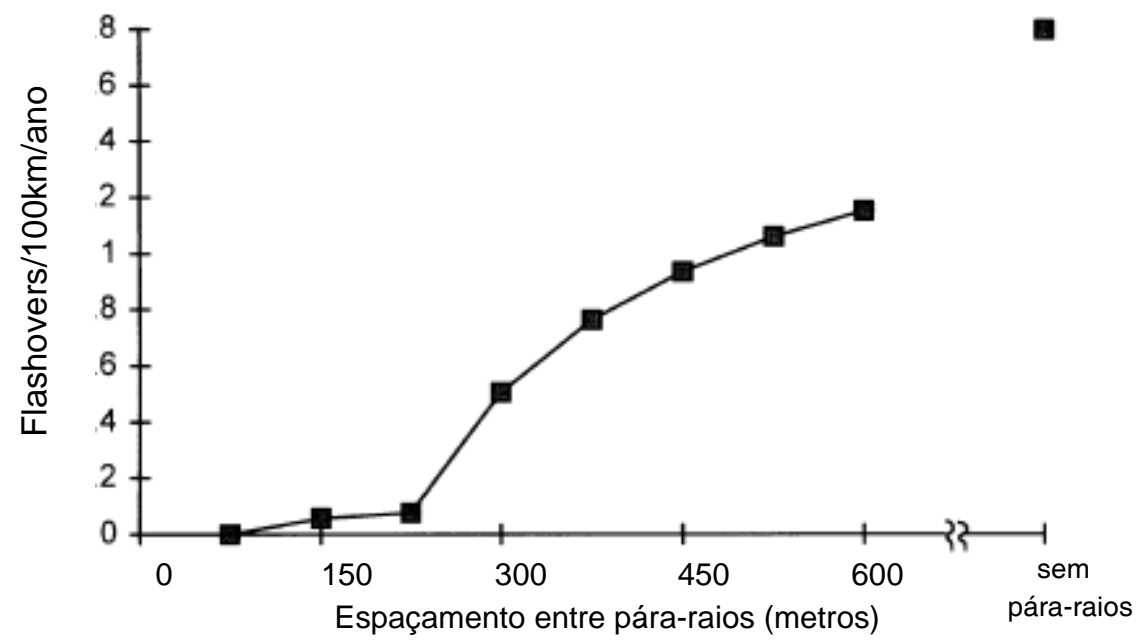

Figura 4.7 - Espaçamento entre pára-raios para descargas indiretas.

\section{b) Instalação de Cabo Guarda}

A eficiência da proteção usando o cabo guarda depende de muitos fatores como o ângulo de proteção (geometria), do sistema de aterramento e do ângulo de incidência da descarga atmosférica. Descargas diretas no cabo guarda podem induzir tensões nos condutores de fase. A magnitude da tensão induzida é função da amplitude da corrente de descarga, da resistência do cabo guarda e do aterramento, bem como do acoplamento magnético do sistema. Correntes de descarga acima de um determinado valor crítico podem induzir tensões suficientemente elevadas para gerar uma disrupção (flashover) em isoladores, bem como danificar equipamentos como transformadores e, conseqüentemente, retirar o alimentador de serviço. Condutores fase com o menor acoplamento magnético são os mais severamente atingidos. 
Normalmente, as linhas de distribuição urbanas são pouco susceptíveis às descargas diretas devido à proteção natural exercida pelas edificações e vegetação de grande porte. Desta maneira, a instalação de cabo-guarda pode não representar uma melhoria significativa no desempenho quanto às descargas atmosféricas, além também de ser complexa a sua instalação em áreas urbanas. As linhas rurais e suburbanas são naturalmente mais expostas de forma que a combinação de cabo guarda e pára-raios vem a melhorar o desempenho da proteção contra sobretensões de origem atmosférica.

O desempenho de uma linha dotada de cabo guarda com relação às sobretensões de descarga atmosférica pode ser avaliado por meio dos seguintes fatores [14]:

- SFFOR (Shielding Failure FlashOver Rate): Número de flashovers em uma linha decorrentes da falha na blindagem por unidade de comprimento e por ano.

- BFR (Back Flashover Failure Rate): Número de flashovers em uma linha decorrentes da tensão induzida nos condutores fase quando a intensidade da descarga no cabo-guarda é suficientemente elevada por unidade de comprimento e por ano. Esse evento pode ou não causar um disrupção (flashover).

Ambos os fatores são linearmente dependentes da densidade de descargas ao solo por quilômetro quadrado por ano. Os métodos para a determinação desses fatores são fornecidos na norma IEEE Std. 1243/1997 [13] e no CIGRE Technical Bulletin 63.

\section{c) Aumento da Classe de Isolação de Estruturas, Isoladores e Equipamentos}

O aumento da tensão crítica de descarga sob impulso do sistema de distribuição deve ser implementado quando não é possível estabelecer uma coordenação de isolamento dentro de margens de proteção adequadas. Na decisão por esta abordagem deve-se pesar o risco em manter a susceptibilidade às falhas no isolamento e os investimentos envolvidos no aumento da tensão crítica de descarga sob impulso nos setores mais expostos.

\subsection{OS PÁRA-RAIOS DE ÓXIDO DE ZINCO (ZnO)}

Em sistemas de distribuição, os pára-raios são os principais dispositivos empregados na proteção contra sobretensões em virtude de sua eficiência, custo e facilidade de instalação. Devido às inerentes vantagens dos pára-raios baseados em Oxido de Zinco (ZnO), esse vem substituindo gradativamente os pára-raios baseados em Carboneto de Silício (SiC). 
Os pára-raios ZnO utilizam uma ou mais colunas de elemento (pastilhas) de Óxido de Zinco em paralelo. A característica típica V-I dessa classe de pára-raios é apresentada na Figura 4.8. Acima do "joelho" da curva, os elementos apresentam um comportamento não linear que pode ser aproximada pela seguinte relação:

$$
I=K \cdot V^{\alpha}
$$

onde $I$ é a corrente de descarga; $V$ é a tensão sobre o pára-raios e $\alpha$ é o coeficiente que depende das características construtivas do pára-raios.

Os valores do expoente $\alpha$ variam de 10 a 50 dependendo das características químicas dos elementos e da corrente de descarga considerada. Tipicamente, elevadas correntes de descarga e elevadas tensões de operação impõem pequenos valores para $\alpha$. A tensão disruptiva $\left(V_{D}\right)$ para uma dada corrente de surto depende da altura da coluna de pastilhas e da Tensão Máxima de Operação em Regime Contínuo (TMORC). Adicionalmente, a tensão disruptiva é função da taxa de crescimento da frente de onda do surto de corrente, de forma que grandes taxas de variação geram elevadas tensões disruptivas. Normalmente, para a mesma magnitude de corrente, a tensão disruptiva para frente de onda de $1 \mu$ s é de 8 a 12\% maior que aquela que ocorre para um surto padrão 8/20 $\mu$ s [15].

A TMORC é tipicamente de 75 a 85\% da tensão fase-fase do sistema elétrico eficazmente aterrado. Na TMORC a corrente de fuga é tipicamente menor que $10 \mathrm{~mA}$, fato este que contribui na sensibilidade dos esquemas de proteção de falta à terra. Quando um surto de tensão atinge seu terminal, com tensão de disrupção também alcançada, estabelece-se uma corrente de descarga que gera uma Tensão Residual (TR) dado pela característica V-I do páraraios. À medida que a corrente decresce, a tensão residual decai até ao valor de pré-surto. 


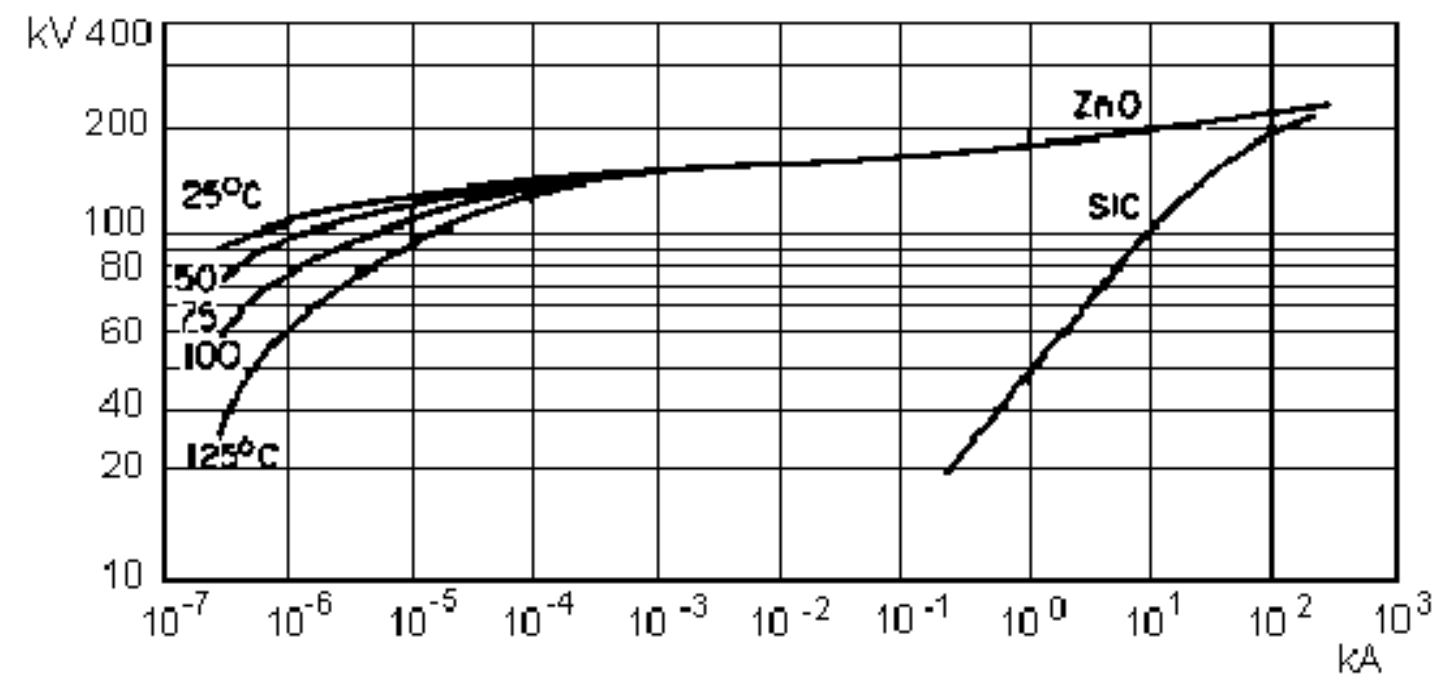

Figura 4.8 - Característica V-I típica para pára-raios ZnO e SiC.

As características elétricas dos pára-raios ZnO são as seguintes:

\section{a) Tensão Nominal}

A tensão nominal de um pára-raios é o valor máximo eficaz da tensão (na freqüência industrial) aplicada aos seus terminais no ensaio de ciclo de serviço, para a qual o pára-raios foi projetado e tem condições de operar satisfatoriamente. O valor da tensão nominal é utilizado como um parâmetro de referência para a especificação de suas características de operação.

\section{b) Tensão Máxima de Operação em Regime Contínuo (TMORC)}

A tensão máxima de operação em regime contínuo é o maior valor eficaz de tensão para o qual o pára-raios é projetado, de modo a operar continuamente quando esta tensão é aplicada em seus terminais, de forma a garantir a isolação do sistema [14].

\section{c) Capacidade de Sobretensão Temporária (CST)}

A capacidade de sobretensão temporária é definida em função da característica de suportabilidade tensão-tempo, onde é indicado o tempo para o qual é permitida a aplicação de uma tensão superior à tensão máxima de operação em regime contínuo nos terminais do páraraios. Este parâmetro está associado à elevação de temperatura do resistor não-linear. A Figura 4.9 apresenta a característica típica para os pára-raios ZnO. Períodos de exposição maiores que o permitido para uma dada sobretensão reduzirão a vida útil do pára-raios. 


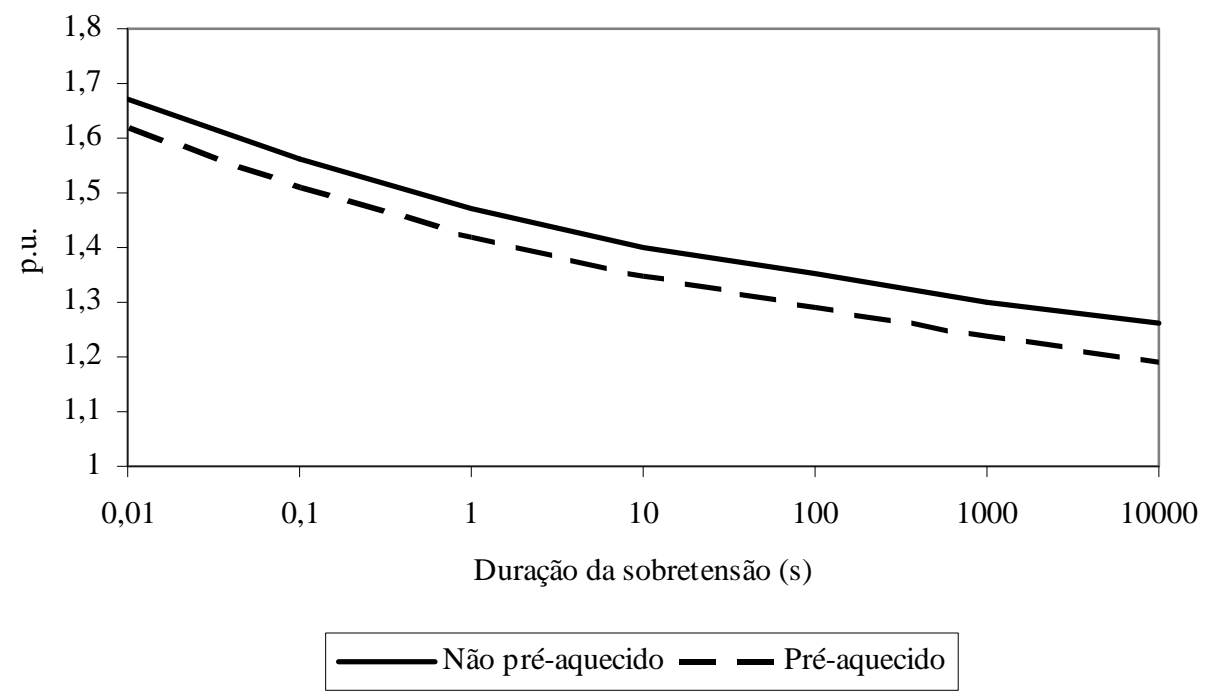

Figura 4.9 - Capacidade de sobretensão temporária típica para pára-raios ZnO.

\section{d) Nível de Proteção a Impulso de Manobra}

O nível de proteção a impulso de manobra depende da corrente de condução no páraraios, a qual aumenta à medida que o valor do impulso de tensão aumenta. Com o intuito de definir o nível de proteção a impulso de manobra, um valor para a corrente de coordenação deve ser estabelecido. Geralmente, o valor de 3 kA é adotado na ausência de estudos específicos, uma vez que este valor dificilmente será ultrapassado na prática.

\section{e) Tensão Residual (TR)}

A tensão residual é a tensão que surge no pára-raios quando da passagem de uma corrente de descarga 8/20 $\mu$ s. Normalmente, a tensão residual máxima (tensão disruptiva - $V_{D}$ ) é determinada através de ensaios realizados para impulsos de corrente de valor 1,5; 3; 5; 10; 15; 20 e $40 \mathrm{kA}$, com frente de onda de 0,5 $\mu$ s. A tensão residual depende da forma de onda do impulso aplicado e, geralmente, os fabricantes fornecem informações relacionando a tensão residual máxima com o tempo de frente de onda do impulso aplicado, tal como indicado na Figura 4.10 e na Tabela 4.5. 


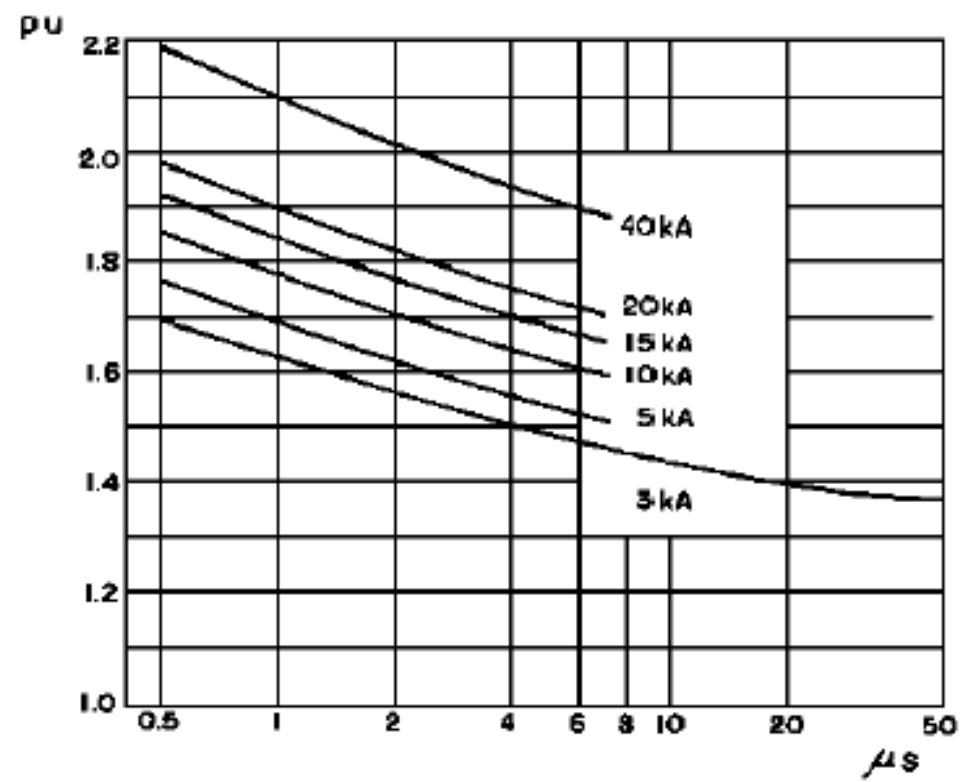

Figura 4.10 - Tensão residual em função do tempo da frente de onda para as correntes de descarga normalizadas para pára-raios do fabricante GE.

Tabela 4.5 - Níveis de proteção típicos de pára-raios do fabricante ABB.

\begin{tabular}{|c|c|c|}
\hline Corrente de descarga & Forma de onda & $\begin{array}{c}\text { Nível de proteção do pára-raios } \\
\text { (TR/TMORC) }\end{array}$ \\
\hline \hline $2,5 \ldots . .30 \mathrm{kA}$ & $8 / 20 \mu \mathrm{s}$ & $1,7 \ldots 2,2$ \\
\hline $65 \ldots 100 \mathrm{kA}$ & $4 / 10 \mu \mathrm{s}$ & $2,5 \ldots .2,9$ \\
\hline $125 \ldots 3000 \mathrm{~A}$ & $30 / 60 \mu \mathrm{s}$ & $1,5 \ldots 1,8$ \\
\hline
\end{tabular}

Nota-se que, o valor real da tensão residual ou do nível de proteção do pára-raios para surtos de origem atmosférica depende principalmente da amplitude da corrente de descarga e, em menor grau, da frente de onda do surto.

\section{f) Capacidade de Absorção de Energia}

A capacidade de absorção de energia do pára-raios é de grande importância nos sistemas de EAT e UAT, onde a energia disponível é muito elevada e devido à possibilidade de repartição dela entre pára-raios de uma subestação. 


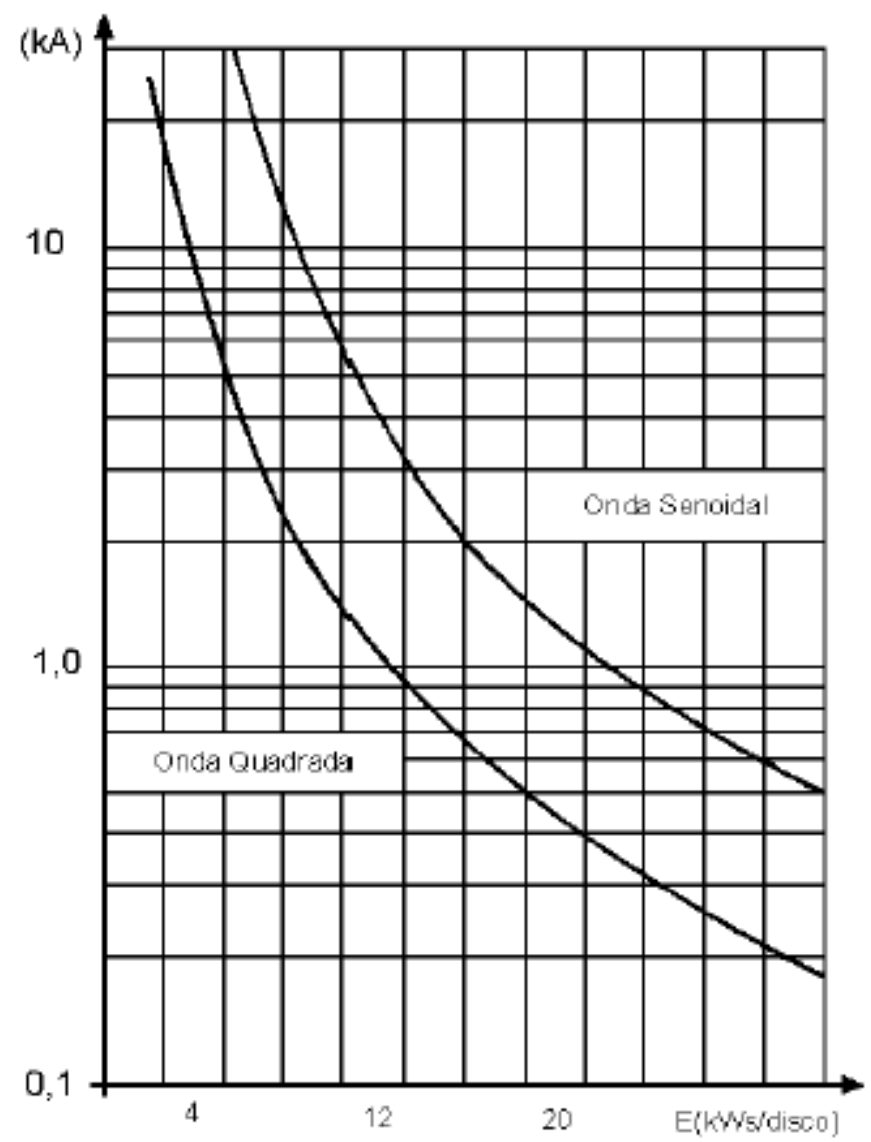

Figura 4.11 - Energia máxima dissipada em função da corrente de descarga.

Os catálogos dos fabricantes, normalmente, indicam a capacidade máxima de energia em kW por kV de tensão nominal, sendo esta capacidade função da tensão nominal e da corrente de condução do pára-raios. Geralmente, os pára-raios utilizados em sistemas de EAT têm uma capacidade de absorção de energia na faixa de 7 a $8 \mathrm{~kW}$ por kV de tensão nominal. A Figura 4.11 apresenta a variação da capacidade de absorção de energia de pára-raios em função da corrente de condução.

\subsection{COORDENAÇÃO DE ISOLAMENTO EM SISTEMAS DE DISTRIBUIÇÃO}

A aplicação do método convencional, como descrito na Seção 4.2, no procedimento de coordenação de isolamento em sistema de distribuição consiste nos seguintes passos:

๑ Determinação das sobretensões no sistema elétrico.

\ Seleção de sistemas de isolação que permitam uma determinada probabilidade de falha, ou seja, a suportabilidade de um determinado equipamento (isoladores, 
espaçamentos de condutores, transformadores, dentre outros) às sobretensões inerentes aos sistemas elétricos.

• Seleção de técnicas e/ou dispositivos de proteção que limitem a susceptibilidade e/ou amplitude das sobretensões de origem atmosférica.

A determinação das sobretensões advém de modelos computacionais, os quais geram os comportamentos das sobretensões, sejam elas de origem atmosférica, de manobra ou temporárias. No caso das sobretensões de origem atmosférica, além dos modelos matemáticos de tensões induzidas, fazem-se necessárias informações georeferenciadas relacionadas à magnitude das descargas (valor de crista) e a densidade de raios à terra.

A determinação da suportabilidade de um sistema de isolação tem origem nos ensaios de sobretensões normalizados e não normalizados sob diversas condições ambientais e operacionais do sistema. Os níveis de isolamento para tensões máximas de equipamentos iguais ou inferiores a $242 \mathrm{kV}$ são apresentados na Tabela 4.6.

Tabela 4.6 - Níveis de isolamento para tensões máximas de equipamentos entre 7,2 e 36,2 kV.

\begin{tabular}{|c|c|c|c|c|}
\hline $\begin{array}{l}\text { Tensão máxima do } \\
\text { equipamento }\end{array}$ & \multicolumn{2}{|c|}{$\begin{array}{c}\text { Tensão suportável nominal } \\
\text { de impulso atmosférico } \\
\text { (NBI) }\end{array}$} & \multirow{2}{*}{\multicolumn{2}{|c|}{$\begin{array}{c}\text { Tensão suportável nominal à } \\
\text { freqüência industrial durante } \\
1 \text { minuto } \\
\mathrm{kV} \text { (eficaz) }\end{array}$}} \\
\hline kV (eficaz) & $\begin{array}{l}\text { Pleno kV } \\
\text { (crista) }\end{array}$ & $\begin{array}{l}\text { Cortado kV } \\
\quad \text { (crista) }\end{array}$ & & \\
\hline 72 & 40 & 44 & ח & \\
\hline 1,2 & 60 & 66 & 20 & \\
\hline 15 & 95 & 105 & & \\
\hline 10 & 110 & 121 & 34 & \\
\hline 24 & 125 & 138 & & \\
\hline 24,2 & 150 & 165 & & 50 \\
\hline & 150 & 165 & & \\
\hline 36,2 & 170 & 187 & 70 & \\
\hline & 200 & 220 & & \\
\hline
\end{tabular}

Fonte: [17]

A seleção da suportabilidade dos equipamentos do sistema e dos dispositivos de proteção envolve fatores probabilísticos como a freqüência de ocorrência de raios, a amplitude das descargas, a polaridade da descarga, a taxa de variação da frente de onda do surto e o grau de exposição da linha de distribuição; além de fatores determinísticos, tais como comportamento 
dos dispositivos de proteção e sistemas de isolação mediante um surto de tensão, e ainda daqueles fatores ambientais como a umidade do ar, temperatura ambiente, contaminação por agentes poluentes.

Para sistemas com tensão entre 1 e $242 \mathrm{kV}$ a suportabilidade dos equipamentos como transformadores, capacitores, religadores, reguladores de tensão deve ser avaliada pelos seguintes parâmetros [16]:

• Tensão suportável nominal à freqüência industrial durante 1 minuto.

- Tensão suportável nominal de impulso atmosférico (NBI).

Deve-se observar que para sistemas de distribuição, as sobretensões de manobra não são consideradas, conforme mencionado na Seção 4.2.

Nesse contexto, a seleção dos componentes com relação à suportabilidade consiste na seleção de níveis de proteção normalizados acrescidos de uma margem de segurança que estejam acima das sobretensões esperadas para o sistema elétrico.

\subsubsection{Proteção Contra Sobretensões em Sistemas de Distribuição}

Dentre as técnicas de proteção de sistemas de distribuição contra sobretensões, os dispositivos pára-raios em óxido de zinco $(\mathrm{ZnO})$ formam a “primeira linha de defesa” já que a instalação de cabo guarda em sistemas de distribuição de áreas urbanas é de difícil execução, além de pouco contribuir para o desempenho da proteção. Para a aplicação de pára-raios ZnO, diversos parâmetros com relação às características de proteção devem ser conhecidos, ou seja:

\section{a) Tensão Máxima de Operação em Regime Contínuo (TMORC)}

A tensão nominal de um pára-raios convencional deve ser igual ou superior à maior sobretensão na freqüência industrial que pode ocorrer no sistema, visando-se evitar que o páraraios seja submetido a descargas consecutivas e, eventualmente, se danifique.

As causas mais freqüentes para a ocorrência de sobretensões temporárias são as seguintes: faltas monofásicas fase-terra, rejeição de carga, ferro-ressonância, indução em circuitos paralelos e perda de conexão à terra em sistemas aterrados. As características de suportabilidade para sobretensões temporárias devem ser utilizadas de acordo com as informações específicas para cada fabricante.

Em sistemas de distribuição, o curto-circuito monofásico à terra define a tensão máxima de operação em regime contínuo (TMORC). Assim, a TMORC depende da configuração do 
sistema e do valor da impedância inserida no neutro do transformador de origem do alimentador, quando este tem enrolamento secundário ligado em estrela com o neutro acessível.

A determinação da TMORC de um pára-raios pode ser feita através da fixação do valor do fator de aterramento $\left(f_{A T}\right)$ para o ponto de instalação do sistema, ou seja:

$$
T M O R C=V_{F F} \cdot f_{A T}
$$

A experiência mostra que, para a aplicação de pára-raios, o fator de aterramento pode ser classificado dentro de um limitado número de grupos, ou seja:

- O fator de aterramento é igual ou inferior a 0,80, caracterizando-se então um sistema eficazmente aterrado;

\ O fator de aterramento excede 0,80 , caracterizando-se então um sistema não eficazmente aterrado, aterrado por ressonância ou com neutro isolado.

Em muitas situações, não se dispõe dos parâmetros necessários para a determinação do fator de aterramento. Então, a Tabela 4.7 resume os elementos de orientação para a escolha do pára-raios em função da tensão máxima em regime contínuo do sistema de distribuição, que pode ser determinada em qualquer ponto do sistema.

Tabela 4.7 - Tabela de escolha de pára-raios ZnO para sistemas de distribuição.

\begin{tabular}{|c|c|c|c|c|}
\hline \multicolumn{2}{|c|}{ Sistema elétrico (V eficaz) } & \multicolumn{3}{|c|}{ Tensão nominal e máxima do pára-raios (kV eficaz) } \\
\hline Tensão Nominal & Tensão máxima & $\begin{array}{l}\text { Sistema a } 4 \text { fios } \\
\text { com neutro } \\
\text { multiaterrado }\end{array}$ & $\begin{array}{l}\text { Sistema a } 3 \text { fios } \\
\text { aterrado com } \\
\text { baixa impedância }\end{array}$ & $\begin{array}{c}\text { Sistema a } 3 \text { fios } \\
\text { aterrado com alta } \\
\text { impedância }\end{array}$ \\
\hline 2400 & 2540 & & & $3(2,55)$ \\
\hline $4160 \mathrm{Y} / 2400$ & $4400 Y / 2540$ & $3(2,55)$ & $6(5,1)$ & $6(5,1)$ \\
\hline 4260 & 4400 & & & $6(5,1)$ \\
\hline 4800 & 5080 & & & $6(5,1)$ \\
\hline 6900 & 7260 & & & $9(7,65)$ \\
\hline $8320 Y / 4800$ & $8800 Y / 5080$ & $6(5,1)$ & $9(7,65)$ & \\
\hline 12000Y/6930 & $12700 Y 7330$ & $9(7,65)$ & $12(10,2)$ & \\
\hline $12470 Y / 7200$ & $13200 Y / 7620$ & $9(7,65)$ ou $10(8,4)$ & $15(12,7)$ & \\
\hline $13200 Y / 7620$ & $13970 Y / 8070$ & $10(8,4)$ & $15(12,7)$ & \\
\hline $13800 Y 7970$ & $14520 / 8388$ & $10(8,4)$ e $12(10,2)$ & $15(12,7)$ & \\
\hline 13800 & 14520 & & & $18(15,3)$ \\
\hline 20780Y/12000 & $22000 Y / 12700$ & $15(12,7)$ & $21(17,0)$ & \\
\hline $22860 Y / 12000$ & $22000 Y / 12700$ & $15(12,7)$ & $21(17,0)$ & \\
\hline 23000 & 24340 & & & $30(24,4)$ \\
\hline $24940 \mathrm{Y} / 14400$ & $26400 Y / 15240$ & $18(15,3)$ & $27(22,0)$ & \\
\hline $27600 Y / 15935$ & $29255 Y / 16890$ & $21(17,0)$ & $30(24,4)$ & \\
\hline 34500Y19920 & $36510 Y / 21080$ & $27(22,0)$ & $36(29,0)$ & \\
\hline
\end{tabular}




\section{b) Capacidade de Sobretensão Temporária}

Em sistemas de distribuição não eficazmente aterrados, o fator de aterramento pode ser 1,0 ou maior no ponto de instalação dos pára-raios. Então, a duração da sobretensão torna-se um parâmetro importante. Desta forma, no caso de sobretensões de falta à terra, o sistema de proteção de falta à terra deve eliminar as faltas em um tempo suficientemente pequeno para que não ocorra a extrapolação da suportabilidade térmica do pára-raios, como mencionado no item c da Seção 4.8.

\section{c) Capacidade de Descarga}

A intensidade da corrente que circula pelo pára-raios é influenciada pelos parâmetros elétricos da linha, pelo grau de exposição da linha, pelo tipo e magnitude da descarga atmosférica e pelas características do pára-raios. Para uma onda viajante em uma linha aberta, a intensidade da corrente que circula por um pára-raios $\left(I_{D}\right)$ instalado próximo ao fim da linha é dada pela seguinte expressão:

$$
I_{D}=\frac{2 \cdot V_{S}-V_{D}}{Z_{S}}
$$

onde $V_{S}$ é o valor de crista da tensão de surto e $Z_{S}$ é a impedância de surto da linha (entre 350 e $500 \Omega)$.

Um fator preponderante na coordenação de isolamento em sistemas de distribuição é a coordenação da corrente de descarga $\left(I_{D}\right)$ e a capacidade de corrente nominal do pára-raios $\left(I_{N}\right)$. Esta coordenação permite verificar a coerência entre as características locais das descargas ao solo e a capacidade de descarga do pára-raios, além de definir a corrente nominal de descarga $\left(I_{N}\right)$ a ser empregada na coordenação de isolamento. A partir da Figura 4.12, pode-se estimar a magnitude e a taxa de ocorrência de corrente de descarga em pára-raios de distribuição sob várias condições [16].

Por exemplo, em situações admitidas como normais, a corrente de descarga nominal $\left(I_{N}\right)$ é $10 \mathrm{kA}$. Entretanto, para um local onde a densidade de descargas ao solo é 10 raios $/ \mathrm{km}^{2} / \mathrm{ano}$, a Figura 4.12 indica que uma corrente de descarga de $30 \mathrm{kA}$ ou maior poderia ocorrer uma vez a cada 10 anos. Se a vida esperada do pára-raios for 30 anos, então se sugere que a coordenação de isolamento deve ser feita com uma corrente maior que $10 \mathrm{kA}$. Ainda, a decisão de se empregar correntes de descargas diferentes dos valores padronizados pode ter impacto no tipo de páraraios a ser utilizado (serviço normal ou pesado), bem como no arranjo dos pára-raios. 


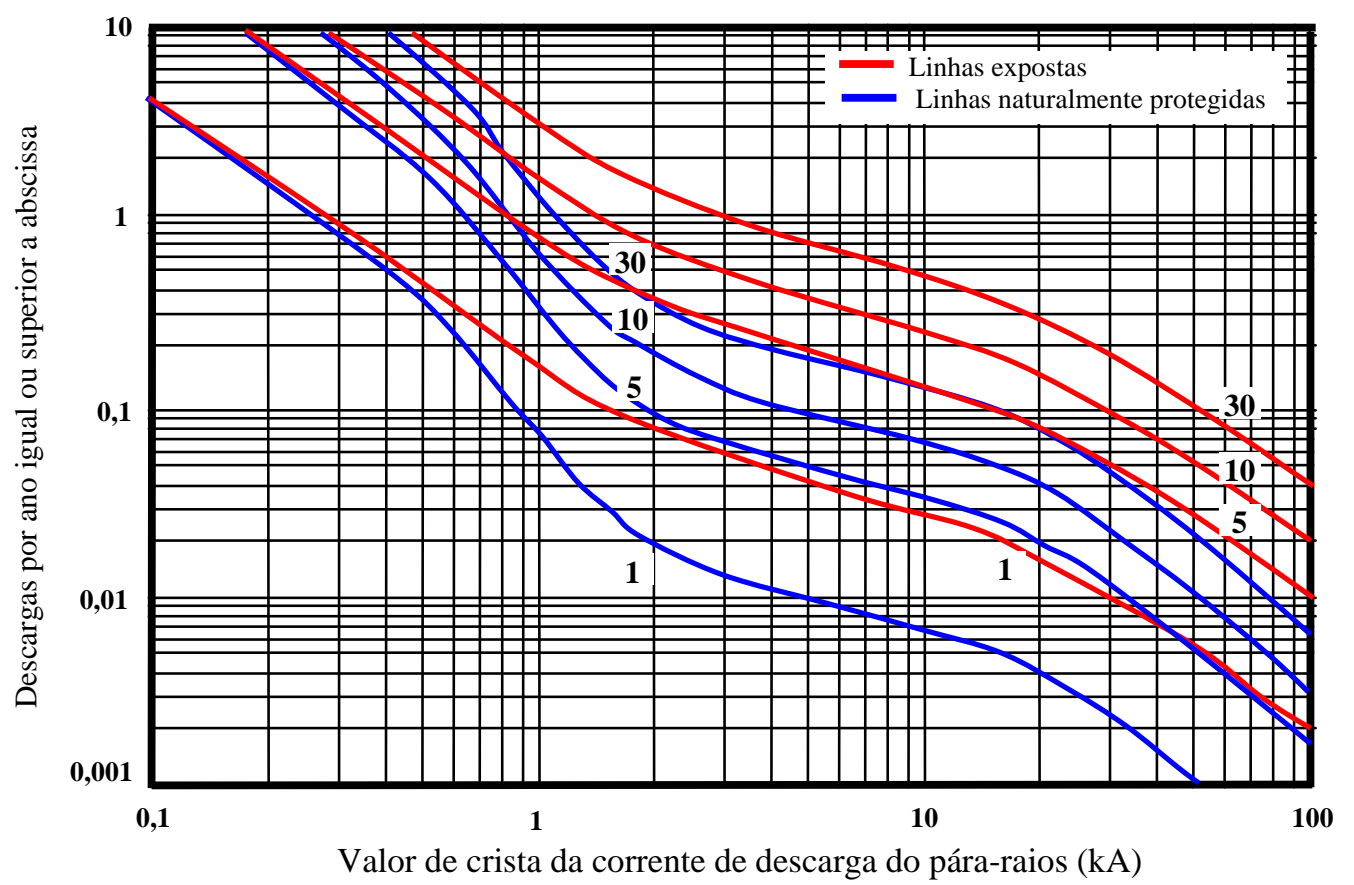

Figura 4.12 - Distribuição das correntes de descargas de pára-raios.

\section{d) Tensão Residual ou Nível de Proteção}

Os níveis de proteção dos pára-raios devem ser conhecidos para que seja possível a determinação da tensão residual total admissível no processo de coordenação de isolamento. A Tabela 4.8 apresenta as características típicas de pára-raios $\mathrm{ZnO}$ para uso em sistemas de distribuição.

Tabela 4.8 - Características típicas dos pára-raios ZnO desprovidos de centelhadores.

\begin{tabular}{|c|c|c|c|c|c|c|c|}
\hline \multirow{3}{*}{$\begin{array}{c}\mathrm{V}_{\mathbf{F F}} \\
\mathbf{k V} \\
\text { (eficaz) }\end{array}$} & \multirow{3}{*}{$\begin{array}{c}\text { TMORC } \\
\text { kV (eficaz) }\end{array}$} & \multicolumn{6}{|c|}{ Nível de Proteção } \\
\hline & & \multicolumn{3}{|c|}{ Frente de onda $(0,5 \mu \mathrm{s})$} & \multicolumn{3}{|c|}{ Onda $8 / 20 \mu \mathrm{s}$} \\
\hline & & $5 \mathbf{k A}$ & $10 \mathrm{kA}$ & $15 \mathrm{kA}$ & $5 \mathbf{~ k A}$ & $10 \mathbf{~ k A}$ & $15 \mathbf{~ k A}$ \\
\hline 3 & 2,55 & $11,2-17,0$ & $13,5-17,0$ & 10,4 & $10,2-16,0$ & $9,1-16,0$ & 8,2 \\
\hline 6 & 5,10 & $22,3-25,5$ & $26,5-35,3$ & $17,4-18,0$ & $20,3-24,0$ & $18,2-25,0$ & 16,2 \\
\hline 9 & 7,65 & $33,5-36,0$ & 26,5-35,3 & $22,5-36,0$ & $30,0-33,5$ & $21,7-31,5$ & $20,0-24,9$ \\
\hline 10 & 8,4 & $36,0-37,2$ & 29,4-39,1 & $26,0-36,0$ & $31,5-33,8$ & $24,5-35,0$ & $22,5-26,6$ \\
\hline 12 & 10,2 & $44,7-50,0$ & $35,3-50,0$ & $34,8-37,5$ & $40,6-44,0$ & $32,1-44,0$ & $30,0-32,4$ \\
\hline 15 & 12,7 & $54,0-58,5$ & $42,0-59,0$ & $39,0-54,0$ & $50,7-52,0$ & $35,9-51,0$ & $33,0-40,2$ \\
\hline 18 & 15,3 & $63,0-67,0$ & $51,0-68,0$ & $47,0-63,0$ & $58,0-60,9$ & $43,3-61,0$ & $40,0-48,0$ \\
\hline 21 & 17.0 & $73.0-80.0$ & $57.0-81,0$ & $52,0-63,1$ & $64,0-75,0$ & $47,8-75,0$ & $44,0-56,1$ \\
\hline 24 & 19,5 & $89,0-92,0$ & $68,0-93,0$ & $63,0-72,5$ & $81,1-83,0$ & $57,6-83,0$ & $53,0-64,7$ \\
\hline 27 & 22,0 & $94,0-100,5$ & $77,0-102,0$ & $71,0-81,9$ & $87,0-91,1$ & $65,1-91,0$ & $60,0-72,1$ \\
\hline 30 & 24,4 & $107,0-180,0$ & $85,0-109,5$ & $78,0-85,1$ & $94,5-99,0$ & $71,8-99,0$ & $66,0-79,5$ \\
\hline 36 & 29,0 & 125,0 & $99,0-136,0$ & $91,0-102,8$ & 116,0 & $83,7-125,0$ & $77,0-96,0$ \\
\hline
\end{tabular}

Fonte: [16] 
A Tensão Residual Total (TRT) advém da tensão disruptiva do pára-raios, da queda de tensão nos condutores de interligação ao aterramento e aos condutores fase e da impedância de aterramento.

\section{e) Margens de Proteção}

Para que exista uma adequada coordenação de isolamento em sistemas de distribuição, as seguintes margens de proteção devem ser consideradas:

๑ Onda Cortada:

$$
M P F O=\left[\frac{V_{O C}}{\left(V_{D}\right)}-1\right] \cdot 100 \%
$$

onde:

MPFO é a margem de proteção para frente de onda;

$V_{O C}$ é a tensão de ensaio de onda cortada do equipamento;

$V_{D}$ é a tensão disruptiva de frente de onda $(0,5 \mu \mathrm{s})$.

๑ Onda Plena:

$$
M P O P=\left[\frac{N B I}{T R}-1\right] \cdot 100 \%
$$

onde:

MPOP é a margem de proteção para a onda plena;

NBI é o nível básico de impulso do equipamento;

$T R$ é a tensão residual do pára-raios para correntes normalizadas de impulso atmosférico $8 / 20 \mu \mathrm{s}$.

Em geral, MPFO e MPOP devem ser superiores a 20\%. Entretanto, a experiência mostra que sistemas de distribuição com tensão inferior a $15 \mathrm{kV}$ têm apresentado margens superiores a 50\%. A Figura 4.13 ilustra graficamente a coordenação de isolamento entre um pára-raios e um transformador imerso em óleo mineral. 


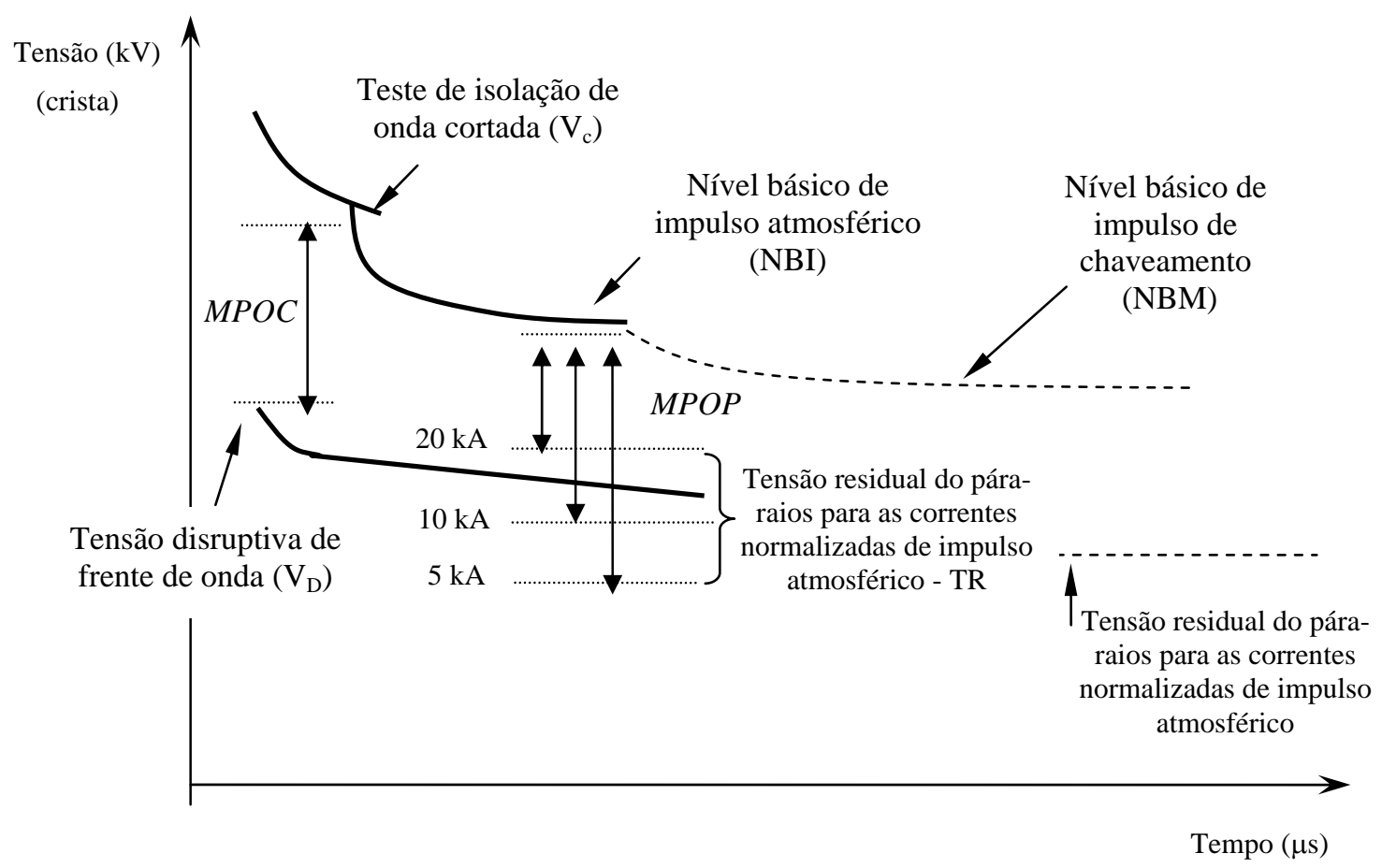

Figura 4.13 - Curva típica de coordenação de isolamento entre pára-raios e transformador imerso em óleo mineral.

\section{f) Distância de Proteção}

O desempenho de um sistema de proteção contra sobretensões baseado em pára-raios depende fortemente da distância de separação entre o dispositivo pára-raios e o equipamento protegido. A melhor localização para um dispositivo anti-surto é nos terminais do equipamento a ser protegido. Entretanto, principalmente por razões de seletividade com os elos fusíveis, os pára-raios são instalados a certa distância dos terminais do equipamento protegido, indicado por $D$ na Figura 4.14, a qual é conhecida como distância de proteção.

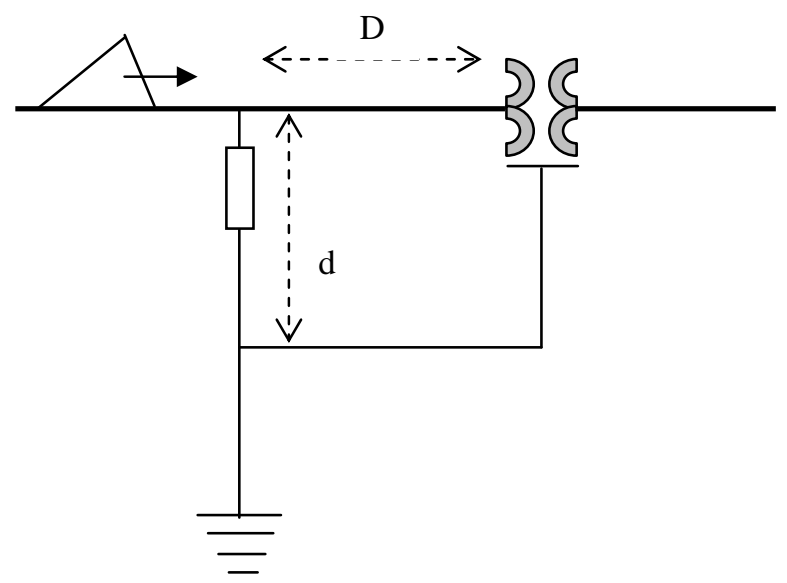

Figura 4.14 - Distâncias de proteção. 
A distância $D$ associada à distância de interligação $d$ entre o pára-raios e a caixa do equipamento protegido pode dar origem a um transiente de tensão que pode superar o NBI do equipamento protegido. Assim, as distâncias $D$ e $d$ devem ser as menores possíveis de forma a preservar os níveis de proteção.

Analisando-se a Figura 4.14, a tensão resultante nos terminais do transformador $\left(V_{T R}\right)$ para o caso mais extremo é dado por:

onde:

$$
V_{T R}=2 \cdot \frac{D}{C} \cdot \frac{d e}{d t}+V_{R}+2 \cdot d \cdot L \cdot \frac{d i}{d t}
$$

$c$ é a velocidade de propagação da onda;

$V_{R}$ é a tensão residual do pára-raios;

$L$ é a indutância dos condutores de interligação;

di/dt é a taxa de variação da corrente de surto;

de/dt é a taxa de variação da tensão de surto.

Portanto, como observado na expressão (4.23), a tensão transitória imposta ao transformador é função da tensão residual imposta pelo pára-raios, da taxa de variação da frente de onda, das características elétricas das interligações e das distancias de proteção $D$ e $d$. Assim, quanto mais próximo for instalado o pára-raios do equipamento protegido, melhor será o desempenho da proteção.

\subsection{CONSIDERAÇÕES PARCIAIS}

Neste capítulo foram realizadas todas as investigações necessárias para a estruturação de critérios técnicos que visam detalhar diversos aspectos que levam à adequada especificação da proteção de transformadores. Desta forma, aspectos relativos ao nível de exposição das linhas de distribuição, às características elétricas das descargas, ao desempenho das linhas de distribuição frente às descargas atmosféricas, aos métodos para a coordenação de isolamento, foram minuciosamente investigados.

Os resultados advindos destas investigações permitiram definir e analisar todos os parâmetros que são importantes ao processo de especificação da proteção de transformadores. Assim sendo, todos os subsídios necessários para a implementação do sistema especialista para auxiliar na especificação da proteção de transformadores contra descargas atmosféricas foram delineados. Como resultado, o sistema especialista poderá computar diversas variáveis que implicam na adequada proteção dos transformadores, tais como o tipo de pára-raios mais 
adequado, o espaçamento correto entre os pára-raios e o número médio de descargas sobre a linha.

\subsection{REFERÊNCIAS BIBLIOGRÁFICAS}

[1] Anderson, R. B., Eriksson, A. J., Kroninger, H., Meal, D. V., and Smith, M. A., "Lightning and Thunderstorm Parameters,” IEE Conference Publication No. 236, Lightning and Power Systems, London, June 1984, pp. 57-61.

[2] MacGorman, D. R., Maier, M. W., and Rust, W. D., "Lightning Strike Density for the Contiguous United States from Thunderstorm Duration Records," Report to U.S. Nuclear Regulatory Commission, \# NUREG/CR-3159, 1984.

[3] Working Group 01 (Lightning) of Study Commitee 33 (Overvoltages and Insulation Coordination), “Guide to Procedures for Estimating the Lightning Performance of Transmission Lines,” CIGRE Brochure \#63, Oct. 1991, Paris

[4] Anderson, J. G., "Lightning Performance of Transmission Lines," Transmission Line Reference Book, 345 kV and Above, E1ectric Power Research Institute: Palo Alto, CA, 1982, ch. 12.

[5] Eriksson, “The Incidence of Lightning Strikes to Power Lines,” IEEE Transactions on Power Delivery, vol. PWRD-2, no.2, pp. 859-870, July 1987.

[6] IEEE Working Group Report, “Estimating Lightning Performance of Transmission Lines II Updates to Ana1ytica1 Models,” IEEE Transactions on Power Delivery, vol. 8, no.3, pp. 12541267, July 1993.

[7] Rusck, S., Lightning, R. H. Golde, ed., "Protection of Distribution Lines,” London: Academic Press, 1977.

[8] Chowdhuri, P., "Estimation of Flashover Rates of Overhead Power Distribution Lines by Lightning Strokes to Nearby Ground,” IEEE Transactions on Power Delivery, vol. 4, no. 3, pp. 1982-1989, July 1989.

[9] Rusck, S., “Induced Lightning Overvoltages on PowerTransmission Lines With Special Reference to the Overvoltage Protection of Low Voltage Networks,” Transactions of the Royal Institute of Technology, Stockholm, no.120, 1958. 
[10] De la Rosa, F., “Assessing the Operation of Distribution Lines in a Lightning Environment,” Proceedings of the IASTED Intemational Symposium on High Technology in the Power Industry, Bozeman, Montana, pp. 316-319, Aug. 20-22,1986.

[11] IEC 60071 part 1 (1993) and 2: Insulation coordination.

[12] D. E. HEDMAN, Eletrobrás: Coordenação de isolamento, p. 200, 1979.

[13] IEEE STD 1410-1997: Guide for improving the lighting performance of electric power overhead distribution lines.

[14] IEEE STD 1313.1-1996: Standard for insulation coordination - Definitions, principles and rules.

[15] Sakshaug, E.C., Burke, J.J., Kresge, J.S. "Metal oxide arresters on distribution systems: Fundamental considerations,” IEEE Transactions on Power Delivery, vol. 4, no. 4 , Oct. 1989, pp. $2076-2089$.

[16] IEEE STD C62.22-1997: Guide for Application of Metal-oxide Surge Arresters for Alternating Current.

[17] NBR 6939-2000: Coordenação de Isolamento - Procedimento. 



\section{Capítulo 5}

\section{Sistema Especialista para Seleção de Dispositivos de Proteção de Transformadores}

\subsection{INTRODUÇÃO}

Sistemas especialistas são programas responsáveis pela solução de problemas de domínio especializado no qual a solução do problema requer geralmente uma tomada de decisão que implique em ações que otimize o desempenho do sistema. Assim sendo, um sistema especialista é capaz de emitir uma decisão, apoiado em conhecimentos justificados, a partir de uma base de informações, tal qual um especialista de determinada área do conhecimento.

Para solucionar problemas, os sistemas considerados especialistas precisam acessar as bases de conhecimentos a respeito do domínio da aplicação. Portanto, o sucesso de um sistema especialista depende enormemente da forma de como o conhecimento é representado e dos mecanismos envolvidos com a sua exploração.

Os principais benefícios da utilização dos sistemas especialistas estão pautados na velocidade de cálculo de respostas para o problema, na fundamentação da decisão a partir de módulos (bases) de informações, na segurança, na estabilidade, na flexibilidade e na integração com outras ferramentas numéricas e computacionais.

O sistema especialista que foi estruturado para esta aplicação é constituído de quatro módulos de informações que fornecem todos os dados necessários para a especificação correta dos dispositivos de proteção dos transformadores.

A Figura 5.1 mostra um diagrama esquemático do inter-relacionamento entre os módulos de informações do sistema especialista. 


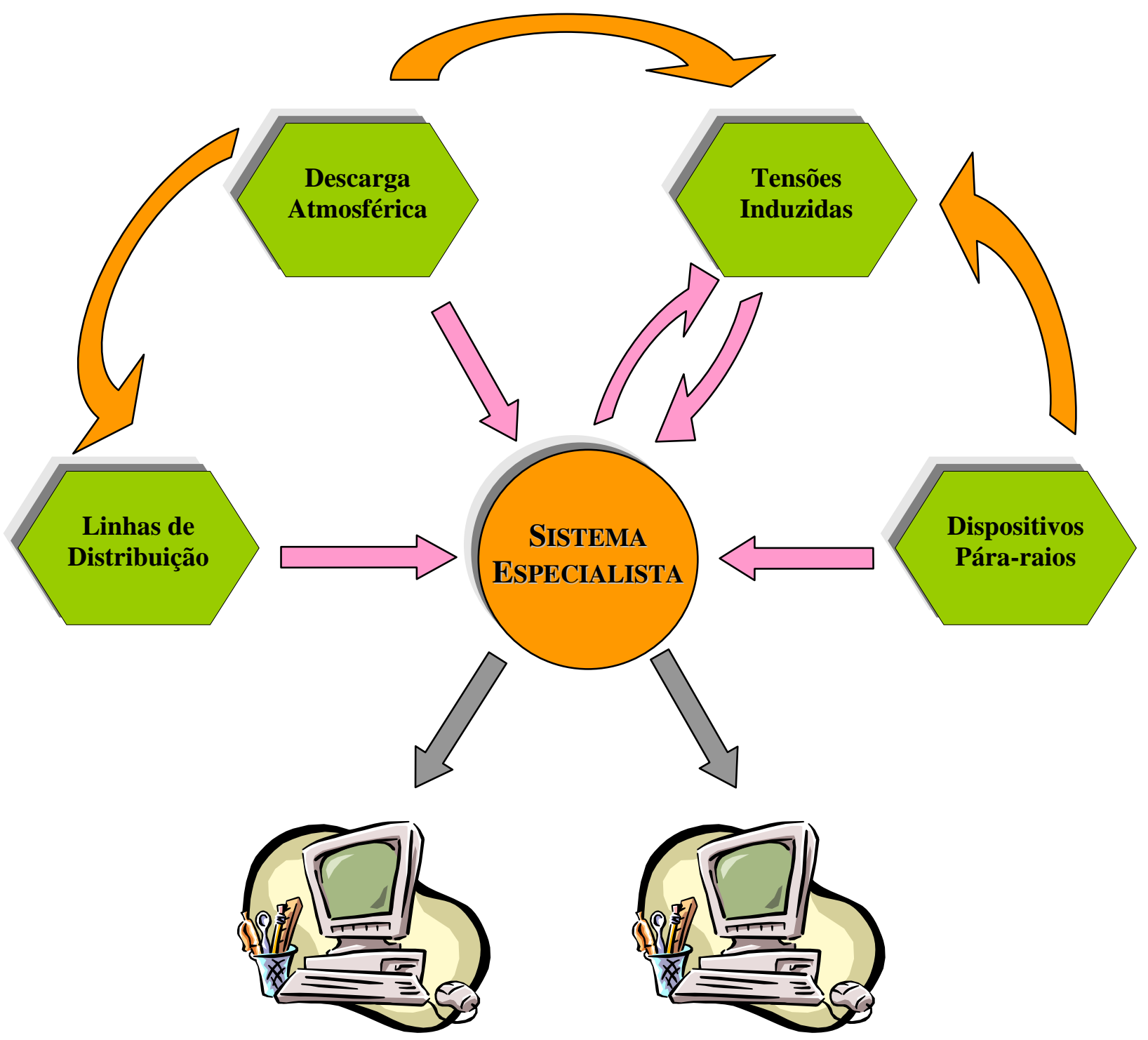

Figura 5.1 - Diagrama esquemático do inter-relacionamento das bases de informações.

As quatro bases de informações que constituem o sistema especialista são formadas por banco de dados que armazenam os parâmetros e características que compõem o sistema de distribuição de energia elétrica das concessionárias, ou sejam:

A)Linhas de Distribuição: responsável pelo armazenamento dos parâmetros que permitem especificar as características de determinado trecho da linha de distribuição da concessionária, tais como o número de condutores, a altura da linha, o diâmetro dos condutores, as impedâncias terminais, etc.

B) Descarga Atmosférica: responsável pelo armazenamento de informações relativas às características das descargas atmosféricas que incidem nas áreas de concessão pertencentes à concessionária. Entre as informações que são guardadas neste módulo 
encontram-se a intensidade de corrente da descarga, o tempo de subida, o valor de crista, o tempo de meia onda, a freqüência de ocorrência, as coordenadas da descarga atmosférica, etc.

C) Tensões Induzidas: módulo responsável pela computação dos valores das sobretensões de origem atmosférica que serão induzidas nas linhas de distribuição. Este módulo recebe informações referentes às características das descargas atmosféricas, bem como as características dos dispositivos de proteção instalados na linha de distribuição. O cálculo das tensões induzidas será efetuado através da plataforma computacional desenvolvida nas etapas anteriores do projeto.

D) Dispositivos Pára-Raios: módulo responsável pelo armazenamento de informações referentes às características e propriedades dos tipos de dispositivos de proteção dos transformadores, especialmente os pára-raios.

Os diferentes módulos de informação são utilizados pelo sistema especialista a fim de produzir como resposta o tipo de proteção mais adequada para o transformador, o qual estará localizado em determinada região servida pela concessionária. Em resumo, alguns processamentos que serão realizados dentro do sistema especialista dizem respeito aos seguintes aspectos:

๑ Cálculo da densidade de descargas atmosféricas nas regiões de concessão.

\ Determinação das probabilidades de ocorrências de correntes de descarga acima de determinado valor de interesse.

• Obtenção da característica de propensão das linhas de distribuição estar sujeitas à incidência de descargas atmosféricas, levando-se em consideração os aspectos construtivos da linha, bem como a influência dos fatores naturais de proteção envoltos na região de localização da respectiva linha.

• Análise dos níveis de isolação das linhas levando-se em consideração os diversos componentes instalados na mesma.

Toda a arquitetura computacional do sistema especialista está sendo feita utilizando a linguagem Visual Basic, a qual permite a estruturação e prototipagem de programas orientados a objetos, permitindo que os processos implementados tenham flexibilidade, portabilidade e facilidade de integração com outros sistemas computacionais. As principais características desta linguagem são as seguintes: 
• Flexibilidade de integração com outras ferramentas computacionais.

• Portabilidade de execução em diversos ambientes operacionais.

Disponibilidade de recursos gráficos avançados.

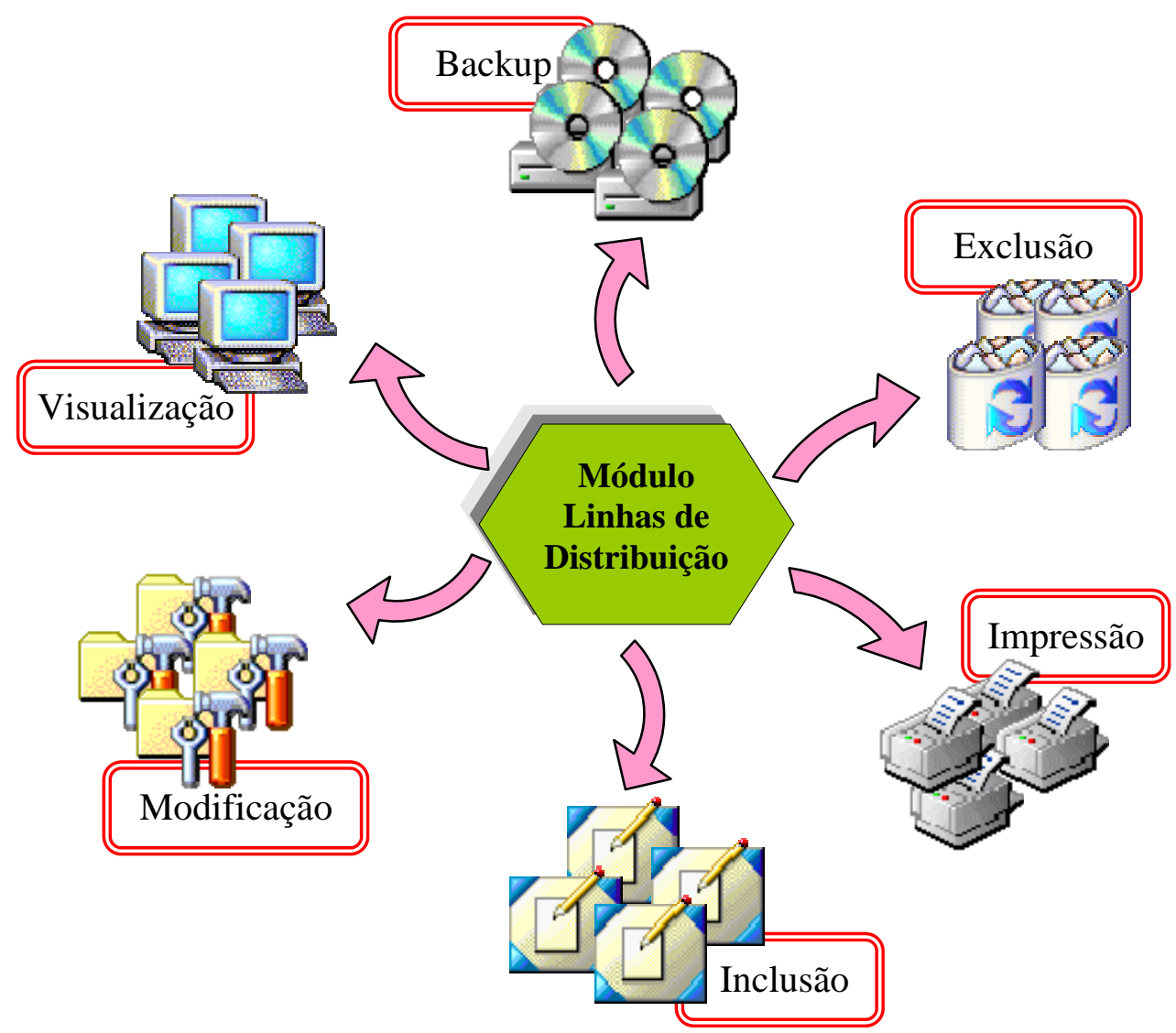

Figura 5.2 - Diagrama ilustrativo dos procedimentos dos módulos.

Cada módulo de informação integrado ao sistema especialista foi confeccionado com o intuito de serem ajustáveis às novas situações que possam surgir no decorrer do tempo. Assim sendo, cada um deles propiciam procedimentos que permitam inclusão, modificação, exclusão, visualização, impressão e armazenamento (backup) de todas as informações. A Figura 5.2 ilustra os procedimentos que estão disponíveis para cada um dos módulos que integra o sistema especialista.

\subsection{RECURSOS E CARACTERÍSTICAS DO SISTEMA ESPECIALISTA}

O sistema especialista foi desenvolvido a fim de se tornar uma ferramenta computacional eficiente no auxílio do dimensionamento e escolha da correta proteção para equipamentos instalados em linhas de distribuição frente à ocorrência de descargas atmosféricas. 
Através da tela principal do programa, apresentada na Figura 5.3, o usuário terá acesso a todas as funcionalidades do sistema especialista.

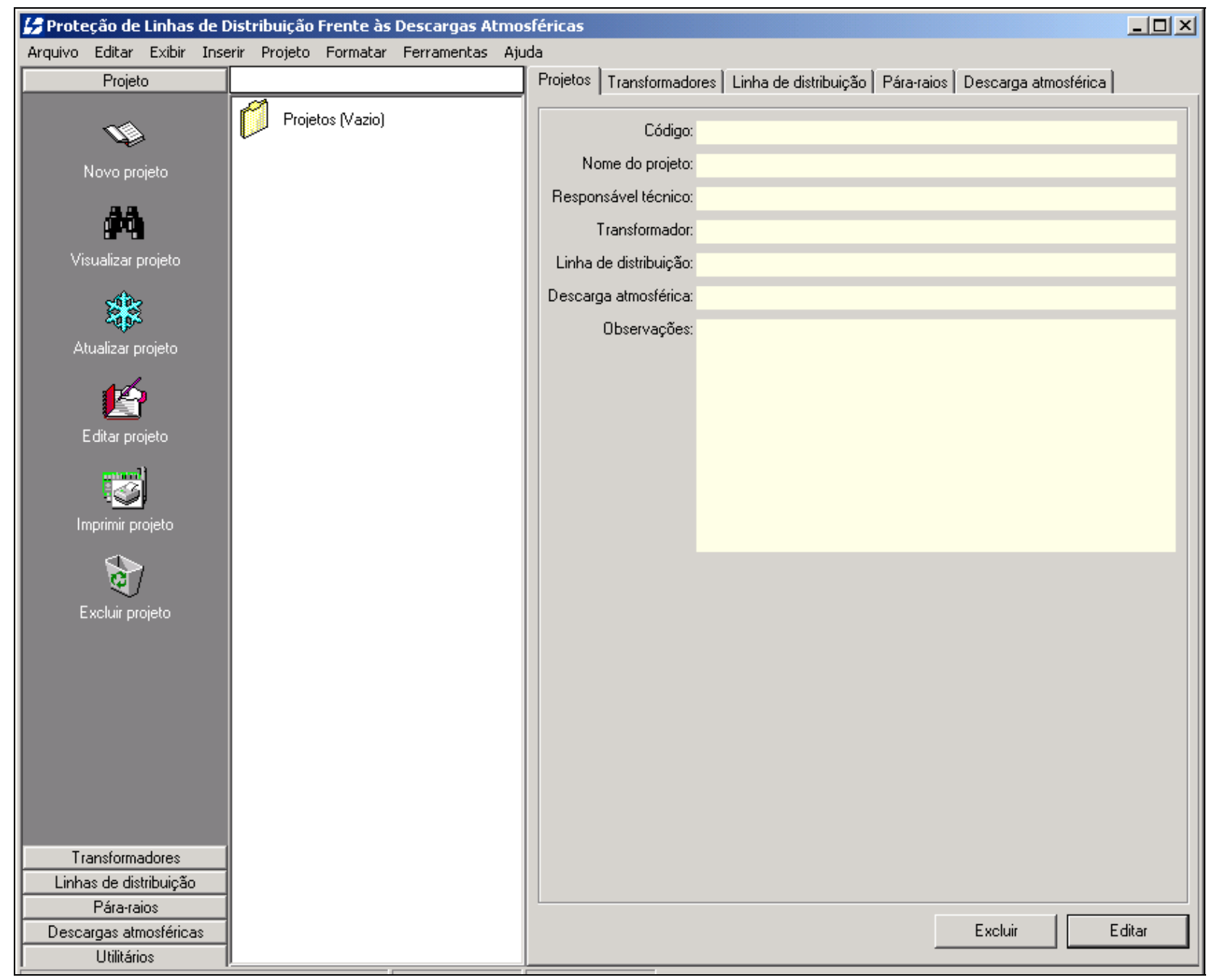

Figura 5.3 - Tela principal do sistema especialista.

Antes da criação de um projeto de proteção é necessário o cadastramento de informações relativas aos transformadores, às linhas de distribuição, aos pára-raios e às descargas atmosféricas junto ao sistema especialista. Em seguida, serão então apresentados os detalhes do cadastro de transformadores, sendo este princípio de cadastramento similar para as linhas de distribuição, pára-raios e descargas atmosféricas.

Para ilustrar o cadastro de transformadores junto ao sistema especialista, será aqui tomado como exemplo o transformador de distribuição de 75 kVA da WEG. Escolhendo, junto ao menu vertical, a aba referente aos transformadores, e clicando no botão "Novo transformador”, será então apresentada ao usuário a tela de cadastro de transformadores, conforme mostra a Figura 5.4. 


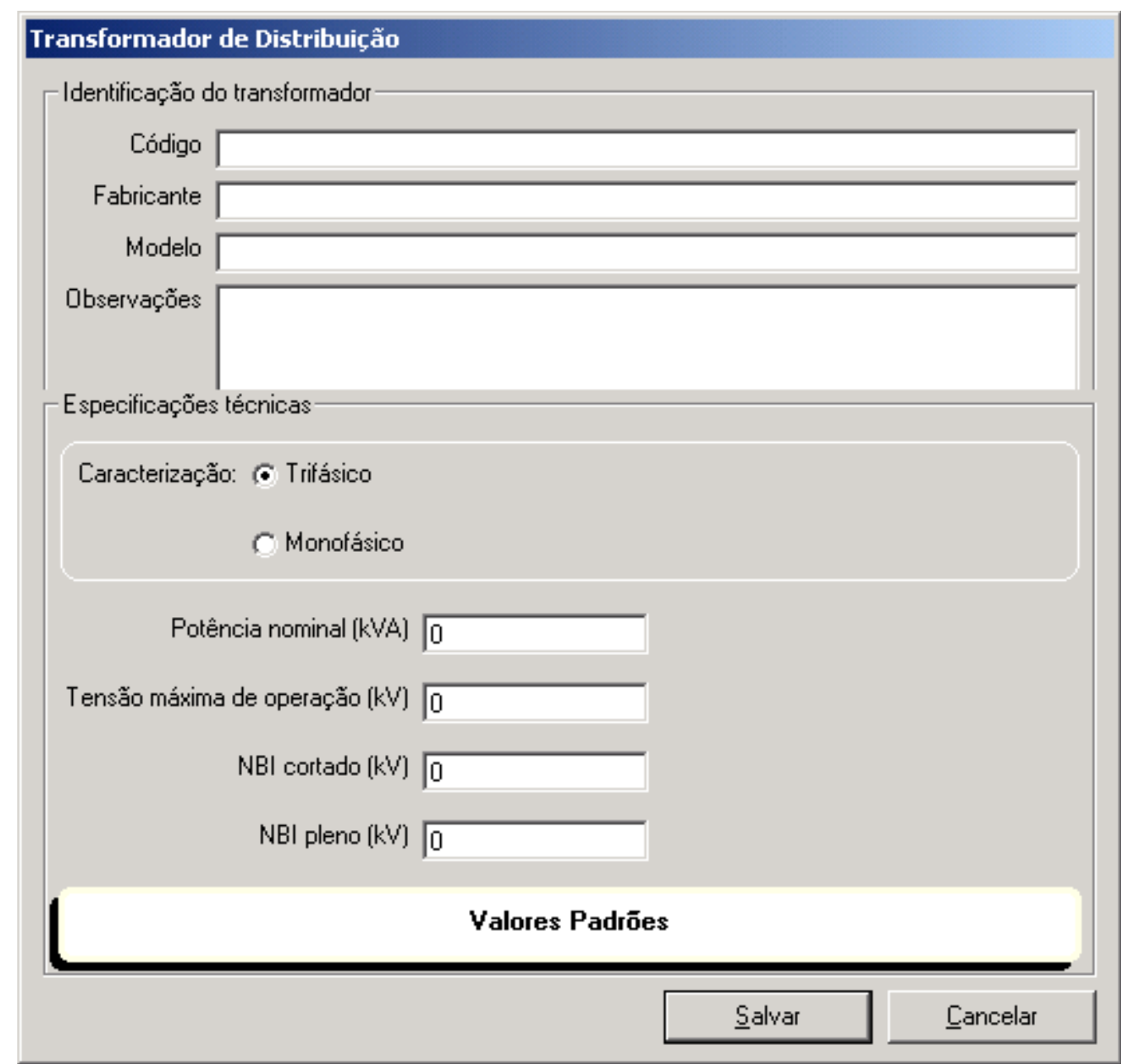

Figura 5.4 - Tela de cadastro de novos transformadores.

A Figura 5.5 apresenta a tela de cadastro de novos transformadores devidamente preenchida com os valores referentes ao transformador de distribuição escolhido.

Após o cadastro do transformador a árvore de cadastros da tela principal é também atualizada, conforme mostra a Figura 5.6. 


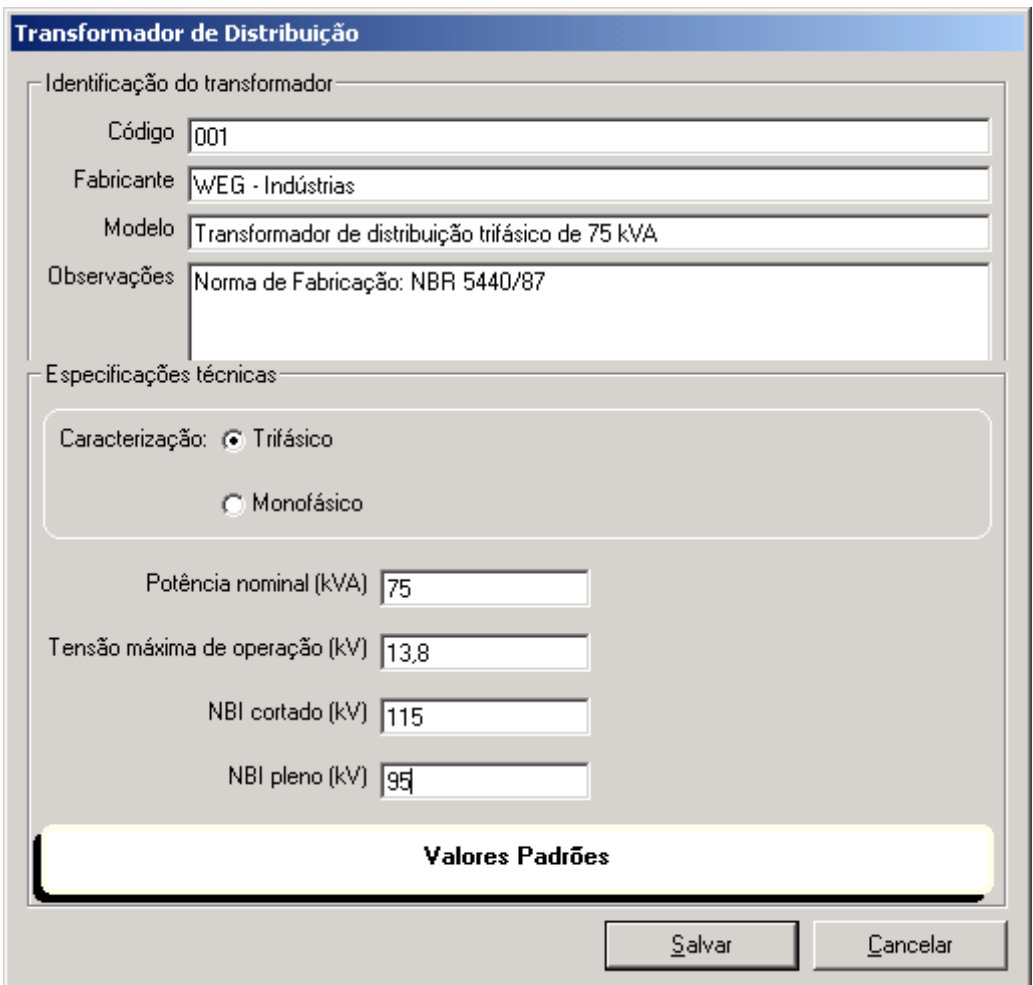

Figura 5.5 - Tela de cadastro de transformador devidamente preenchida.

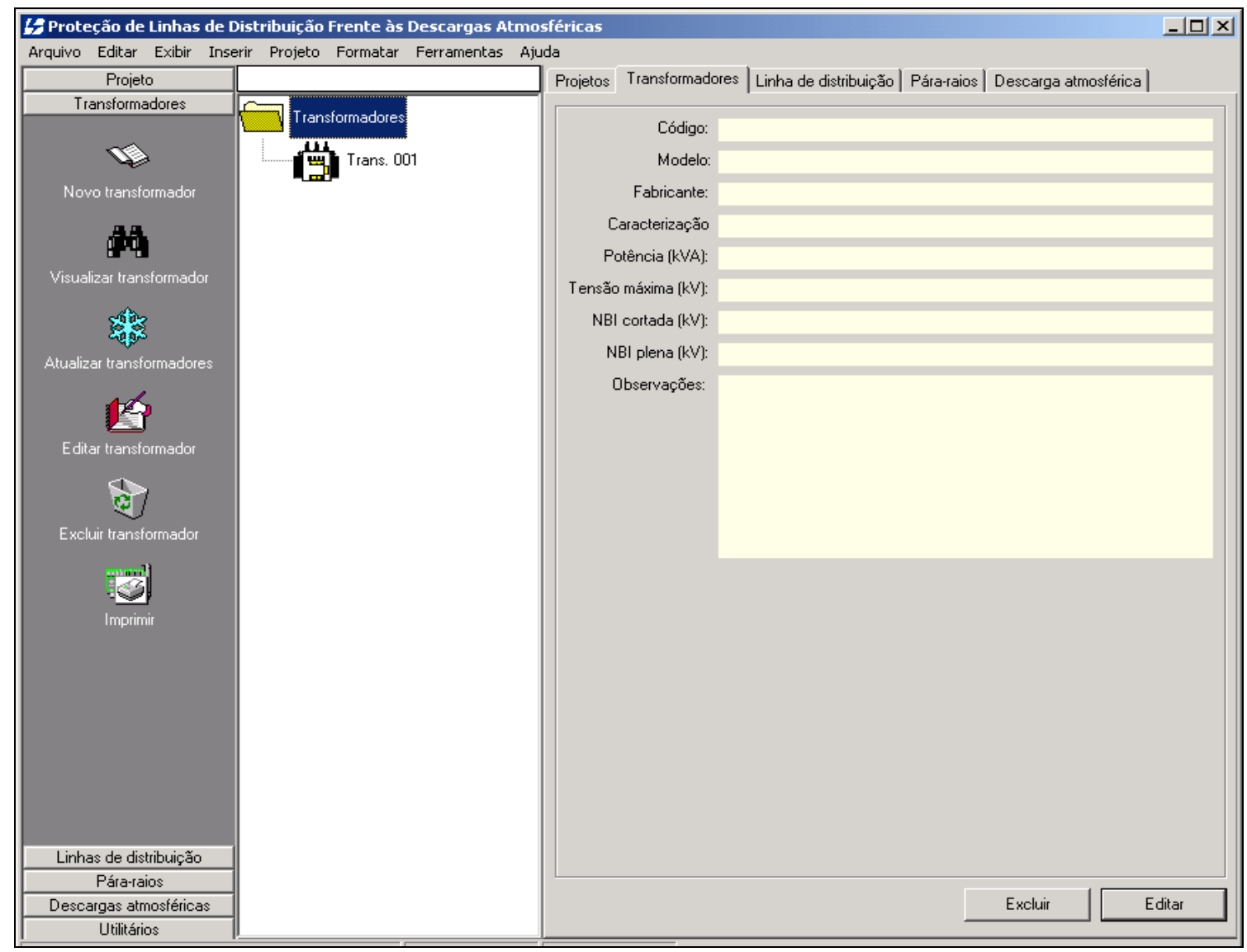

Figura 5.6 - Tela principal após o cadastro do transformador. 
Selecionando-se o item “Trans. 001”, junto à árvore de registro, são então apresentadas à direita da tela principal do Sistema Especialista as informações relativas ao transformador (Figura 5.7).

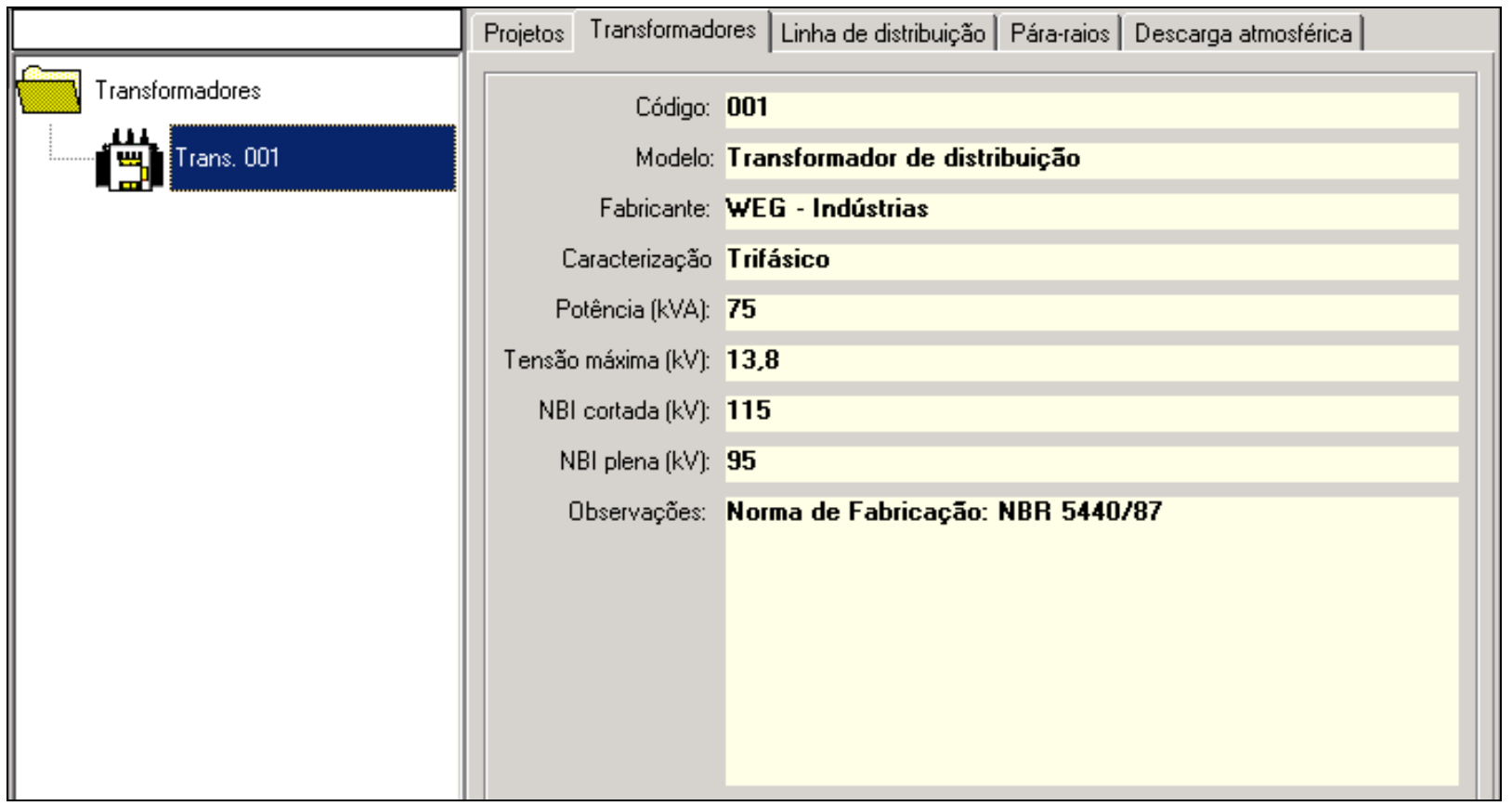

Figura 5.7 - Informações cadastrais do transformador selecionado.

Após o cadastro de um componente do sistema, este pode ser editado, ou mesmo excluído do sistema, caso seu emprego não seja mais efetuado. A edição e a exclusão de um registro do sistema podem ser realizadas por meio dos botões localizados à direita e abaixo da tela principal do sistema (Figura 5.6). De forma alternativa, os procedimentos de exclusão e de edição podem ainda ser acessados clicando-se com o botão direito do mouse sobre o registro de interesse. A Figura 5.8 destaca este procedimento.

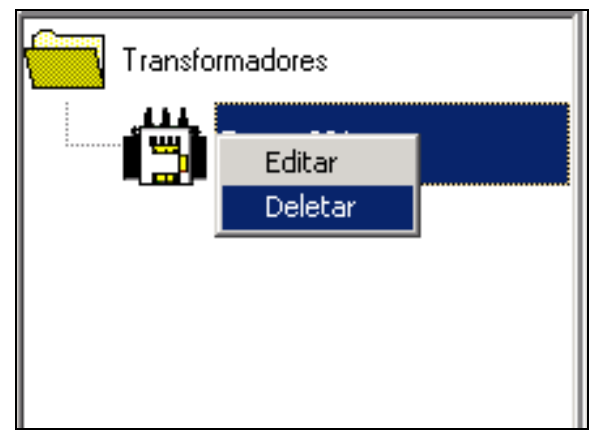

Figura 5.8 - Editando ou excluindo registros através de menu pop-up.

O princípio empregado para o cadastro de transformadores pode ser estendido às demais informações necessárias de cadastramento, tais como as linhas de distribuição, os pára-raios e as 
descargas atmosféricas. A Figura 5.9 apresenta a tela de cadastro de uma linha de distribuição devidamente preenchida.

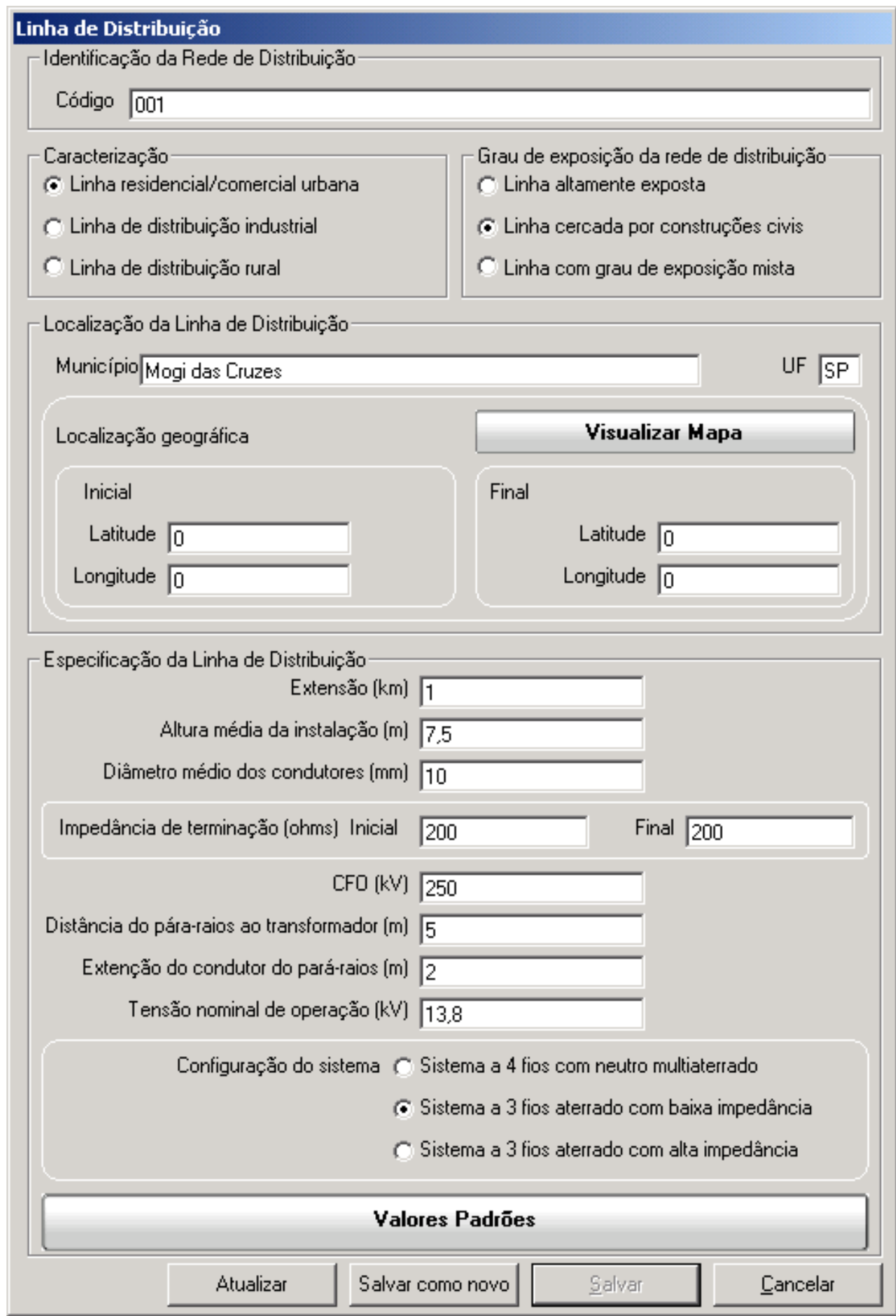

Figura 5.9 - Tela de cadastro de uma nova linha de distribuição devidamente preenchida.

Após o cadastro da linha de distribuição, a árvore de registros, referente às linhas de distribuição, é então atualizada conforme ilustra a Figura 5.10. 


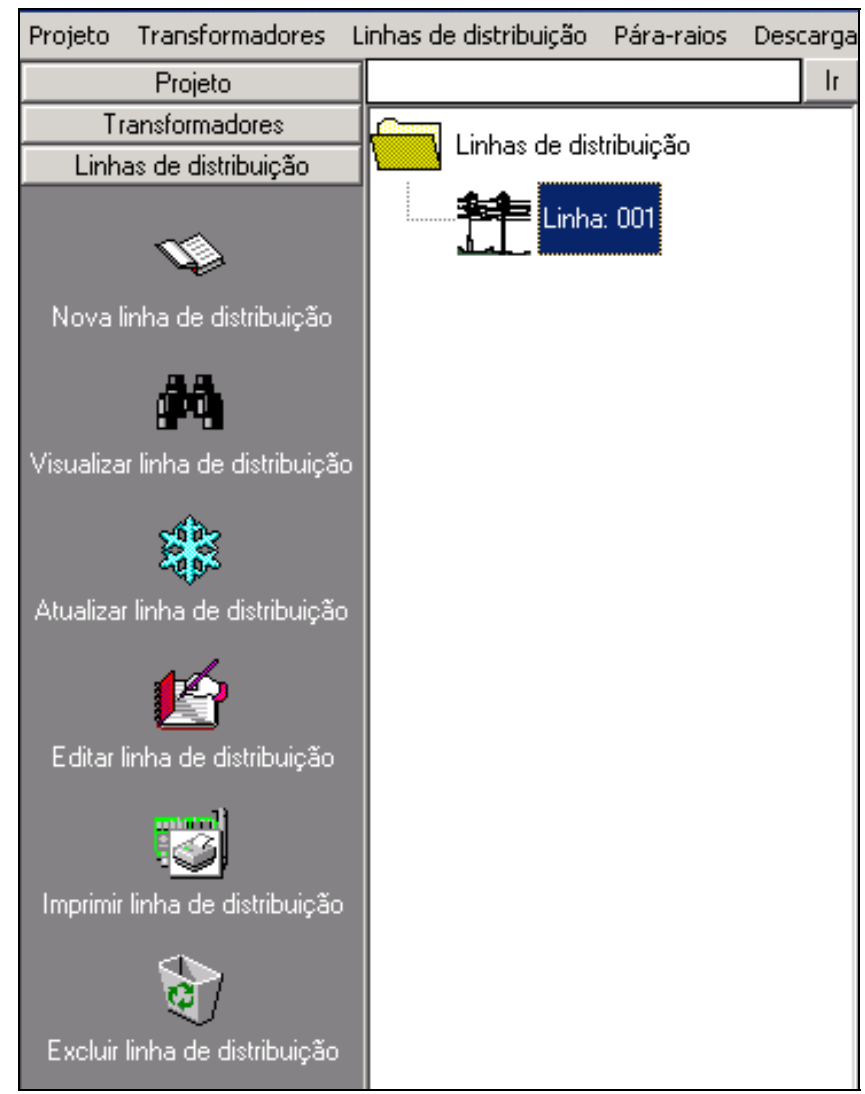

Figura 5.10 - Árvore de registros apresentado a linha de distribuição cadastrada.

Após o cadastro do pára-raios apresentado na Figura 5.11, a árvore de registros da tela principal é atualizada de maneira a refletir a inclusão do novo pára-raios.

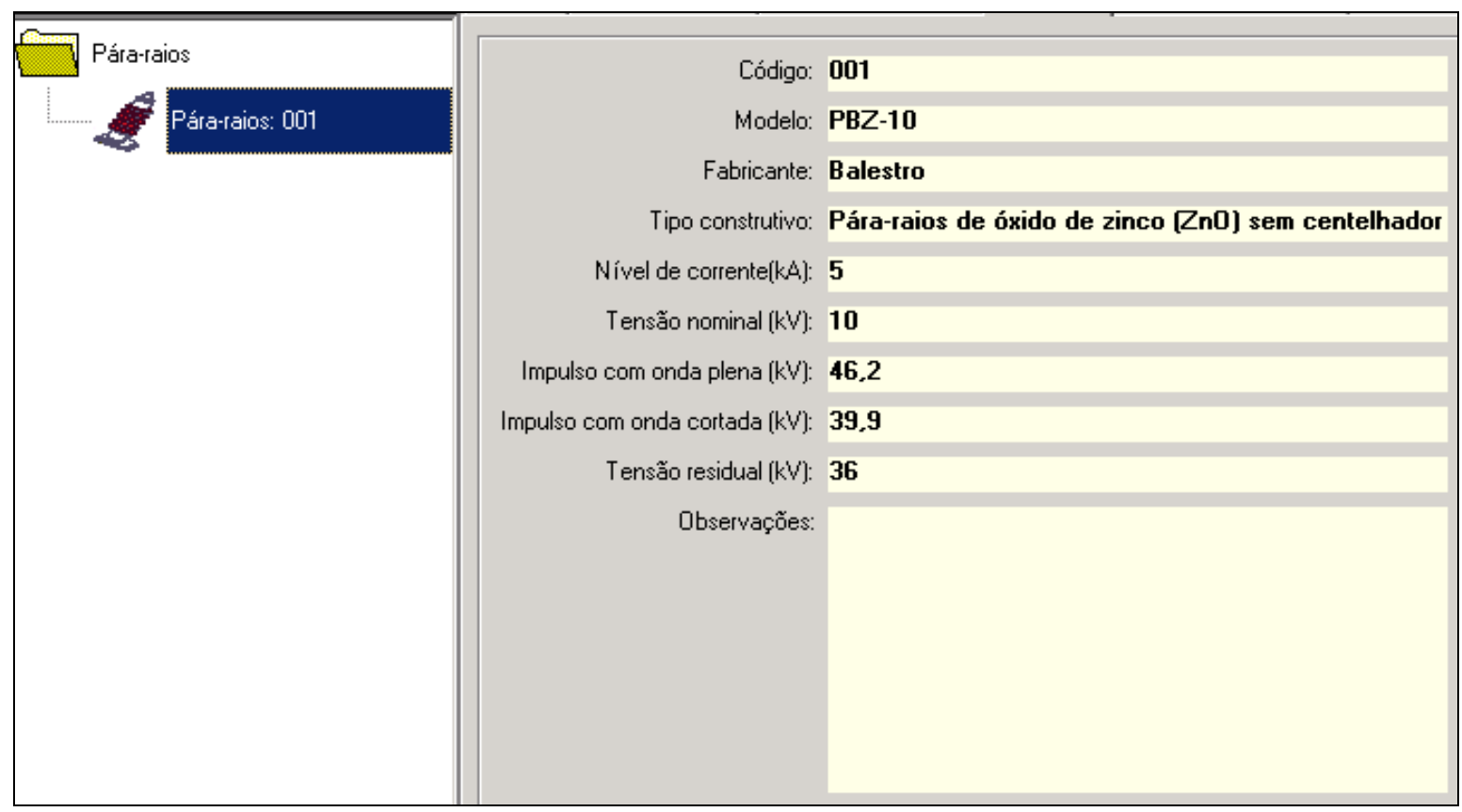

Figura 5.11 - Árvore de registro apresentando o pára-raios cadastrado. 
O cadastro das descargas atmosféricas é realizado de maneira semelhante aos demais cadastros apresentados anteriormente. A Figura 5.12 apresenta uma tela de cadastros de descargas atmosféricas devidamente preenchida.

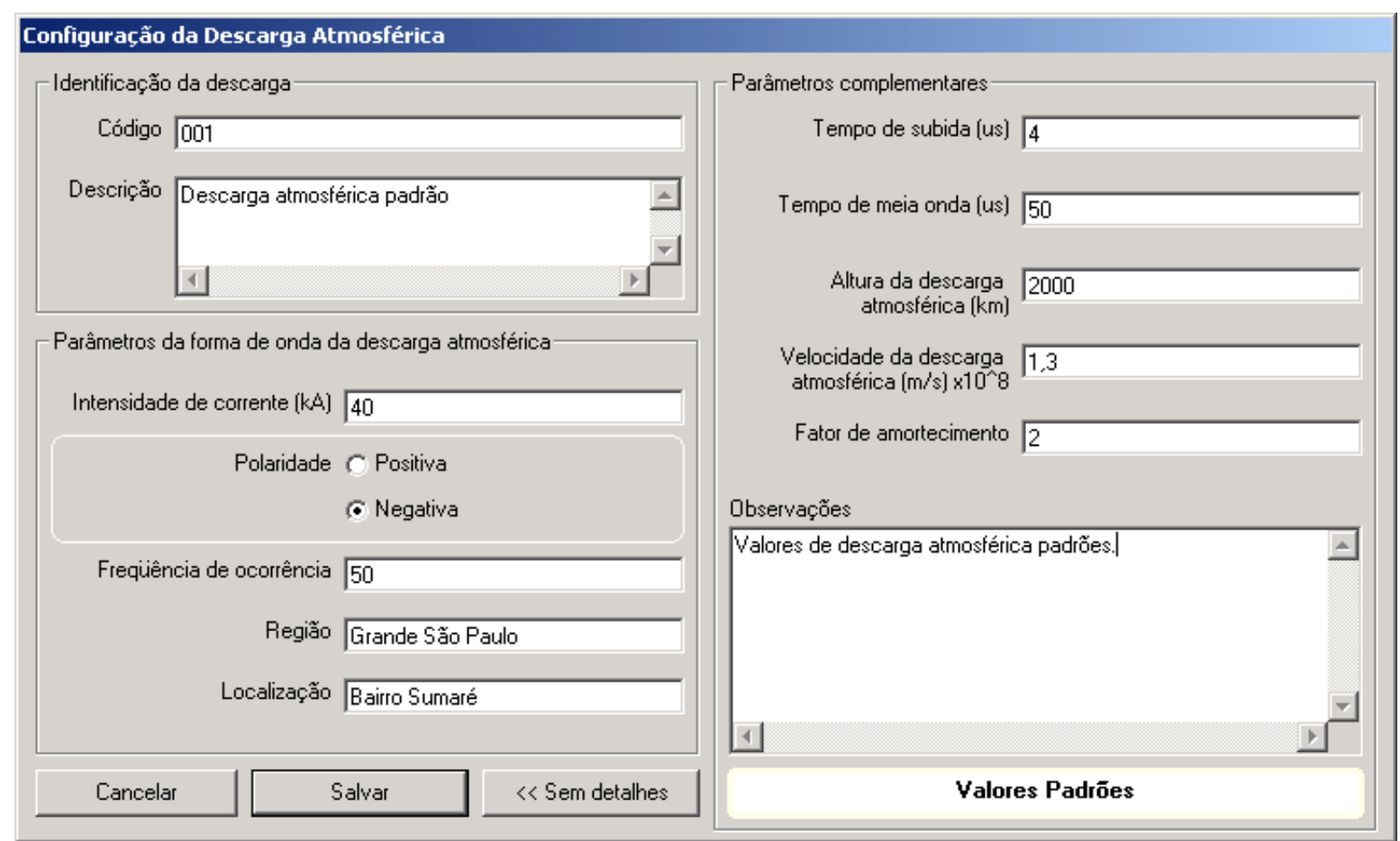

Figura 5.12 - Tela de cadastro de descargas atmosféricas devidamente preenchida.

De forma semelhante, o cadastro da nova descarga atmosférica automaticamente atualiza a árvore de registros, refletindo-se assim o novo cadastro. A Figura 5.13 apresenta a árvore de registro com a nova descarga atmosférica cadastrada. 
Descargas atmostéricas

DA: 001

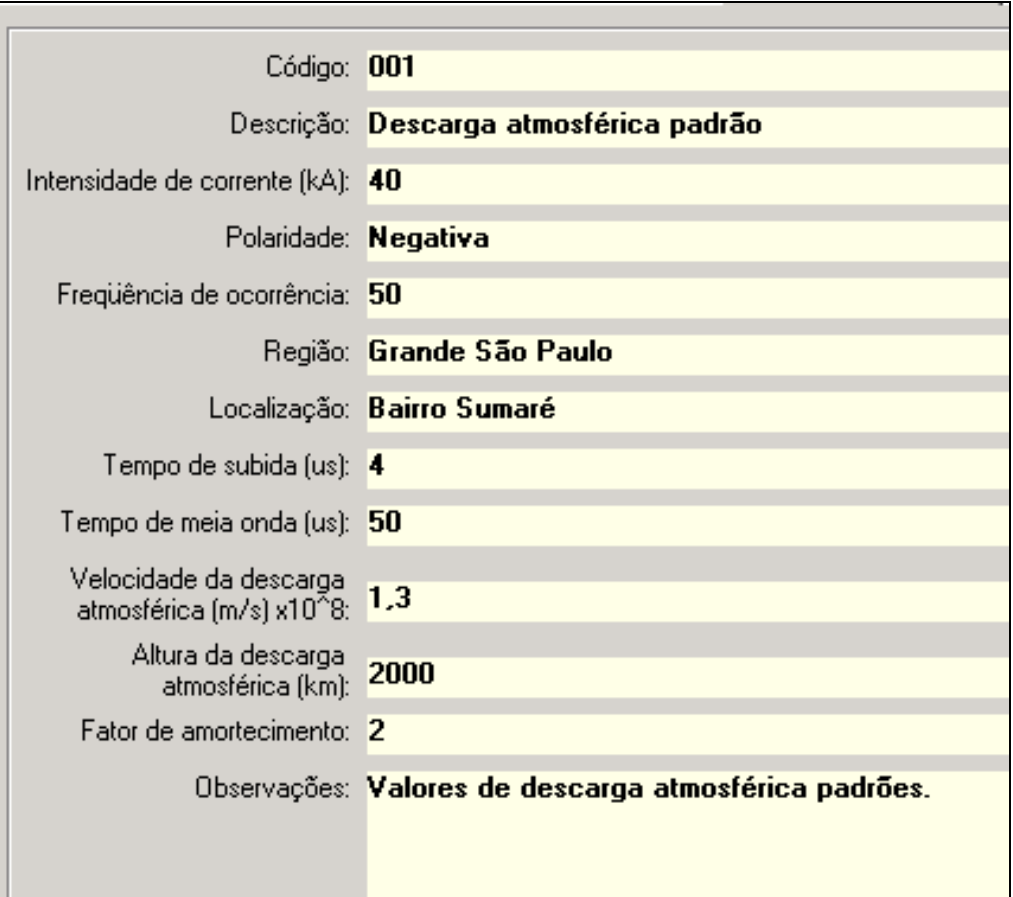

Figura 5.13 - Árvore de registros indicando a descarga atmosférica cadastrada.

A Figura 5.14 apresenta a tela de cadastro de um novo projeto devidamente preenchida e utilizando os dados de transformador, linha de distribuição e descarga atmosférica registrados anteriormente no sistema especialista.

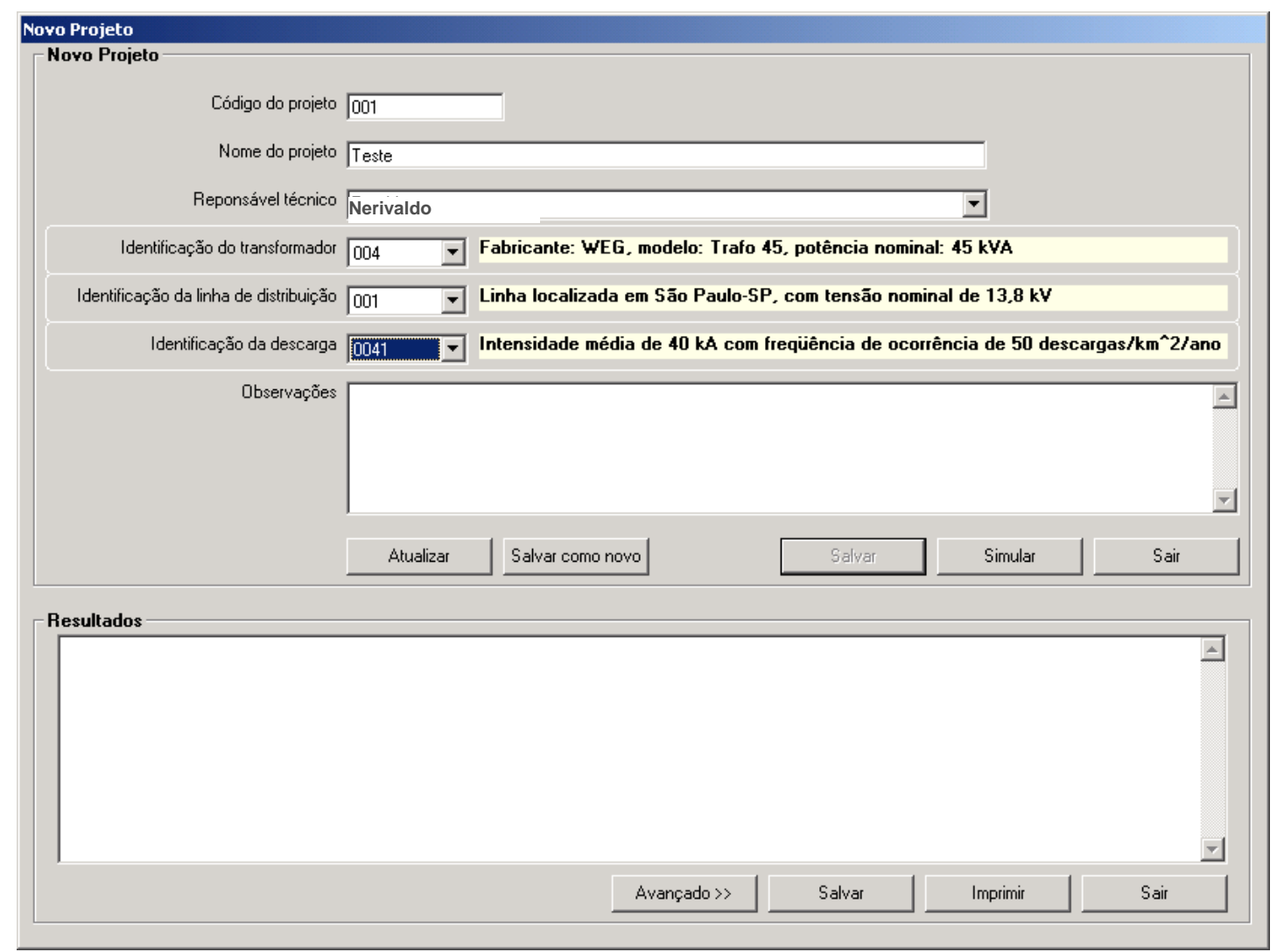

Figura 5.14 - Tela de cadastro de um novo projeto devidamente preenchida. 
Após o cadastro do novo projeto, a árvore de registro é então atualizada a fim de refletir o novo cadastro realizado. A Figura 5.15 ilustra a árvore de registro da tela principal refletindo a inclusão de um novo registro.

\begin{tabular}{|c|c|c|}
\hline \multirow{8}{*}{ Projetos } & \multirow[t]{7}{*}{ Editar } & Excluir \\
\hline & \multicolumn{2}{|c|}{ Código: 001} \\
\hline & & Teste \\
\hline & & $\begin{array}{l}\text { Rogério } \\
\text { Nerivaldo }\end{array}$ \\
\hline & & 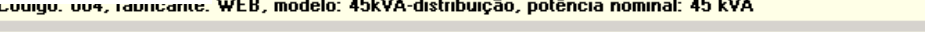 \\
\hline & & Código: 001, Localização: São Paulo-SP \\
\hline & & Código: 0041, intensidade: $40 \mathrm{kA}$, freqüência de ocorrência: 50 descargas $/ \mathrm{km}$ ^2/ano \\
\hline & & $\begin{array}{l}\text { Projeto de teste utilizando os dados cadastrais do transformador, da linha de distribuiçāo e da descarga } \\
\text { atmosférica }\end{array}$ \\
\hline
\end{tabular}

Figura 5.15 - Árvore de registro indicando o novo projeto criado.

A Figura 5.16 ilustra os resultados computados pela plataforma computacional visando à proteção adequada do transformador. Na caixa de diálogo denominada "Resultados", têm-se uma análise sintética de desempenho, bem como a relação de pára-raios que são adequados para a proteção do transformador.

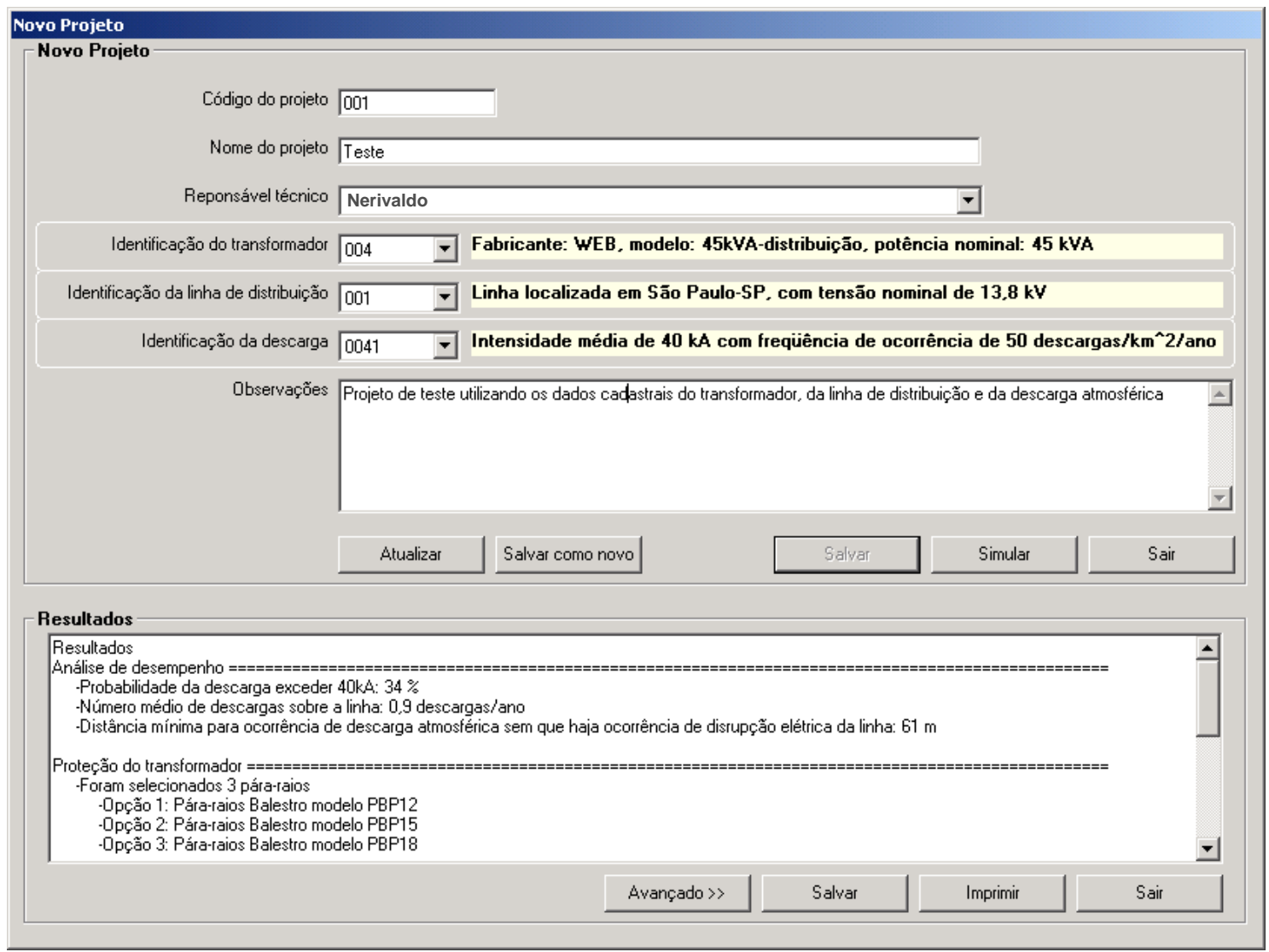

Figura 5.16 - Tela de cadastro de projeto apresentado os resultados de simulação. 
A partir da tela apresentada na Figura 5.16 é possível o acesso às informações mais detalhadas a respeito dos resultados obtidos pelo sistema especialista. Pressionando o botão “Avançado >>”, outro conjunto de telas estará disponível ao usuário. A Figura 5.17 ilustra este outro conjunto de telas mostrando a guia referente à análise de desempenho em relação às características da descarga atmosférica.

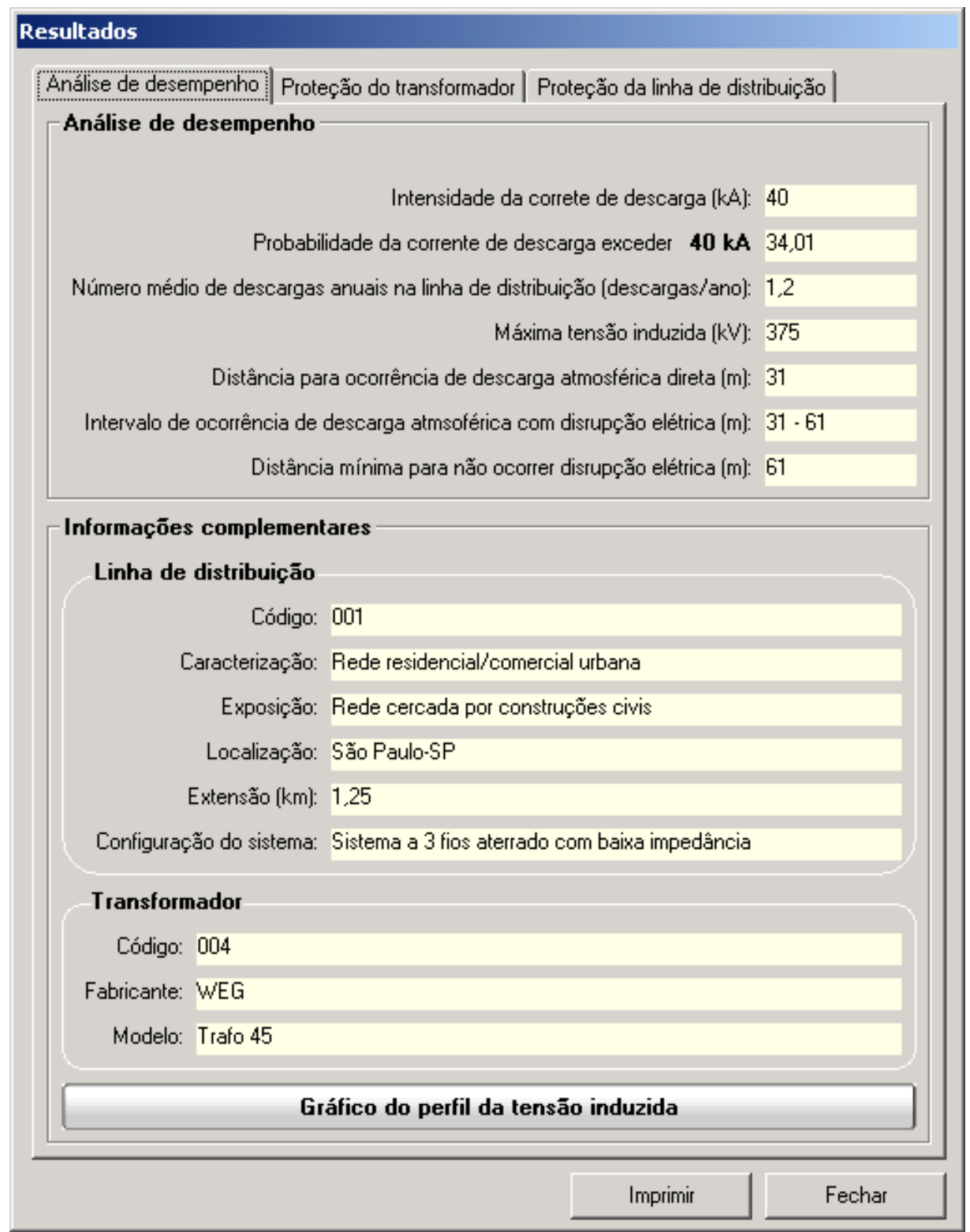

Figura 5.17 - Tela de resultados avançados apresentando a análise de desempenho.

Ainda em relação à tela mostrada na Figura 5.17, pode-se visualizar o gráfico do perfil da tensão induzida (Figura 5.18) na respectiva linha de distribuição por meio do acionamento do botão “Gráfico do perfil da tensão induzida”, localizado na parte inferior desta tela. 


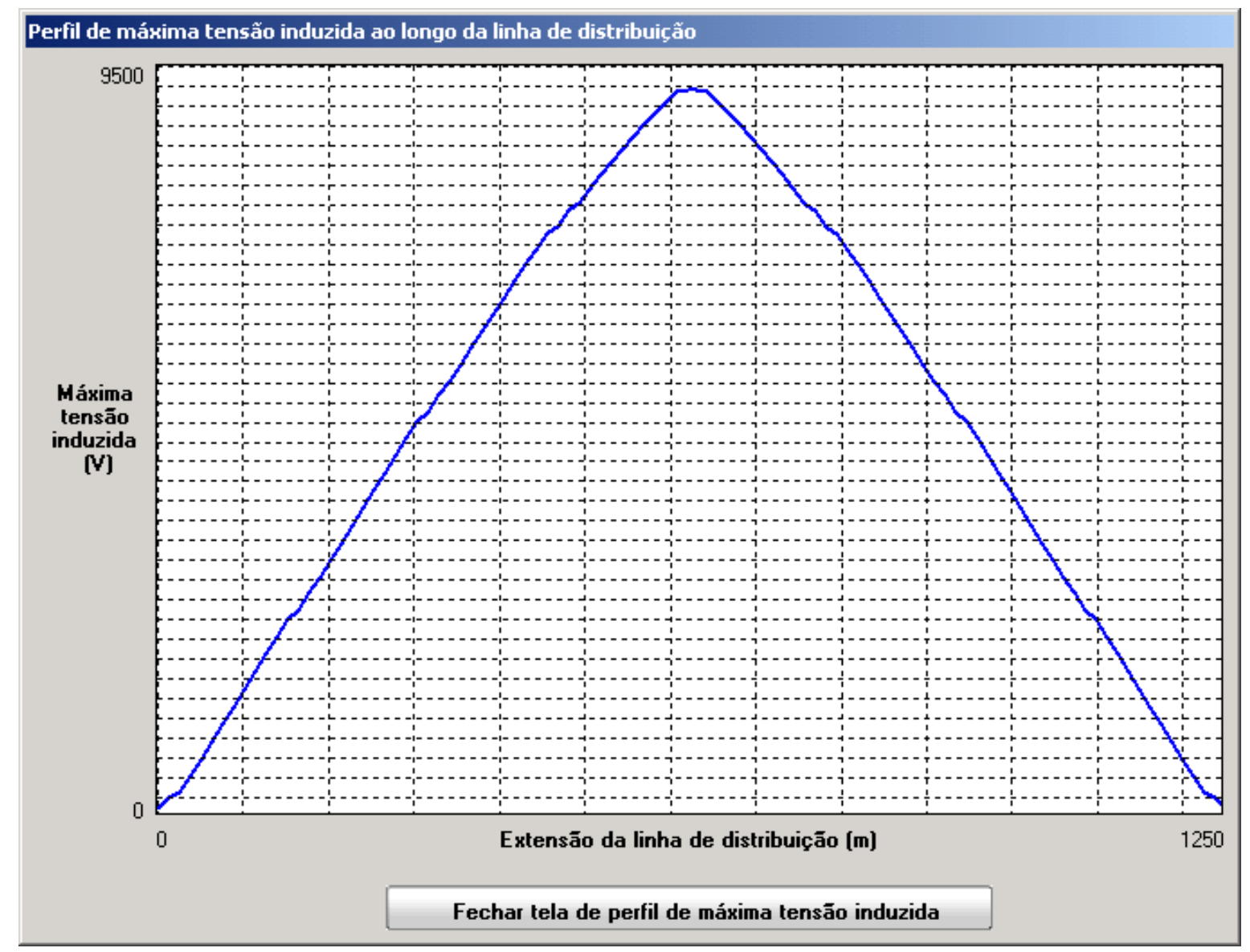

Figura 5.18 - Tela de perfil de tensão induzida ao longo da linha de distribuição.

Acionando a guia referente à "Proteção do transformador”, obtêm-se aqui informações detalhadas referentes ao posto de transformação, bem como detalhes sobre as características dos pára-raios que foram selecionados pelo sistema especialista (Figura 5.19). 


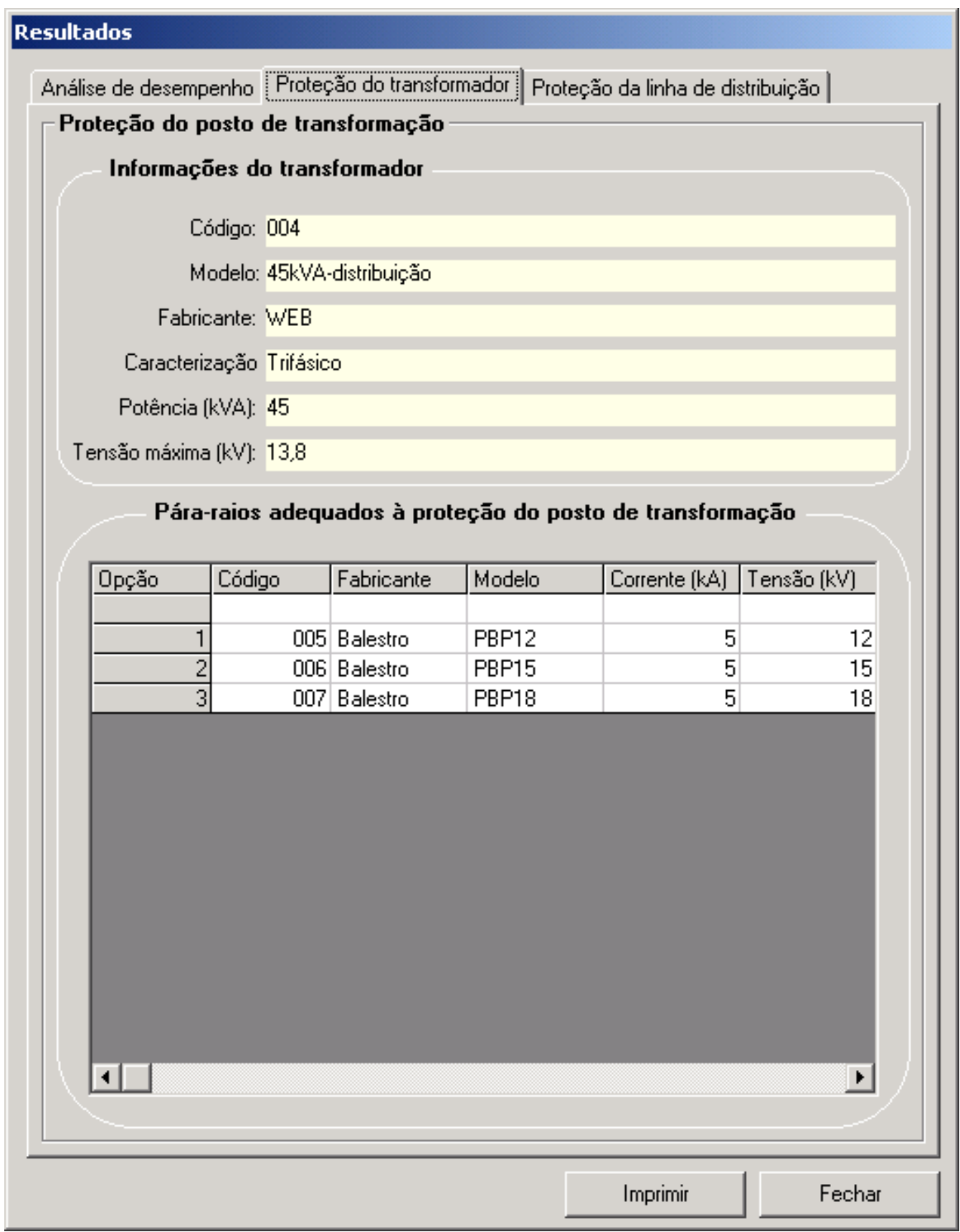

Figura 5.19 - Tela de resultados avançados apresentando informações referentes à proteção do transformador.

Acionando a guia "Proteção da linha de distribuição", obtém-se a listagem dos páraraios adequados à proteção do posto de transformação, com seus respectivos espaçamentos de instalação para a proteção da linha de distribuição frente às descargas atmosféricas diretas e indiretas (Figura 5.20). 


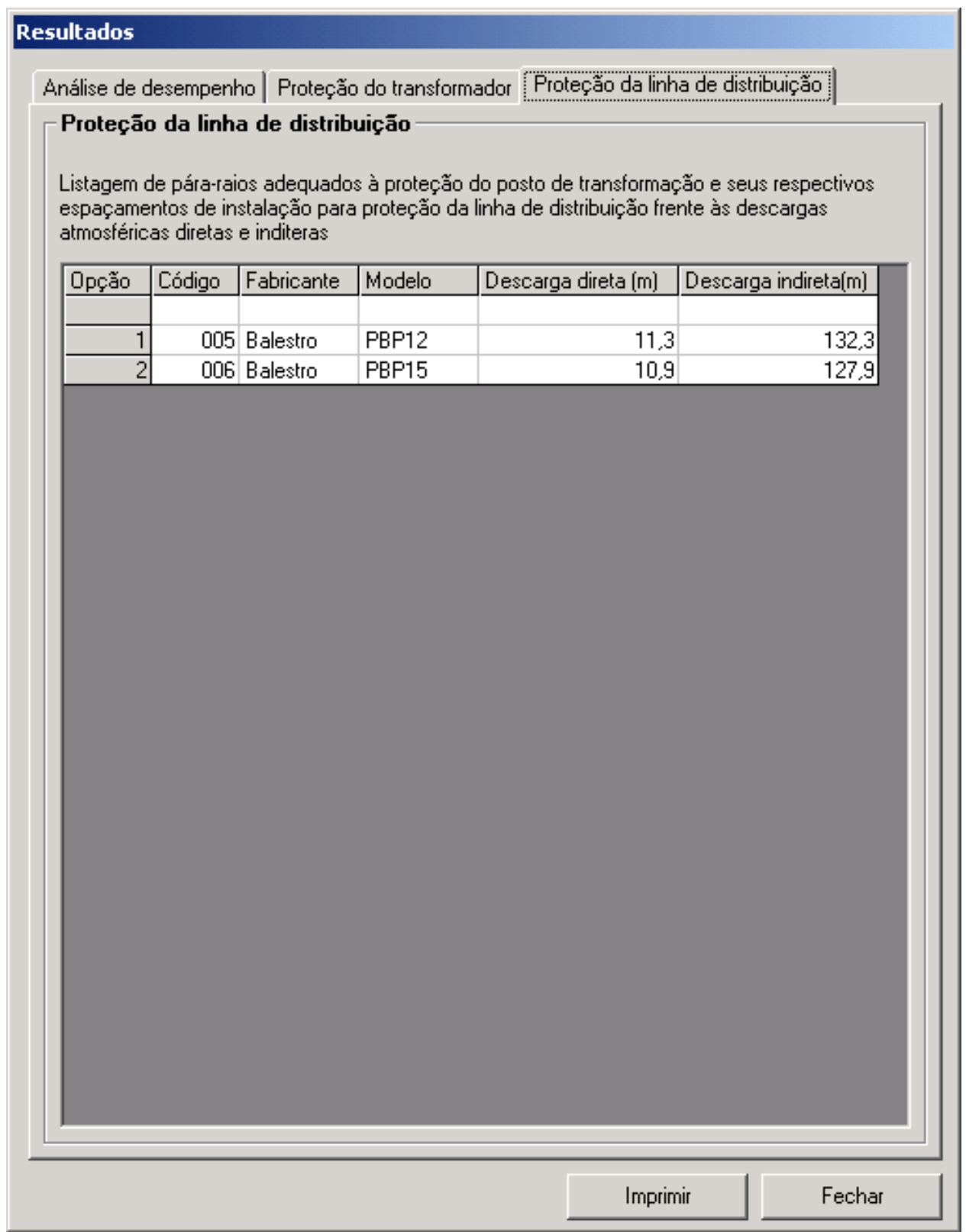

Figura 5.20 - Tela de resultados avançados apresentando os dados referentes à proteção da linha de distribuição.

\subsection{CONSIDERAÇÕES PARCIAIS}

O sistema especialista desenvolvido fornece os elementos necessários que auxiliam na especificação correta dos dispositivos de proteção dos transformadores.

Além disso, por intermédio deste sistema especialista, as estratégias que apóiam todas as tomadas de decisões foram integradas com todos os módulos de informações que foram sendo gerados no decorrer da pesquisa. 
Como conseqüência dessa análise integrada, torna-se possível a otimização dos processos envolvidos com a proteção dos transformadores, pois todos os aspectos relacionadas com as investigações realizadas nas diferentes fases anteriores da pesquisa são agora levados em consideração pelo sistema especialista. 


\section{Capítulo 6}

\section{Conclusões e Trabalhos Futuros}

O desenvolvimento desta pesquisa contribuiu para a integração sistemática de três áreas (Métodos Computacionais, Critérios Técnicos, Aspectos das Descargas Atmosféricas) que foram analisadas no desenvolvimento do projeto, as quais auxiliam na especificação da proteção de transformadores, permitindo-se que uma análise integrada das mesmas possa ser eficientemente tratada pelo sistema especialista. Mais especificamente, as três abordagens investigadas que foram tratadas de forma integrada nesta pesquisa, são as seguintes:

i) Métodos Computacionais: envolve o conjunto de métodos computacionais que são responsáveis pela simulação de sobretensões advindas de descargas atmosféricas.

ii) Critérios Técnicos: envolve os estudos relacionados com a elaboração e especificação de critérios técnicos que permitem definir o tipo de proteção mais adequado para os transformadores.

iii) Aspectos das Descargas Atmosféricas: envolve os estudos que possibilitam mitigar as principais características das descargas atmosféricas, as quais incidem em determinada área de distribuição.

A integração destas três áreas contribui significativamente para a especificação de critérios bastante apurados para o dimensionamento correto da proteção de transformadores, contribuindo fortemente para o incremento da eficiência dos sistemas de proteção envolvidos com os mesmos.

A análise envolvendo a integração de diversas técnicas, as quais foram avaliadas com o objetivo de mapear adequadamente o problema relacionado com a proteção de transformadores, proporcionou também um leque de conhecimentos que culminaram com o desenvolvimento dos dois principais sistemas computacionais gerados por esta pesquisa, ou seja, o SimSurto e o Protection Plus. 
O primeiro produto disponibilizado, denominado de "SimSurto", é uma plataforma computacional que permite a simulação de surtos de tensão ocasionados por descargas atmosféricas em linhas de distribuição, sendo que o objetivo do mesmo é o cálculo de diversos parâmetros envolvidos com os respectivos surtos. O segundo produto disponibilizado, denominado de "Protection Plus", é um sistema especialista que comporta toda a estrutura decisória envolvendo a especificação correta dos dispositivos de proteção dos transformadores, permitindo que estratégias de proteção diferenciadas possam ser especificadas de acordo com as particularidades de cada região. Ambos os sistemas desenvolvidos contribuem efetivamente para incrementar a eficiência dos procedimentos envolvidos com a especificação dos dispositivos de proteção dos transformadores.

Em virtude destes desenvolvimentos, pode-se evitar que sistemas de proteção superdimensionados sejam especificados, os quais poderiam contribuir para onerar os custos de implantação das redes de distribuição. Por outro lado, os sistemas desenvolvidos podem também evitar o subdimensionamento do sistema de proteção, poupando perdas materiais e financeiras, tanto para a concessionária como para o consumidor de energia elétrica, além dos prejuízos quanto ao DEC, FEC e à qualidade da energia fornecida. Além disso, o subdimensionamento do sistema de proteção pode implicar em reflexos, por intermédio dos transformadores, dos surtos de tensão ocorridos na rede primária para a rede secundária. Estes surtos refletidos apontam como uma das principais fontes de danos em equipamentos eletro-eletrônicos dos clientes da concessionária, impondo-se em diversos casos a aplicação de multas e indenizações à concessionária.

Como trabalhos para desenvolvimento futuro, têm-se as seguintes frentes de pesquisa:

i) Estender a metodologia proposta para outros tipos de equipamentos utilizados em distribuição de energia elétrica, tais como os reguladores de tensão.

ii) Integrar ao sistema especialista os aspectos envolvidos com o projeto de sistemas de aterramento, os quais sejam também otimizados em função das características de cada área geográfica. 